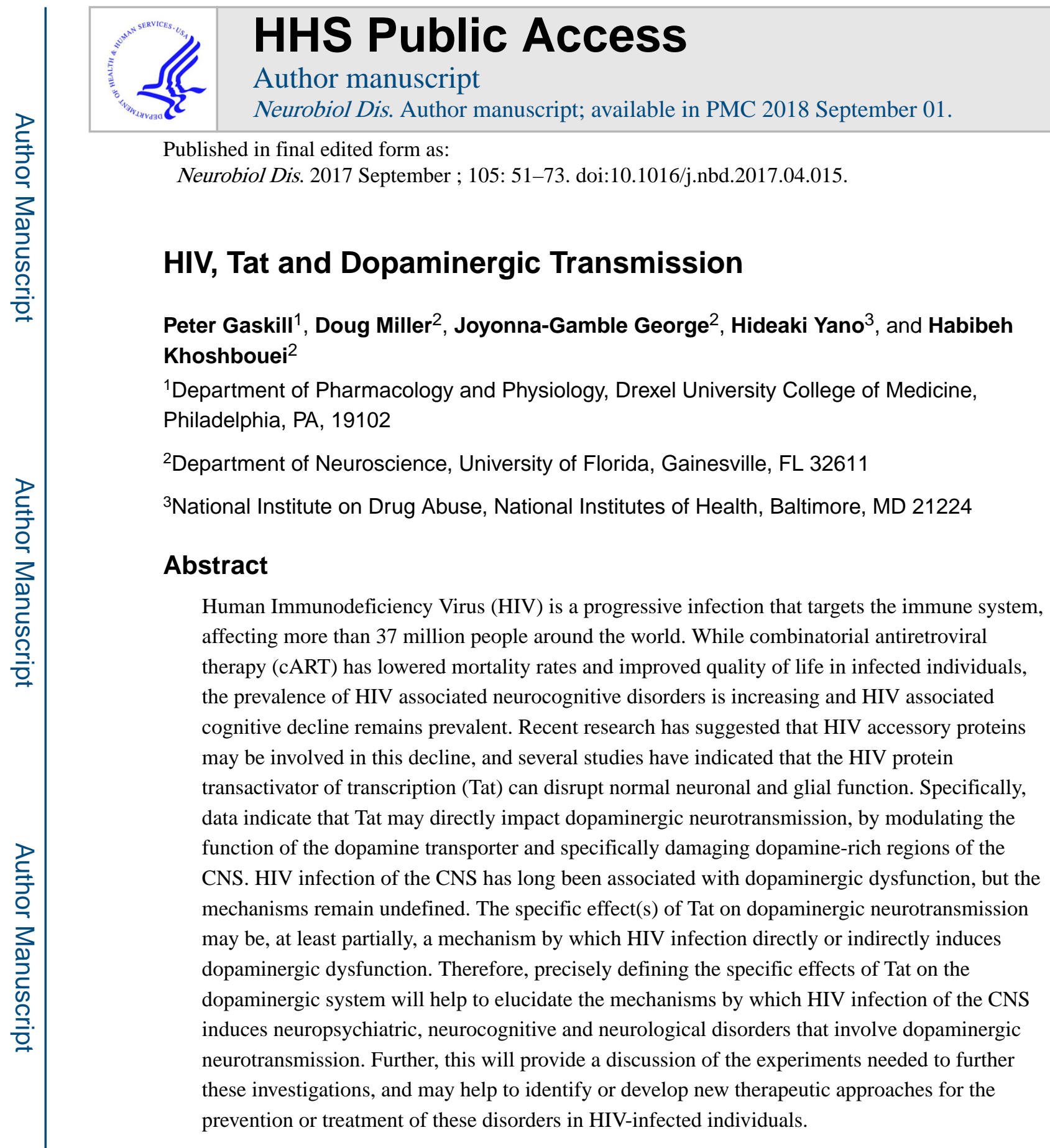

\title{
Introduction
}

There have been a number of excellent reviews detailing the effects of HIV-1 Tat on the $\mathrm{CNS}$, and a growing body of research suggests that HIV infection specifically damages and/or dysregulates the dopaminergic system in the CNS (Cass et al., 2003; Czub et al.,

Corresponding Authors: Peter Gaskill, Department of Pharmacology and Physiology, Drexel University College of Medicine, Peter.gaskill@drexelmed.edu. Habibeh Khoshbouei, Department of Neuroscience, University of Florida, Habibeh@ufl.edu.

Publisher's Disclaimer: This is a PDF file of an unedited manuscript that has been accepted for publication. As a service to our customers we are providing this early version of the manuscript. The manuscript will undergo copyediting, typesetting, and review of the resulting proof before it is published in its final citable form. Please note that during the production process errors may be discovered which could affect the content, and all legal disclaimers that apply to the journal pertain. 
2004; Ferris et al., 2008; Fitting et al., 2015; Gaskill et al., 2013; Gaskill et al., 2014; Koutsilieri et al., 2004; Purohit et al., 2011). A number of recent studies suggest that these changes to the dopaminergic system specifically involve Tat; therefore, this review will focus specifically on the Tat protein and its effect on dopaminergic neurotransmission. This review will briefly discuss both the pathogenesis of HIV in the CNS and dopamine neurotransmission in the brain, and then review what is known about the Tat protein itself. This will be followed by discussion of the model systems used to explore the effects of Tat on the dopaminergic system, the direct effects of Tat on neuropathogenesis and the brain regions implicated in Tat modulation of cognitive function. The review will then explore the direct impact of Tat on the dopamine transporter and on the dopamine receptors. Finally, the discussion will briefly discuss the specific impact of Tat on the dopaminergic effects of psychostimulants, as well as other drugs of abuse. Although the impact of Tat on neuropathogenesis has been covered at length recently (Dahal et al., 2015; Hauser and Knapp, 2014; Maubert et al., 2015; Mediouni et al., 2015a), these sections will provide a distinct viewpoint on the subject, focusing specifically on the potential synergistic effects of Tat and drug abuse on dopaminergic neurotransmission.

\section{HIV Neuropathogenesis}

Globally, approximately 37 million people are infected with the human immunodeficiency virus. In 2014, more than 1.2 million people died as a result of this infection (UNAIDS 2015). HIV is a lentivirus which principally targets the immune system, primarily infecting CD4+ T-cells, macrophages and monocytes. Untreated, HIV infection progressively destroys the immune system, leading to the development of acquired immunodeficiency syndrome (AIDS) (Derdeyn and Silvestri, 2005; Moir et al., 2011; Stevenson, 2003). The development of combinatorial antiretroviral therapy (cART) has successfully reduced rates of death and improved length and quality of life (UNAIDS, 2015; Weber et al., 2013), transitioning HIV infection from a terminal to a chronic diagnosis (Deeks et al., 2013). This success has increased the prevalence of HIV, particularly among vulnerable populations, such as drug abusers (El-Bassel et al., 2014). Currently, the prevalence of HIV is 22 times higher among injection drug users than among the general population (Beyrer et al., 2010; Crime, 2014; Mathers et al., 2008) and even the use of non-injection drugs greatly increases the risk of acquiring HIV (Kipp et al., 2011). The mechanism(s) by which different types of drugs of abuse increase the risk of acquiring or exacerbating HIV is not clear, and understanding these processes is critical, as drug abuse exacerbates the development of AIDS in both the periphery and in the central nervous system (CNS) (Baum et al., 2009; Lucas et al., 2006). The direct effects of HIV infection on the reward pathway and drug-seeking behavior are not fully understood, but numerous studies have suggested HIV affects the dopaminergic system (Aylward et al., 1993; Berger et al., 1994; Chang et al., 2008; Itoh et al., 2000; Jenuwein et al., 2004; Kieburtz et al., 1991; Nath et al., 2000; Obermann et al., 2009a; Sardar et al., 1996; Scheller et al., 2010; Wang et al., 2004).

While a majority of studies on HIV focus on the effects on the peripheral immune system, infection of the CNS is a growing health concern. HIV enters the CNS rapidly following initial infection (Davis et al., 1992; Valcour et al., 2012). Infection of the CNS leads to a constellation of neurocognitive impairments, including cognitive dysfunction, behavioral 
changes, motor deficits, and dementia, that are currently known as HIV-associated neurocognitive disorders (HAND) (Antinori et al., 2007; Navia et al., 1986; Price et al., 1988; Sacktor et al., 2002; Simioni et al., 2010). Prior to the implementation of cART (combinatorial antiretroviral therapy, then called HAART) in 1996, around 16\% of HIVinfected individuals manifested HIV encephalitis (Davies et al., 1998), and between 5 and $20 \%$ were diagnosed with HIV-associated dementia (HAD) (Janssen et al., 1989; Maschke et al., 2000; McArthur et al., 1994; Sacktor, 2002). With cART, the more severe neurological manifestations have become rare (Ellis et al., 2007; Heaton et al., 2010a; Joska et al., 2010; Sacktor, 2002), but $40-70 \%$ of infected individuals still suffer from HAND (Cysique et al., 2004; Heaton et al., 2010a; Heaton et al., 2011a; Simioni et al., 2010; Tozzi et al., 2005). Further, the prevalence of HAND is increasing as these individuals have longer life expectancy (Brew and Chan, 2014; Heaton et al., 2010b; Simioni et al., 2010). HAND is still found among individuals with viral suppression (Heaton et al., 2011b; Robertson et al., 2007), which suggests that factors other than viral replication are involved. A number of studies indicate that drug abuse may exacerbate both the neuropathogenesis of HIV and the neurocognitive impact of infection in both cART-naïve and cART-treated individuals (Chana et al., 2006; Langford et al., 2003b; Meade et al., 2011a; Meyer et al., 2014; Nath, 2010; Starace et al., 1998). However, other studies show that drug-abuse does not increase the neurological deficits induced by HIV+ infection (Basso and Bornstein, 2003; Byrd et al., 2011b; Grassi et al., 1995); hence, the precise impact of drug abuse on HIV neuropathogenesis remains unclear.

HIV is thought to enter the brain primarily by using infected monocytes as "Trojan Horses" to move across the blood-brain barrier (Izquierdo-Useros et al., 2010; Kim et al., 2003; Peluso et al., 1985). Within the brain, the monocytes mature into macrophages and produce new HIV virions, spreading the infection throughout the brain. In the CNS, HIV primarily infects perivascular macrophages and microglia (Gonzalez-Scarano and Martin-Garcia, 2005; Joseph et al., 2015; Kure et al., 1990). The presence of HIV has also been shown in astrocytes both in vitro (Eugenin and Berman, 2007) and in vivo (Churchill et al., 2009; Tornatore et al., 1994), but the mechanism of entry into these cells, and the overall role of astrocytes in HIV neuropathogenesis remains unclear (Gray et al., 2014; Joseph et al., 2014; Luo and He, 2015). Infected cells, primarily macrophages, monocytes and microglia produce and secrete a variety of inflammatory host and viral factors, including cytokines, chemokines and viral proteins. These factors result in chronic neuroinflammation and neurotoxicity, which are thought to be central to the development and persistence of HAND (Gannon et al., 2011; Gill et al., 2012; Hong and Banks, 2015; Kraft-Terry et al., 2009; Zayyad and Spudich, 2015).

\section{The Transactivator of Transcription (Tat)}

Among the neurotoxic viral proteins released by infected cells is the viral protein Tat (Chang et al., 1997; Ensoli et al., 1993; King et al., 2006; Rayne et al., 2010a). Tat is short for transactivator of transcription, and is required for the successful transcription of full-length HIV mRNA. This protein is one of the first genes expressed in the HIV replication cycle. The viral mRNA of Tat consists of two exons. The first exon is comprised of amino acids $1-72$, and contains the transcriptional functions of the protein. The second exon, comprised of 
amino acids $73-101$ or amino acids $73-86$, houses the integrin binding domains. The longer form of Tat ( $101 \mathrm{aa})$ is far more common and is found in the majority of HIV clinical isolates, while the shorter form of Tat ( $~ 86$ aa) is mostly found in laboratory adapted strains and is the result of a single nucleotide polymorphism in the second exon which creates a stop codon (Campbell et al., 2005; Jeang, 1996; Jeang et al., 1999). Perhaps due to the prevalence of this premature stop codon in the laboratory-adapted, clade B strains of HIV that are common in North America and Western Europe, the shorter form of Tat is much more commonly used in research. Some studies examining multiple forms of Tat have shown functional differences between the shorter and wild type forms of Tat (Bertrand et al., 2013; Campbell et al., 2005), while others do not find such differences (Ma and Nath, 1997). Thus, the effects of wild-type Tat on many of the biological functions studied using the shorter forms of Tat are unclear.

The first exon of Tat can be divided into a number of distinct regions generally defined as the N-Terminal (residues 1-21), cysteine-rich (residues 22-37), core (residues 38-48), basic, protein transduction or arginine-rich (residues $49-60$ ) and glutamine-rich or C-Terminal (residues 60 - 72) domains (Campbell and Loret, 2009; Derse et al., 1991; Jeang et al., 1999; Kuppuswamy et al., 1989), as depicted in Figure 1. Each of these regions has been found to have numerous distinct functions, although many functions also span more than one region. For example, the placement of tRNA onto the viral RNA genome involves the cysteine-rich, the core, and the basic and glutamine-rich domains (Kameoka et al., 2002). While the minimal functional domain of Tat encompasses the first 48 amino acids, the role of specific residues in the $\mathrm{N}$-terminal domain, a proline rich region, is undefined (Derse et al., 1991; Jeang et al., 1999). Mutation studies have shown that the cysteine-rich domain is necessary for the transactivation function of Tat (Green and Loewenstein, 1988; Jeang et al., 1999; Kuppuswamy et al., 1989; Rice and Carlotti, 1990), and coordinates $\mathrm{Zn}^{2+}$ binding, which induces folding of the protein and stabilizes the interaction of Tat with microtubules (Egele et al., 2008; Tahirov et al., 2010). This region has also been shown to induce synaptodendritic injury in hippocampal cell culture (Bertrand et al., 2013). The core domain is also necessary for Tat to mediate transactivation, and the residues in this region increase the specificity of binding to the TAR RNA complex and are necessary for Tat function (Jeang et al., 1999; Rana and Jeang, 1999). The arginine-rich or basic domain contains the well-conserved sequence RKKRRQRRRAP. This sequence is critical to the nuclear localization function of the protein, and to the interaction of Tat with the TAR RNA complex, which is a short stem-loop structure in HIV RNA (TAR RNA) bound to a number of cellular factors (Dingwall, 1991; Jeang et al., 1999; Rana and Jeang, 1999; Vives et al., 1997). This region also enables Tat to translocate across the plasma membrane into the cytosol (Futaki et al., 2001), and is responsible for interactions with phosphatidylinositol-4,5-bisphosphate $\left(\mathrm{PI}(4,5) \mathrm{P}_{2}\right)$ that lead to the accumulation of Tat on the cytosolic side of the plasma membrane (Rayne et al., 2010b). The glutamine-rich region is also important for binding the TAR complex (Bayer et al., 1995; Churcher et al., 1993), which greatly enhances transactivation (Green et al., 1989). One study found that mutations in this region alter the ability of Tat to induce T-cell apoptosis (Campbell et al., 2004). The second exon of Tat houses the integrin binding modality. Some studies also indicate that it is necessary for the transactivation function in vitro (Campbell and Loret, 2009). 
Several forms of Tat, including full length Tat-101, a shorter form comprised of only the first exon, Tat 1-72, and another form made up of the first exon and small portion of the second exon, Tat 1-86, are commonly used to study the effects of Tat on the CNS (Aksenova et al., 2009; Eugenin et al., 2007; King et al., 2010; Mishra et al., 2008; Moran et al., 2014) (Figure 1). Although there are numerous studies using these different forms of Tat, the existing literature lacks a comprehensive comparison of different Tat forms on cellular functions in the CNS and specifically dopamine neurotransmission. This review will touch on some of the differences below, but future studies are needed to address this critical knowledge gap.

Tat acts as a transcriptional regulator of HIV gene expression by binding to the TAR element, as well as a complex of cellular transcription factors, such as P-TEFb. These interactions upregulate transcription from the HIV long terminal repeat (LTR) at least 1000fold and promote the elongation phase of HIV transcription (Feinberg et al., 1991; Jeang et al., 1999; Karn and Stoltzfus, 2012). Tat has also been shown to interact with a number of different host proteins and affect a variety of cellular functions, interacting with different cellular structures and signaling pathways, as well as triggering angiogenesis and cell growth (Bagashev and Sawaya, 2013; Emerman and Malim, 1998; Ptak et al., 2008; Romani et al., 2010). Additionally, numerous studies indicate that Tat can be neurotoxic, acting through diverse pathways (Aksenov et al., 2003; Fields et al., 2015; King et al., 2006; Nath, 2002; Silvers et al., 2007).

To initiate the HIV transcription process, Tat is produced during the first round of abortive transcription, before transcription of the full length viral DNA or most other viral proteins. Once translated, Tat returns to the nucleus to enable transcription of full length HIV (Jones and Peterlin, 1994; Kao et al., 1987). In addition to these intracellular functions, Tat is also secreted from infected cells in a temperature dependent manner without lysis of the infected cell (Chang et al., 1997; Ensoli et al., 1990; Ensoli et al., 1993; Rayne et al., 2010a) and in vitro studies demonstrate that Tat can be taken up rapidly by H9, HeLa and U937 cells through lipid-raft dependent micropinocytosis (Frankel and Pabo, 1988; Mann and Frankel, 1991; Wadia et al., 2004). These findings are supported by our own data in Figures $2-4$, which show uptake of Tat from conditioned media by HEK 293 cells, midbrain mouse microglia and midbrain mouse neurons after 48 hours. In vivo, immunohistochemical staining was used to identify Tat protein in monocytes, astrocytes and oligodendrocytes in the frontal cortex and white matter of 3 HIV-infected patients (Del Valle et al., 2000), and in the cytoplasm of astrocytes and microglia in gray and white matter from $10 \mathrm{HIV}$-infected brains (Bonwetsch et al., 1999). A third study also used immunohistochemistry to identify Tat positive cells in the subcortical frontal white matter of 3 out of 4 HIV-infected brain specimens (Hofman et al., 1994). Although the movement and localization of Tat in vivo are not fully resolved, these data suggest that Tat could be taken up by CNS-specific cells in infected areas of the brain. A number of studies have found that low-level HIV replication persists in the CNS of HIV-infected individuals on cART (Chun et al., 2005; Dahl et al., 2014; Eden et al., 2010; Ferretti et al., 2015; Hatano et al., 2010; Palmer et al., 2008). Thus, even in cART-treated patients, Tat could be locally released into the central nervous system by HIV-infected macrophages, microglia or monocytes and influence the surrounding cells. 
In both cART-naïve and cART treated patients, HIV infection of the CNS produces substantial neuropathology in dopaminergic regions. This includes high levels of HIV infection (Brew et al., 1995; Glass et al., 1995), basal ganglial atrophy (Aylward et al., 1995; Aylward et al., 1993; Becker et al., 2011; Hestad et al., 1993), nigral degeneration (Itoh et al., 2000; Reyes et al., 1991), impaired striatal activity (Ortega et al., 2015; Plessis et al., 2015), altered metabolism and metabolite ratios (Gongvatana et al., 2013; Rottenberg et al., 1987; Yiannoutsos et al., 2004) and increased neuroinflammation (Vera et al., 2016).

Decreased expression of both D2 receptors and tyrosine hydroxylase (TH), the rate-limiting enzyme for the dopamine synthesis, as well as changes in the dopamine concentrations, abnormal dopamine metabolism and altered dopamine transporter (DAT) expression and function in the basal ganglia, as measured by fMRI, have been shown to correlate with the cognitive deficits in HIV patients (Chang et al., 2008; di Rocco et al., 2000; Kumar et al., 2011; Obermann et al., 2009b; Zauli et al., 2000). Overall, these data suggest that the infection of CNS macrophages and microglia, and the subsequent release of Tat in dopaminergic regions of the CNS may be one mechanism by which HIV negatively impacts the dopaminergic system. As HIV infection has become a chronic disease, this interaction could persist for the life of the infected individual, causing progressively greater dopaminergic dysfunction. Thus, it is critical to improve our understanding of these effects and to better develop therapeutic strategies that maintain normal dopaminergic function in long-term HIV-infected individuals.

\section{Caveats Regarding the Use of Tat in Model Systems}

Most studies examining the impact of Tat on dopaminergic neurotransmission are performed in vitro or in rodent models, although some studies have also been performed in primate models. Table 1 describes the model system, type and amount of Tat used in the studies referenced in this review. Both in vitro systems and animal models provide an important modality for evaluating the effects of HIV on the dopaminergic system in vivo, and have provided invaluable contributions to our understanding of the mechanisms of HIV- and Tatmediated neuropathology. Although the data from some of the studies in these systems are now being reexamined, it is important to note that these early studies identified important concepts and knowledge gaps in the field. Recent technical and methodological advances have enabled us to build upon these data, leading to new advances in the field while clarifying both the benefits and limitations of each model system. Thus, careful evaluation of data from these systems requires the consideration of a few caveats. First, it is not clear how accurately the amount of Tat used in these studies mimics that found in the CNS of HIVinfected individuals. This is because the precise concentration of Tat and other HIV proteins in the CNS of HIV-infected individuals, and how those concentrations vary across different regions of the CNS, is not known. This is an area that requires further study, and without it the physiological relevance of these systems will remain unclear.

What is known is that Tat is secreted from infected cells (Ensoli et. al., 1990, 1993, Chang et. al., 1997, Rayne et. al., 2010) and taken up rapidly by endocytosis (Frankel and Pabo et. al., 1988, Mann et. al., 1991). This is also shown in Figures 2, 3 and 4, as well as in supplemental Figure 1. These figures demonstrate that HEK 293 cells (Fig. 2, Suppl. Fig. 1), midbrain mouse microglia (Fig. 3) and midbrain mouse neurons (Fig. 4) can both release 
and take up Tat ${ }_{101}$ from the surrounding milieu. While the data presented here, as well as other studies have shown uptake of Tat produced by infected cells, the extent to which this occurs in human CNS cells such as neurons, astrocytes and microglia is not well-defined. In HIV-infected primary CD4+ T-cells, while $2 / 3$ of the Tat produced was released, the concentration resulting from that release was only $0.25 \mathrm{nM} \mathrm{Tat}^{1}$ (Rayne et al., 2010b). The concentration of Tat in the serum of HIV+ individuals is around $0.1 \mathrm{nM}$, and from 0.1 and $0.4 \mathrm{nM}$ in the media of cultures of $\mathrm{HIV}_{\mathrm{IIIB}}$ infected human $\mathrm{H} 9$ T-cells or cultures of transfected mouse T53 cells (Albini et al., 1998; Westendorp et al., 1995). It is still not clear how much Tat is present in specific regions of the human CNS, although 1-3 nM Tat can potentiate or inhibit neurotransmitter release in rodent or human synaptosomes (Feligioni et al., 2003; Musante et al., 2010; Zucchini et al., 2013). Further, the neurotoxic concentration of Tat in vivo is unknown, although the amount of Tat needed to generate neurotoxicity in vitro has been studied extensively and found to be as low as $1 \mathrm{nM}$ (Agrawal et al., 2012; Bansal et al., 2000; Eugenin et al., 2003). Again, this suggests that very low amounts of Tat could potentially impact neurological function. Like many small molecules, local concentrations of Tat may be greater in different compartments, especially in highly infected regions, such as the lymph nodes, lungs or specific regions of the CNS. However, because the concentration and distribution of Tat in the human brain are not known, the extent to which Tat mediates these effects in humans remains unclear.

These concerns are particularly acute regarding the analysis of data from animal models with constitutive protein expression, because these models do not produce viral proteins by means of the same regulatory process(es) as HIV infection. In these systems Tat is not produced from the same type(s) or quantities of cells, nor from the same brain regions, as it is in natural infection. Additionally, the Tat protein aggregates regularly, so it is possible that constitutive production of Tat may produce larger and/or less active Tat multimers (Hategan et al., 2016). Thus, degree to which the concentration, distribution and multimerization of Tat in the CNS of these animal models approximates HIV-infected human CNS is not clear, and therefore careful consideration must be given to the data derived from these systems.

The final caveat, which applies more specifically to animal models examining the effects of Tat on the dopaminergic system, is the dissimilar size of the human brain relative to the brains of primates and rodents (Barton and Harvey, 2000; MacLeod et al., 2003). These increases in size not only lead to changes in the number of specialized sub-regions of the CNS, they also create significant changes in the microstructure of the CNS (Passingham, 2009). Furthermore, while mammalian dopaminergic systems overall are fairly similar, (Joel and Weiner, 2000; Johnston et al., 1990; Murphy et al., 1996) there are substantial anatomical differences between rodents and primates, as well as some between humans and lower primates. For example, in primates there is a distinct separation between the caudate and the putamen that does not exist in rodents. There are species specific differences in the proximity and orientation of globus pallidus and subthalamic nucleus, and the dopaminergic

\footnotetext{
${ }^{1}$ To better compare all experiments, the molar concentration of HIV-Tat in each experiment was calculated from the reported amounts of Tat used in these studies. The molecular weight of HIV-1 Tat is 9860 Daltons (Da), or 9860 grams per mole. This means that $9860 \mathrm{~g}$ of Tat (approximately 1 mole) in $1000 \mathrm{~mL}$ is approximately $1 \mathrm{M}$, and that $9860 \mathrm{ng}$ in $1 \mathrm{~mL}$ is approximately $1 \mu \mathrm{M}$. Using this calculation, $1 \mathrm{ng} / \mathrm{mL}$ is equivalent to $0.1 \mathrm{nM}$, and $4 \mathrm{ng} / \mathrm{mL}$ is equivalent to $0.4 \mathrm{nM}$.
} 
terminals in those regions, relative to other dopamine-rich brain regions, and changes in the amount and destination of striatal projections (Joel and Weiner, 2000; Zeiss, 2005). Primates and rodents also show distinct ratios of different types of neurons in the substantia nigra (Poirier et al., 1983). Primates have greater levels of dopaminergic innervation in the thalamus than do rodents (Garcia-Cabezas et al., 2009), while humans have significantly greater levels of dopaminergic innervation in the frontal cortex than do macaques (Raghanti et al., 2009). Additionally, there are differences in the metabolism of dopamine and other biogenic amines in rodents, primates and humans (Meiser et al., 2013). This could lead to changes in the concentration and/or distribution of dopamine in the CNS, as well as the response to different dopaminergic drugs. For example, the ratios of monoamine oxidases (MAO) A and B are different in rodent versus primate brains, resulting in most dopamine oxidation being carried out by MAO-A in rodent brains but MAO-B in primate brains (Garrick and Murphy, 1980; Napolitano et al., 1995). These comments are not to say that data from in vitro studies and animal models should be ignored, as they are extremely valuable sources of information regarding the direct and indirect impact of HIV proteins on dopaminergic neurotransmission. However, the important caveats associated with these systems must be carefully considered when interpreting the data.

\section{Dopaminergic Neurotransmission, HIV infection and Tat}

Dopamine (DA) plays a critical role in a number of CNS functions, including motor control, reward, cognition, motivation, executive function, and maternal behavior (Beaulieu and Gainetdinov, 2011; Klanker et al., 2013; Nieoullon, 2002; Nutt et al., 2015). Although clusters of dopaminergic neurons can be found in several different regions of the CNS, the majority of dopamine neurotransmission occurs within four known pathways, which are shown in Figure 5. These pathways are the nigrostriatal pathway (pink), the tuberoinfundibular pathway (orange), and the mesolimbic (red) and mesocortical pathways (yellow). In the brain, dopamine is synthesized in dopaminergic and adrenergic neurons, where the rate-limiting enzyme tyrosine hydroxylase $(\mathrm{TH})$ converts L-tyrosine to L-DOPA, the precursor of dopamine (Flatmark, 2000; Hornykiewicz, 2002). Dopamine can be released via two distinct mechanisms. The first mechanism is through classical vesicular release, while the second mechanism is through DAT-mediated dopamine efflux (Gainetdinov et al., 1997; Goodwin et al., 2009; Jones et al., 1999b; Khoshbouei et al., 2003; Wall et al., 1995). The second mechanism, DAT-mediated dopamine efflux, has been predominantly studied in the context amphetamine and methamphetamine regulation of dopamine release. Like other neurotransmitters, dopamine is released from synaptic vesicles fused with the plasma membrane following an action potential (Sulzer and Galli, 2003; Sulzer et al., 2005), shown in Figure 6. However, dopamine-transporter mediated dopamine efflux transports dopamine from inside the neuron to outside via an action potentialindependent mechanism (Sulzer and Galli, 2003; Sulzer et al., 2005), albeit under certain conditions, such as exposure to amphetamines, as detailed in Figure 7. Therefore, changes in the firing rate of dopamine neurons and DAT-mediated dopamine efflux directly affect dopamine concentration in the synapse and extracellular space (Butler et al., 2015).

Early in the HIV epidemic, it was shown that HIV infection impacts the dopaminergic system and dopamine metabolism in the CNS (Berger et al., 1994; di Rocco et al., 2000; 
Kieburtz et al., 1991; Koutsilieri et al., 1997; Koutsilieri et al., 2002a; Koutsilieri et al., 2002b; Larsson et al., 1991; Nath et al., 2000; Sardar et al., 1996; Silvers et al., 2006). Even in the era of cART, several studies have shown HIV infection alters dopamine concentrations and metabolism in the brain (Horn et al., 2013; Kumar et al., 2009; Kumar et al., 2011; Meulendyke et al., 2014; Scheller et al., 2010). Elevated dopamine has been shown to increase HIV infection of macrophages, the primary target for and source of HIV in the CNS (Gaskill et. al., 2009, 2014), potentially creating a vicious cycle by which dopaminergic dysfunction spurs greater infection, which then exacerbates dopaminergic dysfunction. While previous studies have examined the effects of HIV infection and viral protein expression on dopamine neurotransmission indirectly by evaluating changes in dopaminergic proteins, the direct effects of HIV infection, or of the Tat protein, on the regulation of firing activity or excitability of dopamine neurons in the brain remain undetermined.

As shown in Figure 5, there are three primary clusters of DA neurons, two in the mid-brain and one in the hypothalamus. In the midbrain, cluster A9 is found in the substantia nigra pars compacta (SNc) and cluster A10 is in the ventral tegmental area (VTA). A third smaller cluster, A8, can be found in the retrorubral area (RR) (Bjorklund and Dunnett, 2007; Fu et al., 2012; Nestler, 2009; Zaborszky and Vadasz, 2001). Despite resembling each other in many respects, dopamine neurons of the SNc and VTA area mediate distinct functions and exhibit dissimilar responses to toxins and addictive agents (Choi et al., 2015; Teo et al., 2004). Since the discovery of dopamine as a neurotransmitter (Carlsson et al., 1962) and the observation that dopamine was significantly depleted in the SNc of patients with Parkinson's disease (Benazzouz et al., 2014; Hornykiewicz and Kish, 1987; Tremblay et al., 2015), the regionally selective vulnerability of dopamine neurons has been the focus of a large number of studies (Bernheimer et al., 1973; Braak and Braak, 1986; Braak et al., 2003; Burns et al., 1983; Damier et al., 1999; Double et al., 2010; Fearnley and Lees, 1991; German et al., 1992; Gibb and Lees, 1991; Greenfield and Bosanquet, 1953; Halliday and Tork, 1986; Hirsch et al., 1989; Poulin et al., 2014).

It is not clear whether HIV infection or the Tat protein differentially affect distinct clusters of dopamine neurons in the brain. This type of regional difference has been shown in the differential vulnerability of dopaminergic neurons in the VTA and SNc when exposed to neurotoxins such as MPTP (Elsworth et al., 1990; Rothblat and Schneider, 1994; Rothblat et al., 2001; Schneider et al., 1987). Some patients with HIV dementia develop acute onset Parkinsonism and dystonia when treated with dopamine receptor antagonists (Hriso et al., 1991), and patients on cART can also develop parkinsonism (Tisch and Brew, 2009). In methamphetamine-treated rodents, an intra-nigral infusion of $10 \mu \mathrm{g} / \mu \mathrm{L}$ (approximately 1 $\mathrm{mM}$ ) Tat was shown to exacerbate Parkinson-like locomotor deficit (Liu et al., 2014). This is consistent with reports showing methamphetamine-induced behavioral sensitization were enhanced in HIV-1 Tg rats (Kass et al., 2010). These data suggest Tat might directly or indirectly affect the cluster of dopamine neurons involved in regulation of locomotor activity. Recent reports suggest VTA dopamine neurons might also be a target of the Tat protein. In transgenic mice with doxycycline-induced Tat protein expression in the brain (GT-tg bigenic mice), reward thresholds were elevated by $20 \%$ in Tat $^{+}$mice compared with Tat $^{-}$mice. Additionally, dopamine levels were increased in the caudate putamen and 
decreased in the nucleus accumbens (Kesby et al., 2016b). Studies in this animal model have also shown an increased sensitivity to cocaine-induced psychomotor responses in the Tat ${ }^{+}$ GT-tg bigenic mice (Paris et al., 2014a). These studies suggest Tat expression, in the absence of active HIV replication, may target the dopaminergic neurons in the mesolimbic and mesocortical pathways, although the specific mechanism remains undetermined. However, a recent study by Fan and He, using a doxycycline-inducible, astrocyte-specific HIV-1 Tat transgenic mouse model, demonstrated that increased Tat expression led to aggregation of GFAP, and the induction of a UPR in astrocytes (Fan and He, 2016a). The induction of UPR causes increased lysosomal exocytosis from astrocytes, which leads to astrocyte-mediated neurotoxicity (Fan and He, 2016b). This data from the doxycycline-inducible animal model suggests that Tat mediated neurotoxic effects may not be specific to dopaminergic systems, and also reinforces the concerns noted above regarding the unknown effects of Tat expression in animal models.

Although several studies using total striatal tissue homogenates from rodents have examined the impact of Tat on DAT function, these are difficult to correlate with the precise dopaminergic neurons clusters being affected due to the lack of anatomical specificity in the homogenates. To address these concerns, future studies could examine the amount of Tat expressed in different dopaminergic compartments in the brains of Tat-expressing animal models. This could then be correlated with changes in the expression of dopaminergic proteins such as DAT, TH or dopamine receptors in these regions.

In the substantia nigra, studies showed a significant decrease in tyrosine hydroxylase (TH) and phosphorylated TH (pTH) in HIV-infected adult human tissues (Gelman et al., 2006; Silvers et al., 2006). This suggests an alteration in dopamine production, as $\mathrm{TH}$ phosphorylation at Ser40, and to a lesser degree at Ser31, increases TH activity and subsequently catecholamine synthesis (Dunkley et al., 2004; Salvatore et al., 2001). Additionally, in rodents stably transplanted with Tat-producing C6 glioma cells in the striatum, Tat is transported from the striatum to the substantia nigra, resulting in neurotoxicity and decreased TH expression in that region (Bruce-Keller et al., 2003). This is consistent with reports by Zauli and colleagues showing a Tat-mediated decrease in TH expression in rat neurons (Zauli et al., 2000). These data suggest dopaminergic neurons in the substantia nigra may be more susceptible to Tat-induced neurotoxicity, providing an alternate explanation for the reduction of TH staining in Tat exposed model systems. Although the underlying mechanism(s) is not understood, these and other studies suggest that HIV infection and/or Tat expression can result in a loss or dysfunction of dopamine neurons in the substantia nigra (Itoh et al., 2000; Obermann et al., 2009a; Reyes et al., 1991). Positron emission tomography studies have shown decreased DAT expression in the putamen and ventral striatum of infected patients with HIV-associated dementia (Wang et al., 2004); however, Gelman and colleagues found an increase in DAT expression in postmortem human striatal tissue homogenate (Gelman et al., 2006).

This discrepancy might be due to the differences in the development of the infection, as HIV infected patients who display dementia have decreased DAT levels as compared to those with HIV who do not have dementia (Itoh et al., 2000; Wang et al., 2004). The disparate conclusions might be due to methodological differences. For example, Itoh et al., examined 
the size and density of pigmented and non-pigmented neurons in the SNc; whereas, Gelman et al., have used striatal tissue homogenate containing terminal regions. Overall, these and other studies showing HIV and/or Tat-associated neuropathology in dopaminergic regions may describe a potential mechanism for the clinical symptoms, such as Parkinson-like movement disorders, bradykinesia, tremor or postural instability in HIV patients (Arendt et al., 1994; Navia et al., 1986) even after antiretroviral therapy (Valcour et al., 2008). However, the conflicting results of these studies, the relatively small number of region specific studies and the relative difficulty of interrogating these questions in vivo have kept the precise mechanism(s) by which both HIV and/or Tat impact the dopaminergic system unclear. Importantly, the specificity of the untoward effect(s) of Tat on dopaminergic neurons in the SNc is unclear, as there is no information on the effects of Tat on other neuronal types in this brain region. Therefore, further studies specifically examining the effect of Tat and/or HIV infection on the activity of different clusters of dopaminergic neurons and terminal regions are necessary to better understand and potentially treat the various effects of Tat and/or HIV infection on dopamine neurotransmission.

\section{Tat and Cognition: The Dopamine Link}

Due to the success of combined antiretroviral therapy (cART), the prevalence of HIVassociated neurocognitive disorders (HAND) is growing as individuals infected with HIV live longer. While HIV infection of the CNS produces a variety of neurocognitive deficits, (Anderson et al., 2015; Berger et al., 1994; Byun et al., 2016; Heaton et al., 2014; Janssen et al., 2016; Plessis et al., 2015; Plessis et al., 2014), the mechanisms underlying these deficits are poorly understood. Currently, between 40 and $70 \%$ of HIV-infected individuals suffer from some form of HAND (Cysique et al., 2004; Heaton et al., 2010a; Heaton et al., 2011a; Simioni et al., 2010; Tozzi et al., 2005), although the frequency of the more severe pathologies and neurocognitive disorders such as encephalitis and HIV dementia has declined significantly in the cART era. Similarly, the frequency of individuals with HAND who are asymptomatic or have minor cognitive impairments has significantly increased (Ellis et al., 2007; Heaton et al., 2011a). While it is commonly accepted that neuroinflammation and the resultant neurotoxicity play a central role in the development of HAND, there are also a number of studies implicating alterations in neurotransmission in the development of these disorders. Dopaminergic, glutamatergic and cholinergic neurotransmission have all been studied as a central factor in the development of HIVassociated neurological disorders (Fitting et al., 2010; Hargus and Thayer, 2013; Koutsilieri et al., 2000; Ozdener, 2005).

Prior to cART, numerous studies found that patients with HIV Associated Dementia (HAD) exhibit many symptoms common to diseases involving dopaminergic dysfunction, such as damage to the basal ganglia and substantia nigra, psychomotor impairment, attention difficulties, obsessive ruminations and decreases in coordination (Aylward et al., 1994; Aylward et al., 1993; Czub et al., 2001; Itoh et al., 2000; Kieburtz et al., 1991; Koutsilieri et al., 2001; Maj, 1990; Nath et al., 1999; Navia and Price, 1987; Reyes et al., 1991; Sardar et al., 1996). Individuals with HAD on stable cART therapy also show decreased DAT availability in the putamen and ventral striatum, correlating with decreased neurocognitive performance (Chang et al., 2008; Wang et al., 2004). Similar results show association 
between dopamine deficits, microglial activation and regulation of cAMP signaling in the brains of SIV-infected monkeys (Jenuwein et al., 2004; Scheller et al., 2005). Moreover, this and other studies have identified a direct correlation between the higher plasma viral load in patients with HIV dementia and lower DAT expression in the caudate and putamen (Berger et al., 1994; Kramer and Sanger, 1990; Wang et al., 2004). As discussed above, recent studies suggest Tat may influence dopamine neurotransmission by altering DAT function (Midde et al., 2012; Midde et al., 2015b; Yuan et al., 2015b; Yuan et al., 2016; Zhu et al., 2009), and therefore some portion of HIV-mediated cognitive impairment may be the result of impaired dopaminergic neurotransmission due to dysfunction in dopamine transporter proteins. This will be discussed in detail in the following section.

Supporting this idea, several studies treating animals with Tat alone have demonstrated cognitive and behavioral impacts similar to those seen in HIV-infected individuals. Studies using GT-tg bigenic mice have found that doxycycline induction of Tat produces deficits in working and spatial memory. Also, MRI studies in these mice have found a significant reduction in gray matter in areas associated with learning and memory including the entorhinal cortex, hippocampus and amygdala (Carey et al., 2013). Studies in this animal model also suggest the association of Tat with other psychiatric complications. One week of doxycycline-mediated Tat induction produced anhedonia, increased the animals' sensitivity to psychostimulant-induced reward enhancement (Kesby et al., 2016b), and also increased anxiety-like behaviors (Paris et al., 2014b). Similar symptoms can be found in HIV infected individuals, who also display an increased propensity for anxiety disorders and disruption of the reward system (Anderson et al., 2015). In a rat model, intra-hippocampal injection of Tat disrupts the acoustic startle response and pre-pulse inhibition (Fitting et al., 2006). Pre-pulse inhibition (PPI) is a neural mechanism is used to measure adaptive inhibition mechanisms, and has been shown to be decreased in patients with HAND, but not HIV-infected individuals without neurocognitive deficits (Minassian et al., 2013). It is important to note that while suggestive of a direct link with Tat, none of these studies have examined the amount or distribution of Tat in the brain region(s) relevant to the reported neurophysiological measures described above, therefore, the causal bearing of these effects requires further investigation.

Notably, these studies are all focused on the shorter-term impact(s) of Tat on cognition, with the longer-term neurological consequences of Tat exposure not being studied. However, the pivotal role of dopamine neurotransmission in synaptic plasticity and cognition are well established (Backman et al., 2010; Jay, 2003; Otani et al., 2003); therefore, Tat-mediated disruption of DAT function may also impact synaptic plasticity. Treatment of rat CA1 hippocampal slices with Tat suppresses long-term potentiation (LTP), which is representative of suppression of learning and memory (Behnisch et al., 2004; Li et al., 2004). Tat also affects synaptic plasticity by decreasing excitatory synapses and increasing inhibitory synapses (Fitting et al., 2013; Hargus and Thayer, 2013), by altering the expression of dendritic spines and distribution of synaptic proteins (Fitting et al., 2010; Hahn et al., 2015) and by modulating interaction between microglial-neuronal "synapse" interaction (Tremblay et al., 2013). Only one behavioral study has examined the long-term effect of Tat on cognition (Hahn et al., 2015). Hahn and colleagues found mice expressing Tat in the CNS for 3 months exhibited deficits in open-field ambulation, with male mice also demonstrating 
motor memory deficits, both behaviors linked to dopaminergic damage (Hahn et al., 2015). It is essential to increase the number of long-term studies examining the prolonged effect(s) of Tat on cognition, because as antiretroviral therapies continue to improve, so will the number of long-lived HIV-infected individuals with expression of viral proteins in the CNS. Collectively these data strongly suggest HIV and Tat alone can impact the dopaminergic system and thus cognition. Therefore, it is critical to conduct further research addressing the medium and longer term impact of HIV infection and Tat on dopamine-driven cognitive processes, so that we are better prepared to treat the deficiencies resulting from living with HIV long-term.

\section{Tat and Dopamine Transporter Function}

The dopamine transporter (DAT) plays a central role in dopaminergic neurotransmission as the primary regulator of extracellular dopamine concentrations. The DAT removes dopamine from the synapse by transporting it into the pre-synaptic neuron across the plasma membrane using the concentration gradient generated by $\mathrm{Na}^{+} / \mathrm{K}^{+}$ATPase (Khoshbouei et al., 2003; Sonders et al., 1997). Dopamine returned to presynaptic neurons is then placed in synaptic vesicles for storage and reuse. The reuptake process is critical, as it controls the magnitude and duration of dopamine receptor activation on the pre- and postsynaptic neurons (Gainetdinov et al., 1999; Sulzer et al., 2016). Loss of DAT activity leads to decreased tissue dopamine levels (Jones et al., 1999a; Rocha et al., 1998; Salahpour et al., 2008; Zhuang et al., 2001) and has been implicated in several neurodegenerative diseases, attention deficit hyperactivity disorder (ADHD), and altered sensitivity to psychostimulants (Bowton et al., 2010; David et al., 2008; Mazei-Robison et al., 2008; Nakamura et al., 2010; Volkow et al., 2014). A significant number of studies over the last 20 years have led to the discovery of molecular and cellular mechanisms involved in DAT regulation and it availability at the plasma membrane of the dopamine neurons. A plethora of different kinases, scaffolding proteins, and receptors regulate DAT-mediated dopamine uptake, dopamine efflux, conformational state of DAT, oligomerization, and trafficking of the transporter (Aksenov et al., 2008; Bowton et al., 2014; Cartier et al., 2015; Fog et al., 2006; Guptaroy et al., 2009; Hamilton et al., 2014; Hansen et al., 2014; Kahlig et al., 2005; Khoshbouei et al., 2004; Lute et al., 2008; Reddy et al., 2016; Sakrikar et al., 2012; Speed et al., 2011; Wei et al., 2007). The cell specificity and complexity of DAT regulation highlight the potential perils of cursory approach when examining Tat modulation of DAT function. There are a number of studies in the field that have begun to describe the effect of HIV-1 Tat on the activity of DAT (Aksenova et al., 2006; Bucci, 2015; Ferris et al., 2009; Midde et al., 2012; Midde et al., 2013; Midde et al., 2015a; Zhu et al., 2016). While these and other recent studies suggest Tat may interact with DAT to modulate its functions, technical limitations such as the lack of available Tat specific antibodies and the large amount of Tat used in these studies limit interpretation (Midde et al., 2012; Midde et al., 2013; Midde et al., 2015a; Yuan et al., 2015a; Yuan et al., 2016; Zhu et al., 2011; Zhu et al., 2009; Zhu et al., 2015). Despite these limitations, these studies suggest the effects of HIV infection on the dopaminergic system may, at least in part, be mediated by Tat-specific changes in DAT function. (Chang et al., 2008; Maragos et al., 2003; Perry et al., 2010; Wang et al., 2004). In 
order to build upon these results, future studies should focus on examining the molecular mechanisms in the biologically relevant model systems using Tat specific antibodies.

HIV-infected patients who display dementia have decreased DAT levels as compared to both controls and those with HIV who do not have dementia. Specifically, the loss of DAT molecules is most apparent in the caudate and putamen region, similar to Parkinson's disease and other frontal-striatal pathologies (Itoh et al., 2000; Wang et al., 2004). Though the loss of DAT has been implicated in HIV infection of the CNS, and the Tat protein has been shown to regulate DAT activity through decreased DAT expression, a correlation has not been fully established between the rate of HIV-mediated CNS disease progression, loss of neuronal activity and ultimately neuronal damage or death. Therefore, future studies are needed to measure decreased DAT activity at earlier stages of HIV infection using acutely infected individuals prior to the initiation of therapy, and to measure Tat production and loss of DAT at the later stages of HIV-mediated neurological disorders.

Several studies reported that Tat, in the absence of viral replication, may negatively affect dopamine transmission by targeting DAT activity, without affecting total DAT levels in striatal homogenates. In rat striatal synaptosomes, Tat reduced DAT mediated dopamine uptake without changing total DAT immunoreactivity (Aksenova et al., 2006; Wallace et al., 2006; Zhu et al., 2009), although changes in the distribution of DAT to the membrane and intracellular compartments were not examined. As functional DAT molecules are located at the plasma membrane (Bowton et al., 2010; Bowton et al., 2014; Cremona et al., 2011; Sakrikar et al., 2012), a decrease in DAT activity usually correlates with increased intracellular DAT, as internalization represents decreased activity of the transporter. However, it is possible that direct or indirect (via DAT's partner proteins) interaction between DAT and Tat reduces DAT activity by altering DAT conformation to obscure DA binding sites on DAT molecules without affecting its trafficking. Consistent with the latter hypothesis, DAT antagonists have shown to block both the activity and trafficking of the transporter. As the protein is readily detected in tissues or cell lysates, immunolabeling of membrane DAT should be used to more conclusively determine the mechanism(s) of Tat mediated changes in DAT function.

To date there is only one study that has directly examined the role of Tat in the highly regulated cellular processes controlling DAT. This study examined Tat regulation of cell surface redistribution of DAT, and indicated that Tat may induce DAT internalization via a PKC dependent mechanism (Midde et al., 2012). It is not known, however, whether Tat affects regulated DAT trafficking, i.e. amphetamine or methamphetamine regulation of DAT trafficking, or cocaine-induced increases in DAT at the plasma membrane (Daws et al., 2002). Recent studies by Blakley and colleagues have shown that PKC-regulation of the constitutive and regulated DAT trafficking is complex. Accelerated rates of constitutive endocytosis and recycling of DAT may show no change in the total or surface DAT, but significantly affect the kinetics of DAT trafficking (Mazei-Robison et al., 2008; Sakrikar et al., 2012). Given the relatively high percentage of HIV+ individuals who abuse psychostimulants (Beyrer et al., 2010; Crime, 2014; Mathers et al., 2008), it is important to determine whether and how Tat affects the kinetics of DAT at the plasma membrane following methamphetamine or cocaine exposure. For example, it has been shown that 
amphetamines' regulation of DAT trafficking is two-fold; they cause DAT internalization (Guptaroy et al., 2009; Holton et al., 2005; Hong and Amara, 2013; Kahlig and Galli, 2003; Kahlig et al., 2006; Moron et al., 2003; Mortensen and Amara, 2003; Saunders et al., 2000; Wu et al., 2015) via CaMKII and PKC-dependent mechanisms as well as a DAT-dependent membrane depolarization (Boudanova et al., 2008; Hong and Amara, 2013; Mortensen et al., 2008; Navaroli et al., 2011; Richardson et al., 2016). This suggests DAT trafficks via a voltage-dependent mechanism in addition to PKC- and CaMKII-mediated DAT phosphorylation. On the contrary, cocaine has been shown to rapidly increase surface DAT level (Daws et al., 2002). Therefore, a careful examination of the Tat regulation of DAT trafficking will provide critical mechanistic information on how acute or prolonged exposure to Tat regulates dopamine neurotransmission.

Though the time-dependent and the precise level of Tat in the CNS of HIV-infected individuals are unknown, studies have shown that much higher concentrations of Tat, between 1 and $10 \mu \mathrm{M}$, decrease dopamine uptake through DAT (Aksenov et al., 2008; Zhu et al., 2009). But it is not clear whether Tat directly or indirectly regulates dopamine uptake by modulating the activity of other membrane proteins or intracellular targets known to modulate dopamine uptake via DAT. As an example, estrogen appears to reduce Tat enhancement of oxidative stress and protect against DAT loss (Wallace et al., 2006). This may explain why male mice exposed to Tat have more severe motor deficits and greater changes in striatal neuronal morphology as compared to their female counterparts (Hahn et al., 2015). Recent studies have generally focused on the outcome of the interaction of Tat and DAT, but the mechanism underlying this potential interaction remains unclear. Studies by Zhu et al. suggest Tat acts as an allosteric modulator of DAT, as opposed to a reuptake inhibitor or a substrate-type releaser (Zhu et al., 2011; Zhu et al., 2009).

Surface plasmon resonance analysis performed in rat striatal synaptosomes suggests Tat directly interacts with DAT in a concentration-dependent manner (Zhu et al., 2009). Additional studies from this group concluded that Tat binds to Tyr470 on the DAT, as mutation of this residue attenuated the effects of Tat on dopamine uptake in CHO cells transfected with human DAT (Midde et al., 2013). Interactions with the DAT residues Tyr88 and Lys92 have been shown to be required for Tat mediated inhibition of DAT, as mutation of these residues also altered the DAT response to Tat binding (Midde et al., 2015a; Yuan et al., 2015a). Studies by Yuan et al. (2015) suggest Tat may stabilize the inward facing conformation of DAT, which limits the availability of extracellular dopamine binding sites on the transporter molecule, thereby attenuating dopamine uptake (Midde et al., 2015a; Yuan et al., 2015a). However, it is not clear whether Tat regulation of dopamine uptake is a consequence of its binding to the external or internal domains of DAT molecules. Additionally, as the specificity of Tat/DAT interaction has not been examined, it is possible that Tat modulates DAT activity through indirect binding to different membrane proteins. Future studies in this area should address these possibilities, and also address the fact that dopamine uptake and efflux are independently regulated (Khoshbouei et al., 2004). This would enable determination of whether Tat simply increases the inward facing conformation of DAT that is expected to increase dopamine efflux, or if it acts as an antagonist to block both uptake and efflux. 
Currently, there is no information about Tat regulation of DAT conductance and biophysical properties of the transporter. The molecular and biophysical mechanism by which the Tat/DAT interaction governs DAT function, the potential Tat-mediated alterations in $\mathrm{Na}^{+} / \mathrm{Cl}^{-}$ coupling of DAT molecules, lipid rich versus lipid poor membrane distribution of the transporter, the kinetic of DAT trafficking, its interaction with partner proteins or its phosphorylation levels, all of which known to regulate DAT activity, are yet to be determined (Butler et al., 2016; Cervinski et al., 2010; Cremona et al., 2011; Erlendsson et al., 2014; Foster and Vaughan, 2011; Hong and Amara, 2010; Pizzo et al., 2013; Sakrikar et al., 2012; Sorkina et al., 2013). While further investigation is necessary to determine the mechanism(s)by which Tat regulates DAT activity and the firing activity of dopamine neurons, the existing literature suggest that Tat alters dopamine neurotransmission within the CNS. This is consistent with the susceptibility of HIV-1 infected patients to abuse of illicit drugs, such as cocaine and methamphetamine, that target monoaminergic systems such as midbrain dopamine neurons (Goodwin et al., 2009; Lin et al., 2016; Saha et al., 2014), and to the higher sensitivity of (GT-tg bigenic mice) mice to psychostimulants (Kesby et al., 2016a; Mediouni et al., 2015a; Paris et al., 2014a). Further developing our understanding of the precise mechanism(s) by which of Tat regulates DAT might be a key in the development of effective therapeutic approaches designed to ameliorate the damaging and disruptive effects of Tat and HIV infection on DAT activity and the dopaminergic system.

\section{Tat and Dopamine Receptors}

The data described above suggest Tat is involved in at least some of the dopaminergic dysfunction described in HIV-infected individuals. While studies clearly show a link between Tat and DAT, the direct effect(s) of Tat on the dopamine receptors is unclear. Dopamine mediates its regulatory actions by means of G-protein coupled receptors (GPCR) called dopamine receptors, which can be separated into two subtypes: D1-like (D1 and D5) and D2-like (D2, D3 and D4) receptors (Figure 6). The D1-like receptors couple to $\mathrm{Ga}_{\mathrm{s} / \mathrm{olf}}$, activating adenylyl cyclase and D2-like receptors couple to $\mathrm{Ga}_{\mathrm{i} / \mathrm{o}}$, inhibiting it. The difference subtypes of dopamine receptors also activate a number of other distinct and overlapping signaling pathways. (Beaulieu and Gainetdinov, 2011; Missale et al., 1998).

There are few studies investigating the direct interaction of dopamine receptors and Tat. A number of studies by Booze and colleagues have found, in rat midbrain neurons, blockade of D1-like receptor by SCH23390 decreases the neurotoxic effects of Tat in the presence or absence of methamphetamine (Aksenova et al., 2006; Silvers et al., 2007). These data suggest that D1-like receptors play a role in Tat-mediated neurotoxicity, albeit with a less understood molecular mechanism. There are even fewer studies that have specifically examined the interaction of Tat with D2-like dopamine receptors, either on neurons or on cell types such as macrophages, which are infected with HIV and express D2-like receptors (Gaskill et al., 2009; Gaskill et al., 2012). In a recent study, Gaskill and colleagues proposed there might be a link between HIV entry and $\mathrm{Ca}^{2+}$ flux that is mediated by activation of both D1-like and D2-like receptors, but this study did not investigate the specific interaction of the Tat protein with either subtype of dopamine receptor (Gaskill et al., 2014). 
This paucity of data suggests that there is a significant need for studies directly addressing the impact of Tat on dopamine receptor mediated signaling. To this end, other studies examining the impact of Tat on other drug-related GPCR, such as opioid and cannabinoid receptors, might provide a template for investigation of possible mechanisms for Tat regulation of dopamine receptors. For example, studies by Turchan-Cholewo et al. found that Tat prevented morphine-induced downregulation of opioid receptor expression on the plasma membrane of microglia and astrocytes (Turchan-Cholewo et al., 2008). A more recent study found that macrophage migration toward the Tat protein was significantly inhibited by endogenous cannabinoid agonists for the CB2 receptor (Raborn and Cabral, 2010). These reports suggest Tat could potentially influence multiple cellular processes, such as receptor expression and cell migration, potentially through interactions with GPCR. $\mathrm{G}_{\alpha}$-subtype coupled receptors are promiscuous, where the nature of host environment will determine their signaling outcomes. Thus, it is possible that Tat-GPCR interactions mediate diverse signaling cascade per the nature of host system and its level of activity. Future investigations will determine the specific molecular interaction(s) between the dopamine receptors and Tat, and the possible functional outcomes of this interaction.

\section{Tat and Psychostimulant Abuse}

Throughout the AIDS epidemic, drug abuse has been an important comorbidity in HIV infection (El-Bassel et al., 2014; Halkitis et al., 2001; Kumar et al., 2014; Vongsheree et al., 2001). Substance abuse is far more common among HIV-infected individuals than in the general population (Beyrer et al., 2010; Crime, 2014; Mathers et al., 2008), and increases the risk of acquiring HIV infection by engendering risky behaviors (El-Bassel et al., 2014; Halkitis et al., 2001; Huff, 2006), but the biological effects of drugs of abuse on HIV infection are less clear. While a number of studies have found that psychostimulant abuse accelerates the progression of HIV and related diseases, irrespective of its effects on adherence (Baum et al., 2009; Burbano et al., 2001; Kipp et al., 2011; Lucas et al., 2006; Moore et al., 2004; Webber et al., 1999), other reports contradict this finding. (Cofrancesco et al., 2008; Edelman et al., 2015; Milloy et al., 2016; Thames et al., 2016).

The effects of drugs of abuse on HIV neuropathogenesis are similarly unclear. A number of studies have found that the interaction of HIV and drug abuse accelerated neuropathology and/or neurocognitive dysfunction, compared with both non-HIV infected drug abusers (Gray et al., 1992; Makrigeorgi-Butera et al., 1996) or HIV-infected non-drug abusers (Carey et al., 2006; Kousik et al., 2012; Langford et al., 2003a; Meade et al., 2011b; Nath et al., 2002; Rippeth et al., 2004; Starace et al., 1998; Tomlinson et al., 1999). However, many of these studies examine therapy-naïve individuals, and several studies have also shown that drug abuse combined with HIV has little impact on cognition (Basso and Bornstein, 2003; Byrd et al., 2012; Byrd et al., 2011a). Therefore, the precise impact of drug abuse on the development of HIV-associated neurocognitive disorders, particularly in the era of cART remains undefined. Numerous studies have also examined specifically the effects of the Tat protein in conjunction with drugs of abuse, both as a surrogate for general HIV infection and as a stand-alone protein (Bokhari et al., 2009; Cass et al., 2003; El-Hage et al., 2008; ElHage et al., 2005; Fitting et al., 2014; Flora et al., 2005). Much of this data is summarized in several excellent recent reviews (Fitting et al., 2015; Hauser and Knapp, 2014; Maubert et 
al., 2015; Mediouni et al., 2015b), thus this section will focus on the direct impact of Tat specifically on the dopaminergic system.

In both the pre- and post-cART eras, research in infected individuals has shown high levels of HIV infection and associated neuropathology throughout the basal ganglia (Aylward et al., 1993; Becker et al., 2011; Fujimura et al., 1997; Gongvatana et al., 2013; Hestad et al., 1993; Vera et al., 2016; Wright et al., 2014; Yiannoutsos et al., 2004) where the highest density of dopaminergic terminals are located (Alexander et al., 1986; Haber, 2014; Lanciego et al., 2012). Therefore, the neurotoxic effects of psychostimulants, such as cocaine and methamphetamine, on the dopaminergic terminals are predicted to be exacerbated in during HIV infection. These drugs directly target dopamine neurons in the basal ganglia, and increase CNS dopamine by blocking dopamine reuptake (Ritz et al., 1987; Volkow et al., 1997) and inducing dopamine efflux (Branch and Beckstead, 2012; Goodwin et al., 2009; Sulzer et al., 2005).

Although the underlying mechanisms for the interaction between HIV and methamphetamine are not fully understood, methamphetamine seems to synergize with Tat to affect a number of neurocognitive processes (Mediouni et al., 2015a), including direct damage the dopaminergic system. Using proton magnetic resonance spectroscopy $\left({ }^{1} \mathrm{H}\right.$ MRS), Chang and colleagues have found additive effects of HIV and chronic methamphetamine abuse on brain metabolite abnormalities (Chang et al., 2005). In an in vivo rodent model, Tat and methamphetamine synergistically increase loss of striatal dopamine terminals (Cass et al., 2003; Maragos et al., 2002; Theodore et al., 2006a; Theodore et al., 2006b; Theodore et al., 2007). The cooperative effects of Tat and methamphetamine have also been shown to enhance the motor-stimulant response to a recurrent exposure to methamphetamine, a demonstration of behavioral sensitization (Liu et al., 2009). One possible mechanism by which methamphetamine could enhance the effects of Tat in humans is through an increase in extracellular dopamine by inhibition of dopamine uptake, which could increase HIV replication (Gaskill et al., 2009; Scheller et al., 2000). However, the synergy between methamphetamine and Tat seen in the studies described above cannot result from this mechanism because there is no HIV replication in rodents.

In vitro studies also show Tat and methamphetamine synergistically increase the neurotoxicity in human fetal cortical dopaminergic neurons (Maragos et al., 2002) and rodent midbrain neurons (Aksenov et al., 2012) relative to either substance alone. Similarly, in SH-SY5Y (neuroblastoma) cells, Tat and methamphetamine together induce a small but significant increase in apoptosis (Qi et al., 2011). In methamphetamine treated rats, where Tat was delivered directly to the substantia nigra, Tat potentiated methamphetamine induced dopamine deficits in the striatum and enhanced deficits in dopamine-driven behaviors such as the rotarod and open field tests (Liu et al., 2014). Rodents treated with both Tat and methamphetamine show $60 \%-78 \%$ reductions in the basal ganglia dopamine levels, particularly striatal dopamine levels. These are accompanied by a severe loss of tyrosine hydroxylase (TH) immunoreactivity relative to animals treated with Tat or methamphetamine alone (Cass et al., 2003; Maragos et al., 2002; Theodore et al., 2006b). The loss of TH positive neurons in dopaminergic regions may also be the mechanism by 
which Tat exaggerates methamphetamine-mediated disruption of pre-pulse inhibition (Moran et al., 2012).

Notably, serotonin levels in the CNS of these animals are unaffected (Maragos et al., 2002), suggesting that the interaction of Tat and methamphetamine uniquely impacts the dopaminergic system. Similar data are found in human HIV-infected methamphetamine abusers, who are at increased risk for basal ganglia dysfunction (Chang et al., 2005; Taylor et al., 2007) and show decreased levels of the brain metabolite $N$-acetylaspartate (NAA), a marker correlated with dementia and other neuropathological disorders (Ben Salem et al., 2003; Enzinger et al., 2004; Griffith et al., 2008).

Cocaine has also been shown to increase viral replication in macrophages (Swepson et al., 2016), as well as Tat-induced oxidative stress and neurotoxicity in rat hippocampal neurons (Aksenov et al., 2006). In mice treated with Tat, cocaine has been shown to induce a hyperdopaminergic tone suggesting a profound dysregulation of dopamine transmission in these animals (Ferris et al., 2010). These data suggest cocaine and methamphetamine may potentiate Tat-induced damage to dopaminergic terminals. Changes in the dopamineregulated behavioral responses in rodents exposed to Tat and cocaine support this conclusion. Rats injected with Tat and treated with cocaine show a significant elevation in cocaine-induced locomotor behavior relative to control (Harrod et al., 2008). Expression of Tat in the CNS of animals treated with cocaine results in increased conditioned place preference to cocaine (Paris et al., 2014a), increased sensitivity to the reinforcing effects of cocaine and an increased abundance of low-affinity DAT binding sites in animals receiving chronic cocaine (McIntosh et al., 2015). Because HIV does not infect neurons directly, nor do rodent models involve HIV replication, it is not yet clear how well these data model the impact of Tat on the human dopaminergic system during HIV infection. However, there are a number of similarities between the neurobiological and behavioral effects seen in rodents and humans. Taken together with the data discussed in earlier sections, these data suggest the direct effects of Tat on the dopaminergic system could be amplified by the concurrent use of psychostimulants, resulting in a much broader impact on dopamine system that is induced by either Tat or drugs of abuse alone.

\section{Tat and Other Substances of Abuse}

Unlike psychostimulants, other drugs of abuse such as opioids, as well as a number of legal abused substances, such as cannabinoids, nicotine and alcohol indirectly act on the dopaminergic system. Opioids, cannabinoids and nicotine act primarily through their cognate receptors (Dani et al., 2011; Iversen, 2003; Pathan and Williams, 2012), while alcohol has effects on multiple receptor systems including GABA, opioid and cannabinoid receptors (Cruz et al., 2008; Cui et al., 2013). While the use of these drugs does not directly increase CNS dopamine, they do increase extracellular dopamine concentrations through activation of the mesolimbic dopaminergic system, with the precise mechanism and release pattern varying with the substance used (Dani et al., 2011; Di Chiara, 1995; Fadda et al., 2005; Nestler, 2005; Vander Weele et al., 2014; Yorgason et al., 2014). 
The neuropathological interactions of Tat with different drugs of abuse have been studied extensively, particularly in conjunction with opioids, but relatively little research has examined the direct effects of Tat and non-psychostimulant drugs on dopaminergic neurotransmission. Studies show that Tat in conjunction with morphine induces large reductions in dendritic spine density within the striatum (Fitting et al., 2010). This brain region has the highest number of DAT-positive terminals, and damage to this region may enhance LTD (Monfils and Teskey, 2004; Nagerl et al., 2004; Zhou et al., 2004). Further, dendritic spines aid in neurotransmission and plasticity (Chen et al., 2014), and alterations in dendritic spines in dopaminergic regions could accelerate the development of dopaminergic dysfunction in HAND. Indeed, both postmortem and fMRI studies of patients with HIV-1 have revealed extensive white matter and cortical damage along with large losses in neocortical dendrites (Archibald et al., 2004; Masliah et al., 1992). Additionally, increases in neuronal intracellular of $\mathrm{Ca}^{2+}$ induced by Tat and opioids in astrocytes and neurons (Haughey et al., 1999) could disrupt alternative dopamine receptor signaling through the PLC / $\mathrm{G}_{\mathrm{aq}}$ pathway (Beaulieu and Gainetdinov, 2011; Bergson et al., 2003), as well as damage to dopaminergic neurons (Fitting et al., 2014).

In addition to opioids, a few studies also suggest that the substances nicotine, cannabinoids and ethanol may also synergize with Tat to impact the dopaminergic system. In rats, injection of Tat into the VTA alters nicotine-induced locomotor activity as well as cAMP and ERK1/2 signaling (Zhu et al., 2015). As nicotine can modulate dopamine release through nicotinic acetylcholine receptors expressed on dopaminergic neurons in the VTA (Zoli et al., 2002), these data suggest Tat may modulate the impact of nicotine on dopaminergic neurons in this region. Research on the synergistic effects of cannabinoids and Tat have shown that the injection of Tat into the pre-frontal cortex of rats induced a decrease in GABAergic neurotransmission, which could be blocked with a CB1R antagonist (Xu et al., 2016). Hyperpolarization of GABAergic neurons can result in excitation of dopaminergic neurons through disinhibition mechanism (Johnson et al., 1992). Therefore, these effects could also increase dopamine concentrations in the pre-frontal cortex. Moreover, in Gt-tg bigenic mice, there is a 3-fold increase in ethanol-induced conditioned place preference (McLaughlin et al., 2014), suggesting that Tat potentiates the rewarding effects of alcohol. The biological relevance of these effects is not clear; future research will reveal whether Tat directly or indirectly alters dopaminergic neurotransmission and behavioral sequelae. Nevertheless, together with the findings detailed in the previous section, these data suggest Tat could have a significant impact on the dopaminergic system in the CNS of drug abusers, albeit with less understood mechanism. Further studies specifically evaluating the impact of Tat on the dopaminergic effects induced by different types of drugs of abuse are needed to help develop drug-type specific therapies for HIVinfected substance abusers using those substances.

\section{Concluding remarks}

This review has examined recent investigations into the interactions between the Tat protein and dopaminergic neurotransmission. The studies described herein provide a large amount of information regarding the impact of HIV, and the Tat protein, on the brain, specifically regarding neurotransmission. Although we have seen correlations between HIV infection 
and dopaminergic dysfunction for more than 20 years, understanding the causal mechanism(s) requires further investigation. The majority of the existing studies have examined the effects of Tat in the context of individual brain structures or heterologous systems in vitro, resulting in a great deal of information about the neurotoxic and immunomodulatory effects of Tat. Over the past decade there have also been a small but growing number of studies examining the effects of HIV and Tat on dopaminergic system proteins, using both in vitro systems and rodent models, and this is the area of research that has been and needs to continue to grow. However, as noted above, while data from model systems and in vitro studies are valuable, they come with significant caveats, and further efforts should be made to better correlate these research modalities with the hallmarks of HIV neuropathogenesis in the human brain.

Future studies warrant development of more sophisticated and relevant animal models that accommodate the current problems and lack of information regarding the expression, localization and concentration of Tat in the CNS. Animal models must also carefully account for the significant species specific differences between primate and rodent dopaminergic systems (Garcia-Cabezas et al., 2009; Garrick and Murphy, 1980; Raghanti et al., 2009). Additional investigation is needed to elucidate the possible differences in the mechanism(s) by which Tat alters neuronal circuits and affects communication in distinct brain regions. For instance, it is not clear if the untoward effects of Tat are similar between the dopamine neurons in the ventral tegmental area involved in motivated behavior and the more sensitive dopamine neurons in the substantia nigra involved in movement disorder, or if other regional differences exist. Technological advances in imaging and electrophysiology, as well as the development of more sophisticated rodent models, can further reveal how synaptic connectivity is altered in response to HIV-1 Tat.

Improving our understanding of the effect of HIV on dopamine transmission is of specific importance, because a substantial percentage of the HIV-infected population abuse illicit drugs that directly or indirectly target the dopamine system. Further, significant numbers of HIV infected individuals suffer from psychiatric disorders, such as major depressive disorder or generalized anxiety disorder (Brandt, 2009; Jallow et al., 2017; Nanni et al., 2015; Salters et al., 2016). HIV induced changes in dopaminergic neurotransmission could worsen the impact of drugs of abuse, or hinder the effectiveness of different treatments for mental illness. Overall, a better understanding of the mechanism(s) by which Tat interactions with and disrupts the dopaminergic system will provide better avenues for treatment of HIVassociated neurocognitive disorders, and perhaps a greater understanding of the overall mechanism of HIV neuropathogenesis.

\section{Supplementary Material}

Refer to Web version on PubMed Central for supplementary material.

\section{Acknowledgments}

We would like to thank Dr. Howard Fox for his critical review of this manuscript and insightful suggestions. We would also like to thank the microscopy facility at the University of Florida for assistance in generating the images of Tat production and uptake. These studies were funded by grants from the National Institutes of Drug Abuse, 
DA039005 (PJG), DA026947S1 (JGG), intramural funding (HY) and DA026947 (HK), the National Institutes on Neurological Disease and Stroke, NS071122 (HK) and the Office of Research Infrastructure Program, OD020026 (HK), DA043895 (HK).

\section{References}

Agrawal L, et al. HIV-1 Tat neurotoxicity: a model of acute and chronic exposure, and neuroprotection by gene delivery of antioxidant enzymes. Neurobiol Dis. 2012; 45:657-70. [PubMed: 22036626]

Aksenov MY, et al. D1/NMDA Receptors and Concurrent Methamphetamine+HIV-1 Tat Neurotoxicity. Journal of Neuroimmune Pharmacology. 2012; 7:599-608. [PubMed: 22552781]

Aksenov MY, et al. Cocaine-mediated enhancement of Tat toxicity in rat hippocampal cell cultures: the role of oxidative stress and D1 dopamine receptor. Neurotoxicology. 2006; 27:217-28. [PubMed: 16386305]

Aksenov MY, et al. Different effects of selective dopamine uptake inhibitors, GBR 12909 and WIN 35428 , on HIV-1 Tat toxicity in rat fetal midbrain neurons. Neurotoxicology. 2008; 29:971-7. [PubMed: 18606182]

Aksenov MY, et al. Temporal relationships between HIV-1 Tat-induced neuronal degeneration, OX-42 immunoreactivity, reactive astrocytosis, and protein oxidation in the rat striatum. Brain Res. 2003; 987:1-9. [PubMed: 14499939]

Aksenova MV, et al. Neuronal survival and resistance to HIV-1 Tat toxicity in the primary culture of rat fetal neurons. Exp Neurol. 2009; 215:253-63. [PubMed: 19013459]

Aksenova MV, et al. HIV-1 Tat neurotoxicity in primary cultures of rat midbrain fetal neurons: changes in dopamine transporter binding and immunoreactivity. Neurosci Lett. 2006; 395:235-9. [PubMed: 16356633]

Albini A, et al. Identification of a novel domain of HIV tat involved in monocyte chemotaxis. J Biol Chem. 1998; 273:15895-900. [PubMed: 9632634]

Alexander GE, et al. Parallel organization of functionally segregated circuits linking basal ganglia and cortex. Annu Rev Neurosci. 1986; 9:357-81. [PubMed: 3085570]

Anderson BA, et al. Reward, attention, and HIV-related risk in HIV+ individuals. Neurobiol Dis. 2015

Antinori A, et al. Updated research nosology for HIV-associated neurocognitive disorders. Neurology. 2007; 69:1789-99. [PubMed: 17914061]

Archibald SL, et al. Correlation of in vivo neuroimaging abnormalities with postmortem human immunodeficiency virus encephalitis and dendritic loss. Arch Neurol. 2004; 61:369-76. [PubMed: 15023814]

Aylward EH, et al. Reduced basal ganglia volume associated with the gene for Huntington's disease in asymptomatic at-risk persons. Neurology. 1994; 44:823-8. [PubMed: 8190282]

Aylward EH, et al. Magnetic resonance imaging measurement of gray matter volume reductions in HIV dementia. Am J Psychiatry. 1995; 152:987-94. [PubMed: 7793469]

Aylward EH, et al. Reduced basal ganglia volume in HIV-1-associated dementia: results from quantitative neuroimaging. Neurology. 1993; 43:2099-104. [PubMed: 8413973]

Backman L, et al. Linking cognitive aging to alterations in dopamine neurotransmitter functioning: recent data and future avenues. Neurosci Biobehav Rev. 2010; 34:670-7. [PubMed: 20026186]

Bagashev A, Sawaya BE. Roles and functions of HIV-1 Tat protein in the CNS: an overview. Virol J. 2013; 10:358. [PubMed: 24359561]

Bansal AK, et al. Neurotoxicity of HIV-1 proteins gp120 and Tat in the rat striatum. Brain Res. 2000; 879:42-9. [PubMed: 11011004]

Barton RA, Harvey PH. Mosaic evolution of brain structure in mammals. Nature. 2000; 405:1055-8. [PubMed: 10890446]

Basso MR, Bornstein RA. Effects of past noninjection drug abuse upon executive function and working memory in HIV infection. J Clin Exp Neuropsychol. 2003; 25:893-903. [PubMed: 13680438]

Baum MK, et al. Crack-cocaine use accelerates HIV disease progression in a cohort of HIV-positive drug users. J Acquir Immune Defic Syndr. 2009; 50:93-9. [PubMed: 19295339] 
Bayer P, et al. Structural studies of HIV-1 Tat protein. J Mol Biol. 1995; 247:529-35. [PubMed: 7723010]

Beaulieu J-M, Gainetdinov RR. The Physiology, Signaling, and Pharmacology of Dopamine Receptors. Pharmacological Reviews. 2011; 63:182-217. [PubMed: 21303898]

Becker JT, et al. Subcortical brain atrophy persists even in HAART-regulated HIV disease. Brain Imaging Behav. 2011; 5:77-85. [PubMed: 21264551]

Behnisch T, et al. HIV secreted protein Tat prevents long-term potentiation in the hippocampal CA1 region. Brain Res. 2004; 1012:187-9. [PubMed: 15158177]

Ben Salem D, et al. Subcortical gray matter $\mathrm{N}$-acetylaspartate reduction in two cases of vascular dementia. Clin Imaging. 2003; 27:14-7. [PubMed: 12504314]

Benazzouz A, et al. Involvement of dopamine loss in extrastriatal basal ganglia nuclei in the pathophysiology of Parkinson's disease. Front Aging Neurosci. 2014; 6:87. [PubMed: 24860498]

Berger JR, et al. Cerebrospinal fluid dopamine in HIV-1 infection. AIDS. 1994; 8:67-71. [PubMed: 8011238]

Bergson C, et al. Dopamine receptor-interacting proteins: the $\mathrm{Ca}(2+)$ connection in dopamine signaling. Trends Pharmacol Sci. 2003; 24:486-92. [PubMed: 12967774]

Bernheimer $\mathrm{H}$, et al. Brain dopamine and the syndromes of Parkinson and Huntington. Clinical, morphological and neurochemical correlations. J Neurol Sci. 1973; 20:415-55. [PubMed: 4272516]

Bertrand SJ, et al. HIV-1 Tat protein variants: critical role for the cysteine region in synaptodendritic injury. Exp Neurol. 2013; 248:228-35. [PubMed: 23811015]

Beyrer C, et al. Epidemiologic links between drug use and HIV epidemics: an international perspective. J Acquir Immune Defic Syndr. 2010; 55(Suppl 1):S10-6. [PubMed: 21045593]

Bjorklund A, Dunnett SB. Dopamine neuron systems in the brain: an update. Trends Neurosci. 2007; 30:194-202. [PubMed: 17408759]

Bokhari SM, et al. Morphine enhances Tat-induced activation in murine microglia. J Neurovirol. 2009; 15:219-28. [PubMed: 19462331]

Bonwetsch R, et al. Role of HIV-1 Tat and CC chemokine MIP-1alpha in the pathogenesis of HIV associated central nervous system disorders. J Neurovirol. 1999; 5:685-94. [PubMed: 10602409]

Boudanova E, et al. Dopamine transporter endocytic determinants: carboxy terminal residues critical for basal and PKC-stimulated internalization. Mol Cell Neurosci. 2008; 39:211-7. [PubMed: 18638559]

Bowton E, et al. Dysregulation of dopamine transporters via dopamine D2 autoreceptors triggers anomalous dopamine efflux associated with attention-deficit hyperactivity disorder. J Neurosci. 2010; 30:6048-57. [PubMed: 20427663]

Bowton E, et al. SLC6A3 coding variant Ala559Val found in two autism probands alters dopamine transporter function and trafficking. Transl Psychiatry. 2014; 4:e464. [PubMed: 25313507]

Braak H, Braak E. Nuclear configuration and neuronal types of the nucleus niger in the brain of the human adult. Hum Neurobiol. 1986; 5:71-82. [PubMed: 2426228]

Braak H, et al. Staging of brain pathology related to sporadic Parkinson's disease. Neurobiol Aging. 2003; 24:197-211. [PubMed: 12498954]

Branch SY, Beckstead MJ. Methamphetamine produces bidirectional, concentration-dependent effects on dopamine neuron excitability and dopamine-mediated synaptic currents. J Neurophysiol. 2012; 108:802-9. [PubMed: 22592307]

Brandt R. The mental health of people living with HIV/AIDS in Africa: a systematic review. Afr J AIDS Res. 2009; 8:123-33. [PubMed: 25875564]

Brew BJ, Chan P. Update on HIV dementia and HIV-associated neurocognitive disorders. Curr Neurol Neurosci Rep. 2014; 14:468. [PubMed: 24938216]

Brew BJ, et al. AIDS dementia complex and HIV-1 brain infection: clinical-virological correlations. Ann Neurol. 1995; 38:563-70. [PubMed: 7574452]

Bruce-Keller AJ, et al. Synaptic transport of human immunodeficiency virus-Tat protein causes neurotoxicity and gliosis in rat brain. J Neurosci. 2003; 23:8417-22. [PubMed: 12968004]

Bucci M. Viral mechanisms: Tat modulates DAT. Nat Chem Biol. 2015; 11:240. [PubMed: 25785419] 
Burbano X, et al. Thrombocytopenia in HIV-infected drug users in the HAART era. Platelets. 2001; 12:456-61. [PubMed: 11798394]

Burns RS, et al. A primate model of parkinsonism: selective destruction of dopaminergic neurons in the pars compacta of the substantia nigra by N-methyl-4-phenyl-1,2,3,6-tetrahydropyridine. Proc Natl Acad Sci U S A. 1983; 80:4546-50. [PubMed: 6192438]

Butler B, et al. Dopamine Transporter Activity Is Modulated by alpha-Synuclein. J Biol Chem. 2015; 290:29542-54. [PubMed: 26442590]

Butler B, et al. Alpha-synuclein modulates dopamine neurotransmission. J Chem Neuroanat. 2016

Byrd D, et al. Impact of opiate addiction on neuroinflammation in HIV. J Neurovirol. 2012; 18:36473. [PubMed: 22797933]

Byrd DA, et al. Neurocognitive impact of substance use in HIV infection. J Acquir Immune Defic Syndr. 2011a; 58:154-62. [PubMed: 21725250]

Byrd DA, et al. Neurocognitive impact of substance use in HIV infection. J Acquir Immune Defic Syndr. 2011b; 58:154-62. [PubMed: 21725250]

Byun E, et al. Sleep, Fatigue, and Problems With Cognitive Function in Adults Living With HIV. J Assoc Nurses AIDS Care. 2016; 27:5-16. [PubMed: 26547298]

Campbell GR, Loret EP. What does the structure-function relationship of the HIV-1 Tat protein teach us about developing an AIDS vaccine? Retrovirology. 2009; 6:50. [PubMed: 19467159]

Campbell GR, et al. The glutamine-rich region of the HIV-1 Tat protein is involved in T-cell apoptosis. J Biol Chem. 2004; 279:48197-204. [PubMed: 15331610]

Campbell GR, et al. The $\mathrm{C}$ terminus of HIV-1 Tat modulates the extent of CD178-mediated apoptosis of T cells. J Biol Chem. 2005; 280:38376-82. [PubMed: 16155003]

Carey AN, et al. Conditional Tat protein expression in the GT-tg bigenic mouse brain induces gray matter density reductions. Prog Neuropsychopharmacol Biol Psychiatry. 2013; 43:49-54. [PubMed: 23269344]

Carey CL, et al. Additive deleterious effects of methamphetamine dependence and immunosuppression on neuropsychological functioning in HIV infection. AIDS Behav. 2006; 10:185-90. [PubMed: 16477511]

Carlsson A, et al. Cellular localization of brain monoamines. Acta Physiol Scand Suppl. 1962; 56:128.

Cartier E, et al. Rare autism-associated variants implicate syntaxin 1 (STX1 R26Q) phosphorylation and the dopamine transporter (hDAT R51W) in dopamine neurotransmission and behaviors. EBioMedicine. 2015; 2:135-146. [PubMed: 25774383]

Cass WA, et al. HIV-1 protein Tat potentiation of methamphetamine-induced decreases in evoked overflow of dopamine in the striatum of the rat. Brain Res. 2003; 984:133-42. [PubMed: 12932847]

Cervinski MA, et al. Syntaxin 1A regulates dopamine transporter activity, phosphorylation and surface expression. Neuroscience. 2010; 170:408-16. [PubMed: 20643191]

Chana G, et al. Cognitive deficits and degeneration of interneurons in HIV+ methamphetamine users. Neurology. 2006; 67:1486-9. [PubMed: 17060582]

Chang HC, et al. HIV-1 Tat protein exits from cells via a leaderless secretory pathway and binds to extracellular matrix-associated heparan sulfate proteoglycans through its basic region. AIDS. 1997; 11:1421-31. [PubMed: 9342064]

Chang L, et al. Additive effects of HIV and chronic methamphetamine use on brain metabolite abnormalities. Am J Psychiatry. 2005; 162:361-9. [PubMed: 15677602]

Chang L, et al. Decreased brain dopamine transporters are related to cognitive deficits in HIV patients with or without cocaine abuse. Neuroimage. 2008; 42:869-78. [PubMed: 18579413]

Chen CC, et al. Spatiotemporal dynamics of dendritic spines in the living brain. Front Neuroanat. 2014; 8:28. [PubMed: 24847214]

Choi SJ, et al. Changes in neuronal dopamine homeostasis following 1-methyl-4-phenylpyridinium (MPP+) exposure. J Biol Chem. 2015; 290:6799-809. [PubMed: 25596531] 
Chun TW, et al. HIV-infected individuals receiving effective antiviral therapy for extended periods of time continually replenish their viral reservoir. J Clin Invest. 2005; 115:3250-5. [PubMed: 16276421]

Churcher MJ, et al. High affinity binding of TAR RNA by the human immunodeficiency virus type-1 tat protein requires base-pairs in the RNA stem and amino acid residues flanking the basic region. J Mol Biol. 1993; 230:90-110. [PubMed: 8450553]

Churchill MJ, et al. Extensive astrocyte infection is prominent in human immunodeficiency virusassociated dementia. Ann Neurol. 2009; 66:253-8. [PubMed: 19743454]

Cofrancesco J Jr, et al. Illicit drug use and HIV treatment outcomes in a US cohort. AIDS. 2008; 22:357-65. [PubMed: 18195562]

Cremona ML, et al. Flotillin-1 is essential for PKC-triggered endocytosis and membrane microdomain localization of DAT. Nat Neurosci. 2011; 14:469-77. [PubMed: 21399631]

Crime UNOoDa. World Drug Report 2014. 2014.

Cruz MT, et al. Shared mechanisms of alcohol and other drugs. Alcohol Res Health. 2008; 31:137-47. [PubMed: 23584815]

Cui $\mathrm{C}$, et al. New insights on neurobiological mechanisms underlying alcohol addiction. Neuropharmacology. 2013; 67:223-32. [PubMed: 23159531]

Cysique LA, et al. Prevalence and pattern of neuropsychological impairment in human immunodeficiency virus-infected/ acquired immunodeficiency syndrome (HIV/AIDS) patients across pre- and post-highly active antiretroviral therapy eras: a combined study of two cohorts. $\mathbf{J}$ Neurovirol. 2004; 10:350-7. [PubMed: 15765806]

Czub S, et al. Modulation of simian immunodeficiency virus neuropathology by dopaminergic drugs. Acta Neuropathol. 2004; 107:216-26. [PubMed: 14712399]

Czub S, et al. Enhancement of central nervous system pathology in early simian immunodeficiency virus infection by dopaminergic drugs. Acta Neuropathol. 2001; 101:85-91. [PubMed: 11271377]

Dahal S, et al. Interactive effects of cocaine on HIV infection: implication in HIV-associated neurocognitive disorder and neuroAIDS. Front Microbiol. 2015; 6:931. [PubMed: 26441868]

Dahl V, et al. Low levels of HIV-1 RNA detected in the cerebrospinal fluid after up to 10 years of suppressive therapy are associated with local immune activation. AIDS. 2014; 28:2251-8. [PubMed: 25022595]

Dai R, et al. A crucial role for cAMP and protein kinase A in D1 dopamine receptor regulated intracellular calcium transients. Neurosignals. 2008; 16:112-23. [PubMed: 18253052]

Damier P, et al. The substantia nigra of the human brain. II. Patterns of loss of dopamine-containing neurons in Parkinson's disease. Brain. 1999; 122( Pt 8):1437-48. [PubMed: 10430830]

Dani JA, et al. Neurophysiology of Nicotine Addiction. J Addict Res Ther. 2011:S1.

David R, et al. Striatal dopamine transporter levels correlate with apathy in neurodegenerative diseases. A SPECT study with partial volume effect correction. Clinical Neurology and Neurosurgery. 2008; 110:19-24. [PubMed: 17900799]

Davies J, et al. HIV-associated brain pathology: a comparative international study. Neuropathol Appl Neurobiol. 1998; 24:118-24. [PubMed: 9634207]

Davis LE, et al. Early viral brain invasion in iatrogenic human immunodeficiency virus infection. Neurology. 1992; 42:1736-9. [PubMed: 1513462]

Daws LC, et al. Cocaine increases dopamine uptake and cell surface expression of dopamine transporters. Biochem Biophys Res Commun. 2002; 290:1545-50. [PubMed: 11820798]

Deeks SG, et al. The end of AIDS: HIV infection as a chronic disease. Lancet. 2013; 382:1525-33. [PubMed: 24152939]

Del Valle L, et al. Detection of HIV-1 Tat and JCV capsid protein, VP1, in AIDS brain with progressive multifocal leukoencephalopathy. J Neurovirol. 2000; 6:221-8. [PubMed: 10878711]

Derdeyn CA, Silvestri G. Viral and host factors in the pathogenesis of HIV infection. Curr Opin Immunol. 2005; 17:366-73. [PubMed: 15955686]

Derse D, et al. A minimal lentivirus Tat. J Virol. 1991; 65:7012-5. [PubMed: 1658392]

Di Chiara $\mathrm{G}$. The role of dopamine in drug abuse viewed from the perspective of its role in motivation. Drug Alcohol Depend. 1995; 38:95-137. [PubMed: 7671769] 
di Rocco A, et al. Decreased homovanilic acid in cerebrospinal fluid correlates with impaired neuropsychologic function in HIV-1-infected patients. Clin Neuropharmacol. 2000; 23:190-4. [PubMed: 11020122]

Dingwall C. Functional dissection of a viral transactivator. Bioessays. 1991; 13:85-6. [PubMed: 2029270]

Double KL, et al. Selective cell death in neurodegeneration: why are some neurons spared in vulnerable regions? Prog Neurobiol. 2010; 92:316-29. [PubMed: 20541584]

Dunkley PR, et al. Tyrosine hydroxylase phosphorylation: regulation and consequences. J Neurochem. 2004; 91:1025-43. [PubMed: 15569247]

Edelman EJ, et al. Heroin Use and HIV Disease Progression: Results from a Pilot Study of a Russian Cohort. AIDS Behav. 2015; 19:1089-97. [PubMed: 25413642]

Eden A, et al. HIV-1 viral escape in cerebrospinal fluid of subjects on suppressive antiretroviral treatment. J Infect Dis. 2010; 202:1819-25. [PubMed: 21050119]

Egele C, et al. Modulation of microtubule assembly by the HIV-1 Tat protein is strongly dependent on zinc binding to Tat. Retrovirology. 2008; 5:62. [PubMed: 18613978]

El-Bassel N, et al. Drug use as a driver of HIV risks: re-emerging and emerging issues. Curr Opin HIV AIDS. 2014; 9:150-5. [PubMed: 24406532]

El-Hage N, et al. Morphine exacerbates HIV-1 Tat-induced cytokine production in astrocytes through convergent effects on $[\mathrm{Ca}(2+)](\mathrm{i})$, NF-kappaB trafficking and transcription. PLoS One. 2008; 3:e4093. [PubMed: 19116667]

El-Hage N, et al. Synergistic increases in intracellular Ca2+, and the release of MCP-1, RANTES, and IL-6 by astrocytes treated with opiates and HIV-1 Tat. Glia. 2005; 50:91-106. [PubMed: 15630704]

Ellis R, et al. HIV and antiretroviral therapy in the brain: neuronal injury and repair. Nat Rev Neurosci. 2007; 8:33-44. [PubMed: 17180161]

Elsworth JD, et al. MPTP-induced parkinsonism: relative changes in dopamine concentration in subregions of substantia nigra, ventral tegmental area and retrorubral field of symptomatic and asymptomatic vervet monkeys. Brain Res. 1990; 513:320_4. [PubMed: 2350702]

Emerman M, Malim MH. HIV-1 regulatory/accessory genes: keys to unraveling viral and host cell biology. Science. 1998; 280:1880-4. [PubMed: 9632380]

Ensoli B, et al. Tat protein of HIV-1 stimulates growth of cells derived from Kaposi's sarcoma lesions of AIDS patients. Nature. 1990; 345:84-6. [PubMed: 2184372]

Ensoli B, et al. Release, uptake, and effects of extracellular human immunodeficiency virus type 1 Tat protein on cell growth and viral transactivation. J Virol. 1993; 67:277-87. [PubMed: 8416373]

Enzinger C, et al. Accelerated evolution of brain atrophy and "black holes" in MS patients with APOEepsilon 4. Ann Neurol. 2004; 55:563-9. [PubMed: 15048896]

Erlendsson S, et al. Protein interacting with C-kinase 1 (PICK1) binding promiscuity relies on unconventional PSD-95/discs-large/ZO-1 homology (PDZ) binding modes for nonclass II PDZ ligands. J Biol Chem. 2014; 289:25327-40. [PubMed: 25023278]

Eugenin EA, Berman JW. Gap junctions mediate human immunodeficiency virus-bystander killing in astrocytes. J Neurosci. 2007; 27:12844-50. [PubMed: 18032656]

Eugenin EA, et al. MCP-1 (CCL2) protects human neurons and astrocytes from NMDA or HIV-tatinduced apoptosis. J Neurochem. 2003; 85:1299-311. [PubMed: 12753088]

Eugenin EA, et al. HIV-tat induces formation of an LRP-PSD-95-NMDAR-nNOS complex that promotes apoptosis in neurons and astrocytes. Proc Natl Acad Sci U S A. 2007; 104:3438-43. [PubMed: 17360663]

Fadda P, et al. Dopamine and serotonin release in dorsal striatum and nucleus accumbens is differentially modulated by morphine in DBA/2J and C57BL/6J mice. Synapse. 2005; 56:29-38. [PubMed: 15700287]

Fan Y, He JJ. HIV-1 Tat Induces Unfolded Protein Response and Endoplasmic Reticulum Stress in Astrocytes and Causes Neurotoxicity through Glial Fibrillary Acidic Protein (GFAP) Activation and Aggregation. J Biol Chem. 2016a; 291:22819-22829. [PubMed: 27609520] 
Fan Y, He JJ. HIV-1 Tat Promotes Lysosomal Exocytosis in Astrocytes and Contributes to Astrocytemediated Tat Neurotoxicity. J Biol Chem. 2016b; 291:22830-22840. [PubMed: 27609518]

Fearnley JM, Lees AJ. Ageing and Parkinson's disease: substantia nigra regional selectivity. Brain. 1991; 114(Pt 5):2283-301. [PubMed: 1933245]

Feinberg MB, et al. The role of Tat in the human immunodeficiency virus life cycle indicates a primary effect on transcriptional elongation. Proc Natl Acad Sci U S A. 1991; 88:4045-9. [PubMed: 2023953]

Feligioni M, et al. The human immunodeficiency virus-1 protein Tat and its discrete fragments evoke selective release of acetylcholine from human and rat cerebrocortical terminals through speciesspecific mechanisms. J Neurosci. 2003; 23:6810-8. [PubMed: 12890775]

Ferretti F, et al. Cerebrospinal Fluid HIV Escape from Antiretroviral Therapy. Curr HIV/AIDS Rep. 2015; 12:280-8. [PubMed: 25860317]

Ferris MJ, et al. The human immunodeficiency virus-1-associated protein, Tat1-86, impairs dopamine transporters and interacts with cocaine to reduce nerve terminal function: a no-net-flux microdialysis study. Neuroscience. 2009; 159:1292-9. [PubMed: 19344635]

Ferris MJ, et al. Hyperdopaminergic tone in HIV-1 protein treated rats and cocaine sensitization. J Neurochem. 2010; 115:885-96. [PubMed: 20796175]

Ferris MJ, et al. Neurotoxic profiles of HIV, psychostimulant drugs of abuse, and their concerted effect on the brain: current status of dopamine system vulnerability in NeuroAIDS. Neurosci Biobehav Rev. 2008; 32:883-909. [PubMed: 18430470]

Fields JA, et al. Mechanisms of HIV-1 Tat neurotoxicity via CDK5 translocation and hyper-activation: role in HIV-associated neurocognitive disorders. Curr HIV Res. 2015; 13:43-54. [PubMed: 25760044]

Fitting S, et al. Intrahippocampal injections of Tat: effects on prepulse inhibition of the auditory startle response in adult male rats. Pharmacol Biochem Behav. 2006; 84:189-96. [PubMed: 16790267]

Fitting S, et al. HIV-1 Proteins, Tat and gp120, Target the Developing Dopamine System. Curr HIV Res. 2015; 13:21-42. [PubMed: 25613135]

Fitting S, et al. Synaptic dysfunction in the hippocampus accompanies learning and memory deficits in human immunodeficiency virus type-1 Tat transgenic mice. Biol Psychiatry. 2013; 73:443-53. [PubMed: 23218253]

Fitting S, et al. Interactive HIV-1 Tat and morphine-induced synaptodendritic injury is triggered through focal disruptions in $\mathrm{Na}(+)$ influx, mitochondrial instability, and $\mathrm{Ca}(2)(+)$ overload. $\mathrm{J}$ Neurosci. 2014; 34:12850-64. [PubMed: 25232120]

Fitting S, et al. Interactive comorbidity between opioid drug abuse and HIV-1 Tat: chronic exposure augments spine loss and sublethal dendritic pathology in striatal neurons. Am J Pathol. 2010; 177:1397-410. [PubMed: 20651230]

Flatmark T. Catecholamine biosynthesis and physiological regulation in neuroendocrine cells. Acta Physiol Scand. 2000; 168:1-17. [PubMed: 10691773]

Flora G, et al. Proinflammatory synergism of ethanol and HIV-1 Tat protein in brain tissue. Exp Neurol. 2005; 191:2-12. [PubMed: 15589507]

Fog JU, et al. Calmodulin kinase II interacts with the dopamine transporter $\mathrm{C}$ terminus to regulate amphetamine-induced reverse transport. Neuron. 2006; 51:417-29. [PubMed: 16908408]

Foster JD, Vaughan RA. Palmitoylation controls dopamine transporter kinetics, degradation, and protein kinase C-dependent regulation. J Biol Chem. 2011; 286:5175-86. [PubMed: 21118819]

Frankel AD, Pabo CO. Cellular uptake of the tat protein from human immunodeficiency virus. Cell. 1988; 55:1189-93. [PubMed: 2849510]

Frégeau M-O, et al. Mechanism of dopamine D2 receptor-induced Ca2 + release in PC-12 cells. Cellular Signalling. 2013; 25:2871-2877. [PubMed: 24055909]

Friend DM, Keefe KA. A role for D1 dopamine receptors in striatal methamphetamine-induced neurotoxicity. Neuroscience Letters. 2013; 555:243-247. [PubMed: 23994061]

$\mathrm{Fu} \mathrm{Y,} \mathrm{et} \mathrm{al.} \mathrm{A} \mathrm{cytoarchitectonic} \mathrm{and} \mathrm{chemoarchitectonic} \mathrm{analysis} \mathrm{of} \mathrm{the} \mathrm{dopamine} \mathrm{cell} \mathrm{groups} \mathrm{in} \mathrm{the}$ substantia nigra, ventral tegmental area, and retrorubral field in the mouse. Brain Struct Funct. 2012; 217:591-612. [PubMed: 21935672] 
Fujimura RK, et al. HIV-1 proviral DNA load across neuroanatomic regions of individuals with evidence for HIV-1-associated dementia. J Acquir Immune Defic Syndr Hum Retrovirol. 1997; 16:146-52. [PubMed: 9390565]

Futaki S, et al. Arginine-rich peptides. An abundant source of membrane-permeable peptides having potential as carriers for intracellular protein delivery. J Biol Chem. 2001; 276:5836-40. [PubMed: 11084031]

Gainetdinov RR, et al. Dopamine transporter is required for in vivo MPTP neurotoxicity: evidence from mice lacking the transporter. J Neurochem. 1997; 69:1322-5. [PubMed: 9282960]

Gainetdinov RR, et al. Functional hyperdopaminergia in dopamine transporter knock-out mice. Biol Psychiatry. 1999; 46:303-11. [PubMed: 10435196]

Gannon P, et al. Current understanding of HIV-associated neurocognitive disorders pathogenesis. Curr Opin Neurol. 2011; 24:275-83. [PubMed: 21467932]

Garcia-Cabezas MA, et al. Dopamine innervation in the thalamus: monkey versus rat. Cereb Cortex. 2009; 19:424-34. [PubMed: 18550594]

Garrick NA, Murphy DL. Species differences in the deamination of dopamine and other substrates for monoamine oxidase in brain. Psychopharmacology (Berl). 1980; 72:27-33. [PubMed: 6781004]

Gaskill PJ, et al. Drug induced increases in CNS dopamine alter monocyte, macrophage and T cell functions: implications for HAND. J Neuroimmune Pharmacol. 2013; 8:621-42. [PubMed: 23456305]

Gaskill PJ, et al. Human immunodeficiency virus (HIV) infection of human macrophages is increased bydopamine: a bridge between HIV-associated neurologic disorders and drug abuse. Am J Pathol. 2009:175.

Gaskill PJ, et al. Characterization and function of the human macrophage dopaminergic system: implications for CNS disease and drug abuse. Journal of Neuroinflammation. 2012; 9:203. [PubMed: 22901451]

Gaskill PJ, et al. Dopamine Receptor Activation Increases HIV Entry into Primary Human Macrophages. PLoS ONE. 2014; 9:e108232. [PubMed: 25268786]

Gelman BB, et al. Abnormal striatal dopaminergic synapses in National NeuroAIDS Tissue Consortium subjects with HIV encephalitis. J Neuroimmune Pharmacol. 2006; 1:410-20. [PubMed: 18040813]

German DC, et al. Midbrain dopaminergic cell loss in Parkinson's disease and MPTP-induced parkinsonism: sparing of calbindin-D28k-containing cells. Ann N Y Acad Sci. 1992; 648:42-62. [PubMed: 1353337]

Gibb WR, Lees AJ. Anatomy, pigmentation, ventral and dorsal subpopulations of the substantia nigra, and differential cell death in Parkinson's disease. J Neurol Neurosurg Psychiatry. 1991; 54:38896. [PubMed: 1865199]

Gill AF, et al. Hematologic abnormalities associated with simian immunodeficieny virus (SIV) infection mimic those in HIV infection. J Med Primatol. 2012; 41:214-24. [PubMed: 22620272]

Glass JD, et al. Immunocytochemical quantitation of human immunodeficiency virus in the brain: correlations with dementia. Ann Neurol. 1995; 38:755-62. [PubMed: 7486867]

Gongvatana A, et al. Progressive cerebral injury in the setting of chronic HIV infection and antiretroviral therapy. J Neurovirol. 2013; 19:209-18. [PubMed: 23613008]

Gonzalez-Scarano F, Martin-Garcia J. The neuropathogenesis of AIDS. Nat Rev Immunol. 2005; 5:69_ 81. [PubMed: 15630430]

Goodwin JS, et al. Amphetamine and methamphetamine differentially affect dopamine transporters in vitro and in vivo. J Biol Chem. 2009; 284:2978-89. [PubMed: 19047053]

Grassi MP, et al. HIV infection and drug use: influence on cognitive function. AIDS. 1995; 9:165-70. [PubMed: 7718187]

Gray F, et al. Early brain changes in HIV infection: neuropathological study of 11 HIV seropositive, non-AIDS cases. J Neuropathol Exp Neurol. 1992; 51:177-85. [PubMed: 1538241]

Gray LR, et al. HIV-1 entry and trans-infection of astrocytes involves CD81 vesicles. PLoS One. 2014; 9:e90620. [PubMed: 24587404] 
Green M, et al. Mutational analysis of HIV-1 Tat minimal domain peptides: identification of transdominant mutants that suppress HIV-LTR-driven gene expression. Cell. 1989; 58:215-23. [PubMed: 2752420]

Green M, Loewenstein PM. Autonomous functional domains of chemically synthesized human immunodeficiency virus tat trans-activator protein. Cell. 1988; 55:1179-88. [PubMed: 2849509]

Greenfield JG, Bosanquet FD. The brain-stem lesions in Parkinsonism. J Neurol Neurosurg Psychiatry. 1953; 16:213-26. [PubMed: 13109537]

Griffith HR, et al. Brain N-acetylaspartate is reduced in Parkinson disease with dementia. Alzheimer Dis Assoc Disord. 2008; 22:54-60. [PubMed: 18317247]

Guptaroy B, et al. A juxtamembrane mutation in the $\mathrm{N}$ terminus of the dopamine transporter induces preference for an inward-facing conformation. Mol Pharmacol. 2009; 75:514-24. [PubMed: 19098122]

Haber SN. The place of dopamine in the cortico-basal ganglia circuit. Neuroscience. 2014; 282:24857. [PubMed: 25445194]

Hahn YK, et al. Effects of chronic HIV-1 Tat exposure in the CNS: heightened vulnerability of males versus females to changes in cell numbers, synaptic integrity, and behavior. Brain Struct Funct. 2015; 220:605-23. [PubMed: 24352707]

Halkitis PN, et al. A double epidemic: crystal methamphetamine drug use in relation to HIV transmission among gay men. J Homosex. 2001; 41:17-35. [PubMed: 11482426]

Halliday GM, Tork I. Comparative anatomy of the ventromedial mesencephalic tegmentum in the rat, cat, monkey and human. J Comp Neurol. 1986; 252:423-45. [PubMed: 3782510]

Hamilton PJ, et al. PIP2 regulates psychostimulant behaviors through its interaction with a membrane protein. Nat Chem Biol. 2014; 10:582-9. [PubMed: 24880859]

Hansen FH, et al. Missense dopamine transporter mutations associate with adult parkinsonism and ADHD. J Clin Invest. 2014; 124:3107-20. [PubMed: 24911152]

Hargus NJ, Thayer SA. Human immunodeficiency virus-1 Tat protein increases the number of inhibitory synapses between hippocampal neurons in culture. J Neurosci. 2013; 33:17908-20. [PubMed: 24198379]

Harrod SB, et al. Intra-accumbal Tat1-72 alters acute and sensitized responses to cocaine. Pharmacol Biochem Behav. 2008; 90:723-9. [PubMed: 18582493]

Hatano H, et al. Evidence of persistent low-level viremia in long-term HAART-suppressed, HIVinfected individuals. AIDS. 2010; 24:2535-9. [PubMed: 20651585]

Hategan AP, et al. Molecular Study of HIV-Tat Aggregation. Biophysical Journal. 2016; 110:400a. [PubMed: 26789763]

Haughey NJ, et al. Involvement of inositol 1,4,5-trisphosphate-regulated stores of intracellular calcium in calcium dysregulation and neuron cell death caused by HIV-1 protein tat. J Neurochem. 1999; 73:1363-74. [PubMed: 10501179]

Hauser KF, Knapp PE. Interactions of HIV and Drugs of Abuse: The Importance of Glia, Neural Progenitors, and Host Genetic Factors. Int Rev Neurobiol. 2014; 118:231-313. [PubMed: 25175867]

Heaton RK, et al. HIV-associated neurocognitive disorders persist in the era of potent antiretroviral therapy: CHARTER Study. Neurology. 2010a; 75:2087-96. [PubMed: 21135382]

Heaton RK, et al. HIV-associated neurocognitive disorders persist in the era of potent antiretroviral therapy: CHARTER Study. Neurology. 2010b; 75:2087-96. [PubMed: 21135382]

Heaton RK, et al. HIV-associated neurocognitive disorders before and during the era of combination antiretroviral therapy: differences in rates, nature, and predictors. J Neurovirol. 2011a; 17:3-16. [PubMed: 21174240]

Heaton RK, et al. HIV-associated neurocognitive disorders before and during the era of combination antiretroviral therapy: differences in rates, nature, and predictors. J Neurovirol. 2011b; 17:3-16. [PubMed: 21174240]

Heaton RK, et al. Neurocognitive change in the era of HIV combination antiretroviral therapy: A longitudinal CHARTER Study. Clin Infect Dis. 2014 
Hestad K, et al. Regional brain atrophy in HIV-1 infection: association with specific neuropsychological test performance. Acta Neurol Scand. 1993; 88:112-8. [PubMed: 8213054]

Hirsch EC, et al. Selective vulnerability of pigmented dopaminergic neurons in Parkinson's disease. Acta Neurol Scand Suppl. 1989; 126:19-22. [PubMed: 2575832]

Hofman FM, et al. Exogenous tat protein activates central nervous system-derived endothelial cells. J Neuroimmunol. 1994; 54:19-28. [PubMed: 7523444]

Holton KL, et al. Nonclassical, distinct endocytic signals dictate constitutive and PKC-regulated neurotransmitter transporter internalization. Nat Neurosci. 2005; 8:881-8. [PubMed: 15924135]

Hong S, Banks WA. Role of the immune system in HIV-associated neuroinflammation and neurocognitive implications. Brain Behav Immun. 2015; 45:1-12. [PubMed: 25449672]

Hong WC, Amara SG. Membrane cholesterol modulates the outward facing conformation of the dopamine transporter and alters cocaine binding. J Biol Chem. 2010; 285:32616-26. [PubMed: 20688912]

Hong WC, Amara SG. Differential targeting of the dopamine transporter to recycling or degradative pathways during amphetamine- or PKC-regulated endocytosis in dopamine neurons. Faseb j. 2013; 27:2995-3007. [PubMed: 23612789]

Horn A, et al. Increases in CSF dopamine in HIV patients are due to the dopamine transporter 10/10repeat allele which is more frequent in HIV-infected individuals. J Neural Transm. 2013; 120:1411-9. [PubMed: 24057505]

Hornykiewicz O. L-DOPA: from a biologically inactive amino acid to a successful therapeutic agent. Amino Acids. 2002; 23:65-70. [PubMed: 12373520]

Hornykiewicz O, Kish SJ. Biochemical pathophysiology of Parkinson's disease. Adv Neurol. 1987; 45:19-34. [PubMed: 2881444]

Hriso E, et al. Extrapyramidal symptoms due to dopamine-blocking agents in patients with AIDS encephalopathy. Am J Psychiatry. 1991; 148:1558-61. [PubMed: 1681751]

Huff B. Methamphetamine and HIV. BETA. 2006; 18:42-7. [PubMed: 17019790]

Itoh K, et al. Neuronal damage of the substantia nigra in HIV-1 infected brains. Acta Neuropathol. 2000; 99:376-84. [PubMed: 10787036]

Iversen L. Comparing cannabis with tobacco: arithmetic does not add up. BMJ. 2003; 327:165.

Izquierdo-Useros N, et al. HIV and mature dendritic cells: Trojan exosomes riding the Trojan horse? PLoS Pathog. 2010; 6:e1000740. [PubMed: 20360840]

Jallow A, et al. HIV-infection and psychiatric illnesses - A double edged sword that threatens the vision of a contained epidemic: The Greater Stockholm HIV Cohort Study. J Infect. 2017; 74:2228. [PubMed: 27717780]

Janssen MA, et al. Cognitive Decline in Relation to Psychological Wellbeing and HIV Disease- and Treatment Characteristics in HIV-Infected Patients on cART: A One-Year Follow-Up Study. AIDS Behav. 2016

Janssen RS, et al. Human immunodeficiency virus (HIV) infection and the nervous system: report from the American Academy of Neurology AIDS Task Force. Neurology. 1989; 39:119-22. [PubMed: 2642609]

Jay TM. Dopamine: a potential substrate for synaptic plasticity and memory mechanisms. Prog Neurobiol. 2003; 69:375-90. [PubMed: 12880632]

Jeang, KT. Human Retroviruses and AIDS : A Compilation and Analysis of Nucleic Acid and Amino Acid Sequences. Los Alamos National Laboratory; Los Alamos, NM: 1996. HIV-1 Tat Structure and Function; p. III-3-III-18.

Jeang KT, et al. Multifaceted activities of the HIV-1 transactivator of transcription, Tat. J Biol Chem. 1999; 274:28837-40. [PubMed: 10506122]

Jenuwein M, et al. Dopamine deficits and regulation of the cAMP second messenger system in brains of simian immunodeficiency virus-infected rhesus monkeys. J Neurovirol. 2004; 10:163-70. [PubMed: 15204921]

Joel D, Weiner I. The connections of the dopaminergic system with the striatum in rats and primates: an analysis with respect to the functional and compartmental organization of the striatum. Neuroscience. 2000; 96:451-74. [PubMed: 10717427] 
Johnson SW, et al. 5-hydroxytryptamine1B receptors block the GABAB synaptic potential in rat dopamine neurons. J Neurosci. 1992; 12:2000-6. [PubMed: 1578282]

Johnston JG, et al. Mechanisms of striatal pattern formation: conservation of mammalian compartmentalization. Brain Res Dev Brain Res. 1990; 57:93-102. [PubMed: 1965303]

Jones KA, Peterlin BM. Control of RNA initiation and elongation at the HIV-1 promoter. Annu Rev Biochem. 1994; 63:717-43. [PubMed: 7979253]

Jones SR, et al. Loss of autoreceptor functions in mice lacking the dopamine transporter. Nat Neurosci. 1999a; 2:649-55. [PubMed: 10404198]

Jones SR, et al. Dopamine neuronal transport kinetics and effects of amphetamine. J Neurochem. 1999b; 73:2406-14. [PubMed: 10582600]

Joseph SB, et al. HIV-1 target cells in the CNS. J Neurovirol. 2014

Joseph SB, et al. HIV-1 target cells in the CNS. J Neurovirol. 2015; 21:276-89. [PubMed: 25236812]

Joska JA, et al. Does highly active antiretroviral therapy improve neurocognitive function? A systematic review. J Neurovirol. 2010; 16:101-14. [PubMed: 20345318]

Kahlig KM, et al. Amphetamine induces dopamine efflux through a dopamine transporter channel. Proc Natl Acad Sci U S A. 2005; 102:3495-500. [PubMed: 15728379]

Kahlig KM, Galli A. Regulation of dopamine transporter function and plasma membrane expression by dopamine, amphetamine, and cocaine. Eur J Pharmacol. 2003; 479:153-8. [PubMed: 14612146]

Kahlig KM, et al. Regulation of dopamine transporter trafficking by intracellular amphetamine. Mol Pharmacol. 2006; 70:542-8. [PubMed: 16684900]

Kameoka M, et al. The Tat protein of human immunodeficiency virus type 1 (HIV-1) can promote placement of tRNA primer onto viral RNA and suppress later DNA polymerization in HIV-1 reverse transcription. J Virol. 2002; 76:3637-45. [PubMed: 11907203]

Kao SY, et al. Anti-termination of transcription within the long terminal repeat of HIV-1 by tat gene product. Nature. 1987; 330:489-93.

Karn J, Stoltzfus CM. Transcriptional and Posttranscriptional Regulation of HIV-1 Gene Expression. Cold Spring Harb Perspect Med. 2012; 2:a006916. [PubMed: 22355797]

Kass MD, et al. Methamphetamine-induced behavioral and physiological effects in adolescent and adult HIV-1 transgenic rats. J Neuroimmune Pharmacol. 2010; 5:566-73. [PubMed: 20532992]

Kesby JP, et al. The effects of HIV-1 regulatory TAT protein expression on brain reward function, response to psychostimulants and delay-dependent memory in mice. Neuropharmacology. 2016a; 109:205-15. [PubMed: 27316905]

Kesby JP, et al. The effects of HIV-1 regulatory TAT protein expression on brain reward function, response to psychostimulants and delay-dependent memory in mice. Neuropharmacology. 2016b

Khoshbouei $\mathrm{H}$, et al. N-terminal phosphorylation of the dopamine transporter is required for amphetamine-induced efflux. PLoS Biol. 2004; 2:E78. [PubMed: 15024426]

Khoshbouei H, et al. Amphetamine-induced dopamine efflux. A voltage-sensitive and intracellular Na +-dependent mechanism. J Biol Chem. 2003; 278:12070-7. [PubMed: 12556446]

Kieburtz KD, et al. Excitotoxicity and dopaminergic dysfunction in the acquired immunodeficiency syndrome dementia complex. Therapeutic implications. Arch Neurol. 1991; 48:1281-4. [PubMed: 1845034]

Kim BO, et al. Neuropathologies in transgenic mice expressing human immunodeficiency virus type 1 Tat protein under the regulation of the astrocyte-specific glial fibrillary acidic protein promoter and doxycycline. Am J Pathol. 2003; 162:1693-707. [PubMed: 12707054]

King JE, et al. HIV tat and neurotoxicity. Microbes Infect. 2006; 8:1347-57. [PubMed: 16697675]

King JE, et al. Mechanisms of HIV-tat-induced phosphorylation of N-methyl-D-aspartate receptor subunit $2 \mathrm{~A}$ in human primary neurons: implications for neuroAIDS pathogenesis. Am J Pathol. 2010; 176:2819-30. [PubMed: 20448061]

Kipp AM, et al. Non-injection drug use and HIV disease progression in the era of combination antiretroviral therapy. J Subst Abuse Treat. 2011; 40:386-96. [PubMed: 21353444]

Klanker M, et al. Dopaminergic control of cognitive flexibility in humans and animals. Front Neurosci. 2013; 7:201. [PubMed: 24204329] 
Kousik SM, et al. The Effects of Psychostimulant Drugs on Blood Brain Barrier Function and Neuroinflammation. Front Pharmacol. 2012; 3:121. [PubMed: 22754527]

Koutsilieri E, et al. Brain choline acetyltransferase reduction in SIV infection. An index of early dementia? Neuroreport. 2000; 11:2391-3. [PubMed: 10943691]

Koutsilieri E, et al. Monoamine metabolite levels in CSF of SIV-infected rhesus monkeys (Macaca mulatta). Neuroreport. 1997; 8:3833-6. [PubMed: 9427379]

Koutsilieri E, et al. Monoamine oxidase inhibition and CNS immunodeficiency infection. Neurotoxicology. 2004; 25:267-70. [PubMed: 14697901]

Koutsilieri E, et al. Involvement of dopamine in the progression of AIDS Dementia Complex. J Neural Transm (Vienna). 2002a; 109:399-410. [PubMed: 11956960]

Koutsilieri E, et al. Parkinsonism in HIV dementia. J Neural Transm (Vienna). 2002b; 109:767-75. [PubMed: 12111466]

Koutsilieri E, et al. Neurotransmission in HIV associated dementia: a short review. J Neural Transm (Vienna). 2001; 108:767-75. [PubMed: 11478426]

Kraft-Terry SD, et al. A coat of many colors: neuroimmune crosstalk in human immunodeficiency virus infection. Neuron. 2009; 64:133-45. [PubMed: 19840555]

Kramer EL, Sanger JJ. Brain imaging in acquired immunodeficiency syndrome dementia complex. Semin Nucl Med. 1990; 20:353-63. [PubMed: 2237453]

Kumar AM, et al. Human immunodeficiency virus type 1 in the central nervous system leads to decreased dopamine in different regions of postmortem human brains. J Neurovirol. 2009; 15:257-74. [PubMed: 19499455]

Kumar AM, et al. Human immunodeficiency virus infection in the CNS and decreased dopamine availability: relationship with neuropsychological performance. J Neurovirol. 2011; 17:26-40. [PubMed: 21165787]

Kumar S, et al. Drug-drug interactions between anti-retroviral therapies and drugs of abuse in HIV systems. Expert Opin Drug Metab Toxicol. 2014:1-13.

Kuppuswamy M, et al. Multiple functional domains of Tat, the trans-activator of HIV-1, defined by mutational analysis. Nucleic Acids Res. 1989; 17:3551-61. [PubMed: 2542902]

Kure K, et al. Cellular localization of an HIV-1 antigen in subacute AIDS encephalitis using an improved double-labeling immunohistochemical method. Am J Pathol. 1990; 136:1085-92. [PubMed: 1693470]

Lanciego JL, et al. Functional neuroanatomy of the basal ganglia. Cold Spring Harb Perspect Med. 2012; 2:a009621. [PubMed: 23071379]

Langford D, et al. Patterns of selective neuronal damage in methamphetamine-user AIDS patients. $\mathrm{J}$ Acquir Immune Defic Syndr. 2003a; 34:467-74. [PubMed: 14657756]

Langford TD, et al. Changing patterns in the neuropathogenesis of HIV during the HAART era. Brain Pathol. 2003b; 13:195-210. [PubMed: 12744473]

Larsson M, et al. Cerebrospinal fluid catecholamine metabolites in HIV-infected patients. J Neurosci Res. 1991; 28:406-9. [PubMed: 1856886]

Li ST, et al. HIV-1 Tat inhibits long-term potentiation and attenuates spatial learning [corrected]. Ann Neurol. 2004; 55:362-71. [PubMed: 14991814]

Lin M, et al. Methamphetamine Regulation of Firing Activity of Dopamine Neurons. J Neurosci. 2016; 36:10376-10391. [PubMed: 27707972]

Liu X, et al. Methamphetamine-induced behavioral sensitization is enhanced in the HIV-1 transgenic rat. J Neuroimmune Pharmacol. 2009; 4:309-16. [PubMed: 19444617]

Liu Z, et al. HIV transactivator of transcription enhances methamphetamine-induced Parkinson's-like behavior in the rats. Neuroreport. 2014

Lucas GM, et al. Illicit drug use and HIV-1 disease progression: a longitudinal study in the era of highly active antiretroviral therapy. Am J Epidemiol. 2006; 163:412-20. [PubMed: 16394200]

Luo X, He JJ. Cell-cell contact viral transfer contributes to HIV infection and persistence in astrocytes. J Neurovirol. 2015; 21:66-80. [PubMed: 25522787]

Lute BJ, et al. PI3K signaling supports amphetamine-induced dopamine efflux. Biochem Biophys Res Commun. 2008; 372:656-61. [PubMed: 18510945] 
Ma M, Nath A. Molecular determinants for cellular uptake of Tat protein of human immunodeficiency virus type 1 in brain cells. J Virol. 1997; 71:2495-9. [PubMed: 9032389]

MacLeod CE, et al. Expansion of the neocerebellum in Hominoidea. J Hum Evol. 2003; 44:401-29. [PubMed: 12727461]

Maj M. Psychiatric aspects of HIV-1 infection and AIDS. Psychol Med. 1990; 20:547-63. [PubMed: 2236363]

Makrigeorgi-Butera M, et al. Comparative brain pathology of HIV-seronegative and HIV-infected drug addicts. Clin Neuropathol. 1996; 15:324-9. [PubMed: 8937778]

Mann DA, Frankel AD. Endocytosis and targeting of exogenous HIV-1 Tat protein. EMBO J. 1991; 10:1733-9. [PubMed: 2050110]

Maragos WF, et al. Neuronal injury in hippocampus with human immunodeficiency virus transactivating protein, Tat. Neuroscience. 2003; 117:43-53. [PubMed: 12605891]

Maragos WF, et al. Human immunodeficiency virus-1 Tat protein and methamphetamine interact synergistically to impair striatal dopaminergic function. J Neurochem. 2002; 83:955-63. [PubMed: 12421368]

Maschke M, et al. Incidence and prevalence of neurological disorders associated with HIV since the introduction of highly active antiretroviral therapy (HAART). J Neurol Neurosurg Psychiatry. 2000; 69:376-80. [PubMed: 10945813]

Masliah E, et al. Cortical dendritic pathology in human immunodeficiency virus encephalitis. Lab Invest. 1992; 66:285-91. [PubMed: 1538584]

Mathers BM, et al. Global epidemiology of injecting drug use and HIV among people who inject drugs: a systematic review. Lancet. 2008; 372:1733-45. [PubMed: 18817968]

Maubert ME, et al. Interaction between Tat and Drugs of Abuse during HIV-1 Infection and Central Nervous System Disease. Front Microbiol. 2015; 6:1512. [PubMed: 26793168]

Mazei-Robison MS, et al. Anomalous dopamine release associated with a human dopamine transporter coding variant. J Neurosci. 2008; 28:7040-6. [PubMed: 18614672]

McArthur JC, et al. HIV dementia. Incidence and risk factors. Res Publ Assoc Res Nerv Ment Dis. 1994; 72:251-72. [PubMed: 8115717]

McIntosh S, et al. Increased Sensitivity to Cocaine Self-Administration in HIV-1 Transgenic Rats is Associated with Changes in Striatal Dopamine Transporter Binding. J Neuroimmune Pharmacol. 2015; 10:493-505. [PubMed: 25749646]

McLaughlin JP, et al. HIV-1 Tat protein exposure potentiates ethanol reward and reinstates extinguished ethanol-conditioned place preference. Curr HIV Res. 2014; 12:415-23. [PubMed: 25760047]

Meade CS, et al. Neurocognitive impairment and medication adherence in HIV patients with and without cocaine dependence. J Behav Med. 2011a; 34:128-38. [PubMed: 20857187]

Meade CS, et al. fMRI brain activation during a delay discounting task in HIV-positive adults with and without cocaine dependence. Psychiatry Res. 2011b; 192:167-75. [PubMed: 21546221]

Mediouni S, et al. Didehydro-cortistatin A inhibits HIV-1 Tat mediated neuroinflammation and prevents potentiation of cocaine reward in Tat transgenic mice. Curr HIV Res. 2015a; 13:64-79. [PubMed: 25613133]

Mediouni S, et al. The cross-talk of HIV-1 Tat and methamphetamine in HIV-associated neurocognitive disorders. Front Microbiol. 2015b; 6:1164. [PubMed: 26557111]

Meiser J, et al. Complexity of dopamine metabolism. Cell Commun Signal. 2013; 11:34. [PubMed: 23683503]

Meulendyke KA, et al. Elevated brain monoamine oxidase activity in SIV- and HIV-associated neurological disease. J Infect Dis. 2014; 210:904-12. [PubMed: 24688074]

Meyer VJ, et al. Crack cocaine use impairs anterior cingulate and prefrontal cortex function in women with HIV infection. J Neurovirol. 2014; 20:352-61. [PubMed: 24760360]

Midde NM, et al. HIV-1 Tat protein decreases dopamine transporter cell surface expression and vesicular monoamine transporter-2 function in rat striatal synaptosomes. J Neuroimmune Pharmacol. 2012; 7:629-39. [PubMed: 22570010] 
Midde NM, et al. Mutation of tyrosine 470 of human dopamine transporter is critical for HIV-1 Tatinduced inhibition of dopamine transport and transporter conformational transitions. $\mathbf{J}$ Neuroimmune Pharmacol. 2013; 8:975-87. [PubMed: 23645138]

Midde NM, et al. Mutations at tyrosine 88, lysine 92 and tyrosine 470 of human dopamine transporter result in an attenuation of HIV-1 Tat-induced inhibition of dopamine transport. J Neuroimmune Pharmacol. 2015a; 10:122-35. [PubMed: 25604666]

Midde NM, et al. Mutations at Tyrosine 88, Lysine 92 and Tyrosine 470 of Human Dopamine Transporter Result in an Attenuation of HIV-1 Tat-Induced Inhibition of Dopamine Transport. J Neuroimmune Pharmacol. 2015b

Milloy MJ, et al. Increased Prevalence of Controlled Viremia and Decreased Rates of HIV Drug Resistance Among HIV-Positive People Who Use Illicit Drugs During a Community-wide Treatment-as-Prevention Initiative. Clin Infect Dis. 2016; 62:640-7. [PubMed: 26553011]

Minassian A, et al. Prepulse inhibition in HIV-associated neurocognitive disorders. J Int Neuropsychol Soc. 2013; 19:709-17. [PubMed: 23552464]

Mishra M, et al. Clade-specific differences in neurotoxicity of human immunodeficiency virus-1 B and C Tat of human neurons: significance of dicysteine C30C31 motif. Ann Neurol. 2008; 63:36676. [PubMed: 18074388]

Missale C, et al. Dopamine receptors: from structure to function. Physiol Rev. 1998:78.

Moir S, et al. Pathogenic mechanisms of HIV disease. Annu Rev Pathol. 2011; 6:223-48. [PubMed: 21034222]

Monfils MH, Teskey GC. Induction of long-term depression is associated with decreased dendritic length and spine density in layers III and V of sensorimotor neocortex. Synapse. 2004; 53:114 21. [PubMed: 15170823]

Moore RD, et al. Differences in HIV disease progression by injecting drug use in HIV-infected persons in care. J Acquir Immune Defic Syndr. 2004; 35:46-51. [PubMed: 14707791]

Moran LM, et al. Adolescent HIV-1 transgenic rats: evidence for dopaminergic alterations in behavior and neurochemistry revealed by methamphetamine challenge. Curr HIV Res. 2012; 10:415-24. [PubMed: 22591365]

Moran LM, et al. Neonatal intrahippocampal HIV-1 protein Tat(1-86) injection: neurobehavioral alterations in the absence of increased inflammatory cytokine activation. Int J Dev Neurosci. 2014; 38:195-203. [PubMed: 25285887]

Moron JA, et al. Mitogen-activated protein kinase regulates dopamine transporter surface expression and dopamine transport capacity. J Neurosci. 2003; 23:8480-8. [PubMed: 13679416]

Mortensen OV, Amara SG. Dynamic regulation of the dopamine transporter. Eur J Pharmacol. 2003; 479:159-70. [PubMed: 14612147]

Mortensen OV, et al. Genetic complementation screen identifies a mitogen-activated protein kinase phosphatase, MKP3, as a regulator of dopamine transporter trafficking. Mol Biol Cell. 2008; 19:2818-29. [PubMed: 18434601]

Murphy BL, et al. Dopamine and spatial working memory in rats and monkeys: pharmacological reversal of stress-induced impairment. J Neurosci. 1996; 16:7768-75. [PubMed: 8922432]

Musante V, et al. The HIV-1 viral protein Tat increases glutamate and decreases GABA exocytosis from human and mouse neocortical nerve endings. Cereb Cortex. 2010; 20:1974-84. [PubMed: 20034999]

Nagerl UV, et al. Bidirectional activity-dependent morphological plasticity in hippocampal neurons. Neuron. 2004; 44:759-67. [PubMed: 15572108]

Nakamura K, et al. Brain serotonin and dopamine transporter bindings in adults with high-functioning autism. Archives of General Psychiatry. 2010; 67:59-68. [PubMed: 20048223]

Nanni MG, et al. Depression in HIV infected patients: a review. Curr Psychiatry Rep. 2015; 17:530. [PubMed: 25413636]

Napolitano A, et al. The role of monoamine oxidase and catechol O-methyltransferase in dopaminergic neurotransmission. J Neural Transm Suppl. 1995; 45:35-45. [PubMed: 8748607]

Nath A. Human immunodeficiency virus (HIV) proteins in neuropathogenesis of HIV dementia. J Infect Dis. 2002; 186(Suppl 2):S193-8. [PubMed: 12424697] 
Nath A. Human immunodeficiency virus-associated neurocognitive disorder: pathophysiology in relation to drug addiction. Ann N Y Acad Sci. 2010; 1187:122-8. [PubMed: 20201849]

Nath A, et al. Neurotoxicity and dysfunction of dopaminergic systems associated with AIDS dementia. J Psychopharmacol. 2000; 14:222-7. [PubMed: 11106300]

Nath A, et al. Transient exposure to HIV-1 Tat protein results in cytokine production in macrophages and astrocytes. A hit and run phenomenon. J Biol Chem. 1999; 274:17098-102. [PubMed: 10358063]

Nath A, et al. Molecular basis for interactions of HIV and drugs of abuse. J Acquir Immune Defic Syndr. 2002; 31(Suppl 2):S62-9. [PubMed: 12394784]

Nath A, et al. Acceleration of HIV dementia with methamphetamine and cocaine. J Neurovirol. 2001; 7:66-71. [PubMed: 11519485]

Navaroli DM, et al. The plasma membrane-associated GTPase Rin interacts with the dopamine transporter and is required for protein kinase C-regulated dopamine transporter trafficking. J Neurosci. 2011; 31:13758-70. [PubMed: 21957239]

Navia BA, et al. The AIDS dementia complex: I. Clinical features. Ann Neurol. 1986; 19:517-24. [PubMed: 3729308]

Navia BA, Price RW. The acquired immunodeficiency syndrome dementia complex as the presenting or sole manifestation of human immunodeficiency virus infection. Arch Neurol. 1987; 44:65-9. [PubMed: 3800724]

Nestler EJ. Is there a common molecular pathway for addiction? Nat Neurosci. 2005; 8:1445-9. [PubMed: 16251986]

Nestler, EJ., Hyman, SE., Malenka, RC. Molecular Neuropharmacology: A Foundation for Clinical Neuroscience. NewYork: McGraw-Hill Medical; 2009.

Neve, KA. The dopamine receptors. Humana Press; New York, NY: 2010.

Nieoullon A. Dopamine and the regulation of cognition and attention. Prog Neurobiol. 2002; 67:5383. [PubMed: 12126656]

Nutt DJ, et al. The dopamine theory of addiction: 40 years of highs and lows. Nat Rev Neurosci. 2015; 16:305-12. [PubMed: 25873042]

Obermann M, et al. Substantia nigra hyperechogenicity and CSF dopamine depletion in HIV. J Neurol. 2009a; 256:948-53. [PubMed: 19240951]

Obermann M, et al. Substantia nigra hyperechogenicity and CSF dopamine depletion in HIV. J Neurol. 2009b; 256:948-53. [PubMed: 19240951]

Ortega M, et al. Effects of HIV and combination antiretroviral therapy on cortico-striatal functional connectivity. AIDS. 2015; 29:703-12. [PubMed: 25849834]

Otani S, et al. Dopaminergic modulation of long-term synaptic plasticity in rat prefrontal neurons. Cereb Cortex. 2003; 13:1251-6. [PubMed: 14576216]

Ozdener H. Molecular mechanisms of HIV-1 associated neurodegeneration. J Biosci. 2005; 30:391405. [PubMed: 16052077]

Palmer S, et al. Low-level viremia persists for at least 7 years in patients on suppressive antiretroviral therapy. Proc Natl Acad Sci U S A. 2008; 105:3879-84. [PubMed: 18332425]

Paris JJ, et al. Effects of conditional central expression of HIV-1 tat protein to potentiate cocainemediated psychostimulation and reward among male mice. Neuropsychopharmacology. 2014a; 39:380-8. [PubMed: 23945478]

Paris JJ, et al. Anxiety-like behavior of mice produced by conditional central expression of the HIV-1 regulatory protein, Tat. Psychopharmacology (Berl). 2014b; 231:2349-60. [PubMed: 24352568]

Passingham R. How good is the macaque monkey model of the human brain? Curr Opin Neurobiol. 2009; 19:6-11. [PubMed: 19261463]

Pathan H, Williams J. Basic opioid pharmacology: an update. Br J Pain. 2012; 6:11-6. [PubMed: 26516461]

Peluso R, et al. A Trojan Horse mechanism for the spread of visna virus in monocytes. Virology. 1985; 147:231-6. [PubMed: 2998068] 
Perry SW, et al. Human immunodeficiency virus-1 Tat activates calpain proteases via the ryanodine receptor to enhance surface dopamine transporter levels and increase transporter-specific uptake and Vmax. J Neurosci. 2010; 30:14153-64. [PubMed: 20962236]

Pizzo AB, et al. The membrane raft protein Flotillin-1 is essential in dopamine neurons for amphetamine-induced behavior in Drosophila. Mol Psychiatry. 2013; 18:824-33. [PubMed: 22710269]

Plessis S, et al. HIV infection results in ventral-striatal reward system hypo-activation during cue processing. AIDS. 2015; 29:1335-43. [PubMed: 26091294]

Plessis SD, et al. HIV infection and the fronto-striatal system: a systematic review and meta-analysis of fMRI studies. AIDS. 2014; 28:803-11. [PubMed: 24300546]

Poirier LJ, et al. Comparative morphology of the substantia nigra and ventral tegmental area in the monkey, cat and rat. Brain Res Bull. 1983; 11:371-97. [PubMed: 6640366]

Poulin JF, et al. Defining midbrain dopaminergic neuron diversity by single-cell gene expression profiling. Cell Rep. 2014; 9:930-43. [PubMed: 25437550]

Price RW, et al. The brain in AIDS: central nervous system HIV-1 infection and AIDS dementia complex. Science. 1988; 239:586-92. [PubMed: 3277272]

Ptak RG, et al. Cataloguing the HIV type 1 human protein interaction network. AIDS Res Hum Retroviruses. 2008; 24:1497-502. [PubMed: 19025396]

Purohit V, et al. Drugs of abuse, dopamine, and HIV-associated neurocognitive disorders/HIVassociated dementia. Mol Neurobiol. 2011; 44:102-10. [PubMed: 21717292]

Qi L, et al. Programmed neuronal cell death induced by HIV-1 tat and methamphetamine. Microsc Res Tech. 2011; 74:1139-44. [PubMed: 21563266]

Raborn ES, Cabral GA. Cannabinoid Inhibition of Macrophage Migration to the Trans-Activating (Tat) Protein of HIV-1 Is Linked to the $\mathrm{CB}_{2}$ Cannabinoid Receptor. Journal of Pharmacology and Experimental Therapeutics. 2010; 333:319. [PubMed: 20089805]

Raghanti MA, et al. Species-specific distributions of tyrosine hydroxylase-immunoreactive neurons in the prefrontal cortex of anthropoid primates. Neuroscience. 2009; 158:1551-9. [PubMed: 19041377]

Rana TM, Jeang KT. Biochemical and functional interactions between HIV-1 Tat protein and TAR RNA. Arch Biochem Biophys. 1999; 365:175-85. [PubMed: 10328810]

Rayne F, et al. HIV-1 Tat is unconventionally secreted through the plasma membrane. Cell Biol Int. 2010a; 34:409-13. [PubMed: 19995346]

Rayne F, et al. Phosphatidylinositol-(4,5)-bisphosphate enables efficient secretion of HIV-1 Tat by infected T-cells. EMBO J. 2010b; 29:1348-62. [PubMed: 20224549]

Reddy IA, et al. Glucagon-like peptide 1 receptor activation regulates cocaine actions and dopamine homeostasis in the lateral septum by decreasing arachidonic acid levels. Transl Psychiatry. 2016; 6:e809. [PubMed: 27187231]

Reyes MG, et al. Nigral degeneration in acquired immune deficiency syndrome (AIDS). Acta Neuropathol. 1991; 82:39-44. [PubMed: 1950477]

Rice AP, Carlotti F. Mutational analysis of the conserved cysteine-rich region of the human immunodeficiency virus type 1 Tat protein. J Virol. 1990; 64:1864-8. [PubMed: 2181156]

Richardson BD, et al. Membrane potential shapes regulation of dopamine transporter trafficking at the plasma membrane. Nat Commun. 2016; 7:10423. [PubMed: 26804245]

Rippeth JD, et al. Methamphetamine dependence increases risk of neuropsychological impairment in HIV infected persons. J Int Neuropsychol Soc. 2004; 10:1-14. [PubMed: 14751002]

Ritz MC, et al. Cocaine receptors on dopamine transporters are related to self-administration of cocaine. Science. 1987; 237:1219-23. [PubMed: 2820058]

Robertson KR, et al. Pattern of neuropsychological performance among HIV positive patients in Uganda. BMC Neurol. 2007; 7:8. [PubMed: 17411437]

Rocha BA, et al. Cocaine self-administration in dopamine-transporter knockout mice. Nat Neurosci. 1998; 1:132-7. [PubMed: 10195128]

Romani B, et al. Functions of Tat: the versatile protein of human immunodeficiency virus type 1. J Gen Virol. 2010; 91:1-12. [PubMed: 19812265] 
Rothblat DS, Schneider JS. Spontaneous functional recovery from parkinsonism is not due to reinnervation of the dorsal striatum by residual dopaminergic neurons. Brain Res Bull. 1994; 34:309-12. [PubMed: 7914468]

Rothblat DS, et al. Tyrosine hydroxylase and dopamine transporter expression in residual dopaminergic neurons: potential contributors to spontaneous recovery from experimental Parkinsonism. J Neurosci Res. 2001; 65:254-66. [PubMed: 11494360]

Rottenberg DA, et al. The metabolic pathology of the AIDS dementia complex. Ann Neurol. 1987; 22:700-6. [PubMed: 3501695]

Sacktor N. The epidemiology of human immunodeficiency virus-associated neurological disease in the era of highly active antiretroviral therapy. J Neurovirol. 2002; 8(Suppl 2):115-21. [PubMed: 12491162]

Sacktor N, et al. HIV-associated cognitive impairment before and after the advent of combination therapy. J Neurovirol. 2002; 8:136-42. [PubMed: 11935465]

Saha K, et al. Intracellular methamphetamine prevents the dopamine-induced enhancement of neuronal firing. J Biol Chem. 2014; 289:22246-57. [PubMed: 24962577]

Sakrikar D, et al. Attention deficit/hyperactivity disorder-derived coding variation in the dopamine transporter disrupts microdomain targeting and trafficking regulation. J Neurosci. 2012; 32:538597. [PubMed: 22514303]

Salahpour A, et al. Increased amphetamine-induced hyperactivity and reward in mice overexpressing the dopamine transporter. Proc Natl Acad Sci U S A. 2008; 105:4405-10. [PubMed: 18347339]

Salters KA, et al. Harder-to-reach people living with HIV experiencing high prevalence of all-type mental health disorder diagnosis. AIDS Care. 2016:1-9.

Salvatore MF, et al. Depolarization-stimulated catecholamine biosynthesis: involvement of protein kinases and tyrosine hydroxylase phosphorylation sites in situ. J Neurochem. 2001; 79:349-60. [PubMed: 11677263]

Sardar AM, et al. Dopamine deficits in the brain: the neurochemical basis of parkinsonian symptoms in AIDS. Neuroreport. 1996; 7:910-2. [PubMed: 8724671]

Saunders C, et al. Amphetamine-induced loss of human dopamine transporter activity: an internalizationdependent and cocaine-sensitive mechanism. Proc Natl Acad Sci U S A. 2000; 97:6850-5. [PubMed: 10823899]

Scheller C, et al. Increased dopaminergic neurotransmission in therapy-naive asymptomatic HIV patients is not associated with adaptive changes at the dopaminergic synapses. J Neural Transm. 2010; 117:699-705. [PubMed: 20454983]

Scheller C, et al. Dopamine activates HIV in chronically infected T lymphoblasts. J Neural Transm (Vienna). 2000; 107:1483-9. [PubMed: 11459001]

Scheller C, et al. Early impairment in dopaminergic neurotransmission in brains of SIV-infected rhesus monkeys due to microglia activation. J Neurochem. 2005; 95:377-87. [PubMed: 16190867]

Schneider JS, et al. Selective loss of subpopulations of ventral mesencephalic dopaminergic neurons in the monkey following exposure to MPTP. Brain Res. 1987; 411:144-50. [PubMed: 2886180]

Silvers JM, et al. Dopaminergic marker proteins in the substantia nigra of human immunodeficiency virus type 1-infected brains. J Neurovirol. 2006; 12:140-5. [PubMed: 16798675]

Silvers JM, et al. Neurotoxicity of HIV-1 Tat protein: Involvement of D1 dopamine receptor. NeuroToxicology. 2007; 28:1184-1190. [PubMed: 17764744]

Simioni S, et al. Cognitive dysfunction in HIV patients despite long-standing suppression of viremia. AIDS. 2010; 24:1243-50. [PubMed: 19996937]

Sonders MS, et al. Multiple ionic conductances of the human dopamine transporter: the actions of dopamine and psychostimulants. J Neurosci. 1997; 17:960-74. [PubMed: 8994051]

Sorkina T, et al. Flotillins regulate membrane mobility of the dopamine transporter but are not required for its protein kinase C dependent endocytosis. Traffic. 2013; 14:709-24. [PubMed: 23418867]

Speed N, et al. Impaired striatal Akt signaling disrupts dopamine homeostasis and increases feeding. PLoS One. 2011; 6:e25169. [PubMed: 21969871] 
Starace F, et al. Early neuropsychological impairment in HIV-seropositive intravenous drug users: evidence from the Italian Multicentre Neuropsychological HIV Study. Acta Psychiatr Scand. 1998; 97:132-8. [PubMed: 9517907]

Stevenson M. HIV-1 pathogenesis. Nat Med. 2003; 9:853-60. [PubMed: 12835705]

Sulzer D, et al. Striatal dopamine neurotransmission: regulation of release and uptake. Basal Ganglia. 2016; 6:123-148. [PubMed: 27141430]

Sulzer D, Galli A. Dopamine transport currents are promoted from curiosity to physiology. Trends Neurosci. 2003; 26:173-6. [PubMed: 12689764]

Sulzer D, et al. Mechanisms of neurotransmitter release by amphetamines: a review. Prog Neurobiol. 2005; 75:406-33. [PubMed: 15955613]

Swepson C, et al. Cocaine Enhances HIV-1 Transcription in Macrophages by Inducing p38 MAPK Phosphorylation. Front Microbiol. 2016; 7:823. [PubMed: 27375565]

Tahirov TH, et al. Crystal structure of HIV-1 Tat complexed with human P-TEFb. Nature. 2010; 465:747-51. [PubMed: 20535204]

Taylor MJ, et al. Effects of human immunodeficiency virus and methamphetamine on cerebral metabolites measured with magnetic resonance spectroscopy. J Neurovirol. 2007; 13:150-9. [PubMed: 17505983]

Teo MY, et al. Differential effects of nicotine on the activity of substantia nigra and ventral tegmental area dopaminergic neurons in vitro. Acta Neurobiol Exp (Wars). 2004; 64:119-30. [PubMed: 15366245]

Thames AD, et al. Combined effects of HIV and marijuana use on neurocognitive functioning and immune status. AIDS Care. 2016; 28:628-32. [PubMed: 26694807]

Theodore $\mathrm{S}$, et al. Involvement of cytokines in human immunodeficiency virus-1 protein Tat and methamphetamine interactions in the striatum. Exp Neurol. 2006a; 199:490-8. [PubMed: 16510141]

Theodore S, et al. Methamphetamine and human immunodeficiency virus protein Tat synergize to destroy dopaminergic terminals in the rat striatum. Neuroscience. 2006b; 137:925-35. [PubMed: 16338084]

Theodore S, et al. Progress in understanding basal ganglia dysfunction as a common target for methamphetamine abuse and HIV-1 neurodegeneration. Curr HIV Res. 2007; 5:301-13. [PubMed: 17504172]

Tisch S, Brew B. Parkinsonism in hiv-infected patients on highly active antiretroviral therapy. Neurology. 2009; 73:401-3. [PubMed: 19652146]

Tomlinson GS, et al. Upregulation of microglia in drug users with and without pre-symptomatic HIV infection. Neuropathol Appl Neurobiol. 1999; 25:369-79. [PubMed: 10564526]

Tornatore C, et al. HIV-1 infection of subcortical astrocytes in the pediatric central nervous system. Neurology. 1994; 44:481-7. [PubMed: 8145919]

Tozzi V, et al. Neurocognitive impairment and survival in a cohort of HIV-infected patients treated with HAART. AIDS Res Hum Retroviruses. 2005; 21:706-13. [PubMed: 16131310]

Tremblay L, et al. Selective dysfunction of basal ganglia subterritories: From movement to behavioral disorders. Mov Disord. 2015; 30:1155-70. [PubMed: 25772380]

Tremblay ME, et al. Ultrastructure of microglia-synapse interactions in the HIV-1 Tat-injected murine central nervous system. Commun Integr Biol. 2013; 6:e27670. [PubMed: 24563721]

Turchan-Cholewo J, et al. Cell-specific actions of HIV-tat and morphine on opioid receptor expression in glia. Journal of Neuroscience Research. 2008; 86:2100-2110. [PubMed: 18338799]

UNAIDS. How AIDS Changed Everything. 2015.

Valcour V, et al. Central nervous system viral invasion and inflammation during acute HIV infection. J Infect Dis. 2012; 206:275-82. [PubMed: 22551810]

Vallone D, et al. Structure and function of dopamine receptors. Neuroscience \& Biobehavioral Reviews. 2000; 24:125-132. [PubMed: 10654668]

Vander Weele CM, et al. Rapid dopamine transmission within the nucleus accumbens: dramatic difference between morphine and oxycodone delivery. Eur J Neurosci. 2014; 40:3041-54. [PubMed: 25208732] 
Vera JH, et al. Neuroinflammation in treated HIV-positive individuals: A TSPO PET study. Neurology. 2016

Vives E, et al. A truncated HIV-1 Tat protein basic domain rapidly translocates through the plasma membrane and accumulates in the cell nucleus. J Biol Chem. 1997; 272:16010-7. [PubMed: 9188504]

Volkow ND, et al. Stimulant-induced dopamine increases are markedly blunted in active cocaine abusers. Mol Psychiatry. 2014; 19:1037-43. [PubMed: 24912491]

Volkow ND, et al. Relationship between subjective effects of cocaine and dopamine transporter occupancy. Nature. 1997; 386:827-30. [PubMed: 9126740]

Vongsheree S, et al. High HIV-1 prevalence among metamphetamine users in central Thailand, 19992000. J Med Assoc Thai. 2001; 84:1263-7. [PubMed: 11800299]

Wadia JS, et al. Transducible TAT-HA fusogenic peptide enhances escape of TAT-fusion proteins after lipid raft macropinocytosis. Nat Med. 2004; 10:310-5. [PubMed: 14770178]

Wall SC, et al. Biogenic amine flux mediated by cloned transporters stably expressed in cultured cell lines: amphetamine specificity for inhibition and efflux. Mol Pharmacol. 1995; 47:544-50. [PubMed: 7700252]

Wallace DR, et al. Estrogen attenuates gp120- and tat1-72-induced oxidative stress and prevents loss of dopamine transporter function. Synapse. 2006; 59:51-60. [PubMed: 16237680]

Wang GJ, et al. Decreased brain dopaminergic transporters in HIV-associated dementia patients. Brain. 2004; 127:2452-8. [PubMed: 15319273]

Webber MP, et al. A prospective study of HIV disease progression in female and male drug users. AIDS. 1999; 13:257-62. [PubMed: 10202832]

Weber R, et al. Decreasing mortality and changing patterns of causes of death in the Swiss HIV Cohort Study. HIV Med. 2013; 14:195-207. [PubMed: 22998068]

Wei Y, et al. Dopamine transporter activity mediates amphetamine-induced inhibition of Akt through a Ca2+/calmodulin-dependent kinase II-dependent mechanism. Mol Pharmacol. 2007; 71:835-42. [PubMed: 17164407]

Westendorp MO, et al. Sensitization of T cells to CD95-mediated apoptosis by HIV-1 Tat and gp120. Nature. 1995; 375:497-500. [PubMed: 7539892]

Wright PW, et al. Cerebral white matter integrity during primary HIV infection. AIDS. 2014

$\mathrm{Wu} \mathrm{S}$, et al. Ack1 is a dopamine transporter endocytic brake that rescues a trafficking-dysregulated ADHD coding variant. Proc Natl Acad Sci U S A. 2015; 112:15480-5. [PubMed: 26621748]

$\mathrm{Xu}$ C, et al. Cannabinoids Occlude the HIV-1 Tat-Induced Decrease in GABAergic Neurotransmission in Prefrontal Cortex Slices. J Neuroimmune Pharmacol. 2016; 11:316-31. [PubMed: 26993829]

Yiannoutsos CT, et al. Regional patterns of brain metabolites in AIDS dementia complex. Neuroimage. 2004; 23:928-35. [PubMed: 15528093]

Yorgason JT, et al. Frequency-dependent effects of ethanol on dopamine release in the nucleus accumbens. Alcohol Clin Exp Res. 2014; 38:438-47. [PubMed: 24117706]

Yuan Y, et al. Molecular mechanism of HIV-1 Tat interacting with human dopamine transporter. ACS Chem Neurosci. 2015a; 6:658-65. [PubMed: 25695767]

Yuan Y, et al. Molecular Mechanism of HIV-1 Tat Interacting with Human Dopamine Transporter. ACS Chem Neurosci. 2015b

Yuan Y, et al. Role of Histidine 547 of Human Dopamine Transporter in Molecular Interaction with HIV-1 Tat and Dopamine Uptake. Sci Rep. 2016; 6:27314. [PubMed: 27250920]

Zaborszky L, Vadasz C. The midbrain dopaminergic system: anatomy and genetic variation in dopamine neuron number of inbred mouse strains. Behav Genet. 2001; 31:47-59. [PubMed: 11529274]

Zauli G, et al. HIV-1 Tat-mediated inhibition of the tyrosine hydroxylase gene expression in dopaminergic neuronal cells. J Biol Chem. 2000; 275:4159-65. [PubMed: 10660577]

Zayyad Z, Spudich S. Neuropathogenesis of HIV: from initial neuroinvasion to HIV-associated neurocognitive disorder (HAND). Curr HIV/AIDS Rep. 2015; 12:16-24. [PubMed: 25604237]

Zeiss CJ. Neuroanatomical phenotyping in the mouse: the dopaminergic system. Vet Pathol. 2005; 42:753-73. [PubMed: 16301571] 
Zhou Q, et al. Shrinkage of dendritic spines associated with long-term depression of hippocampal synapses. Neuron. 2004; 44:749-57. [PubMed: 15572107]

Zhu J, et al. Recombinant human immunodeficiency virus-1 transactivator of transcription 1-86 allosterically modulates dopamine transporter activity. Synapse. 2011; 65:1251-4. [PubMed: 21538554]

Zhu J, et al. HIV-1 Tat protein-induced rapid and reversible decrease in [3H]dopamine uptake: dissociation of $[3 \mathrm{H}]$ dopamine uptake and $[3 \mathrm{H}] 2$ beta-carbomethoxy-3-beta-(4fluorophenyl)tropane (WIN 35,428) binding in rat striatal synaptosomes. J Pharmacol Exp Ther. 2009; 329:1071-83. [PubMed: 19325033]

Zhu J, et al. Intra-ventral tegmental area HIV-1 Tat1-86 attenuates nicotine-mediated locomotor sensitization and alters mesocorticolimbic ERK and CREB signaling in rats. Front Microbiol. 2015; 6:540. [PubMed: 26150803]

Zhu J, et al. HIV-1 transgenic rats display an increase in [(3)H]dopamine uptake in the prefrontal cortex and striatum. J Neurovirol. 2016; 22:282-92. [PubMed: 26501780]

Zhuang X, et al. Hyperactivity and impaired response habituation in hyperdopaminergic mice. Proc Natl Acad Sci U S A. 2001; 98:1982-7. [PubMed: 11172062]

Zoli M, et al. Identification of the nicotinic receptor subtypes expressed on dopaminergic terminals in the rat striatum. J Neurosci. 2002; 22:8785-9. [PubMed: 12388584]

Zucchini S, et al. Increased excitability in tat-transgenic mice: role of tat in HIV-related neurological disorders. Neurobiol Dis. 2013; 55:110-9. [PubMed: 23454193] 


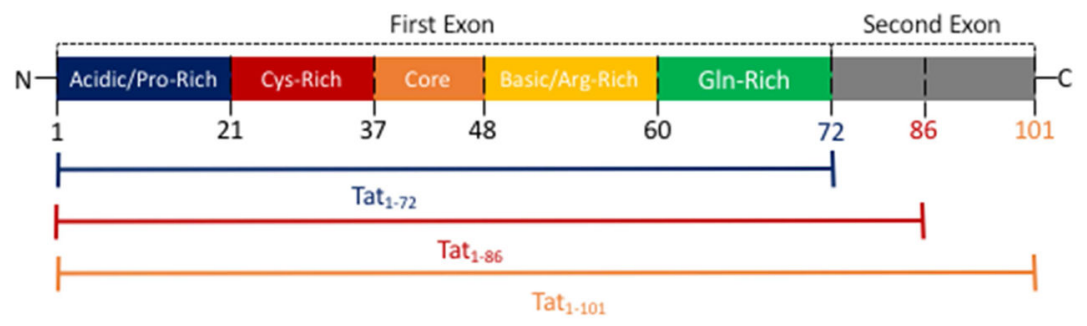

Figure 1. Illustration of the different regions of the HIV-1 Tat protein

The first exon of the HIV-1 Tat protein, which can be found is all three forms of the protein (e.g., Tat $_{1-72}$, Tat ${ }_{1-86}$, and $\mathrm{Tat}_{1-101}$ ), is composed of five distinct regions: an acidic or proline (Pro)-rich domain (the N-terminal), a cysteine (Cys)-rich domain, a core domain, a basic or arginine (Arg)-rich domain, and a glutamine (Gln)-rich domain (the C-terminal). The second exon of the HIV-1 Tat protein, which spans from amino acid residues 73-101, comprises the integrin binding modality and can be found in two forms of the protein (e.g., Tat 1-86 $_{6}$ and Tat $_{1-101}$ ). Note that the letters $\mathrm{N}$ and $\mathrm{C}$ represent the $\mathrm{N}$-terminal and $\mathrm{C}$-terminal of the protein, respectively. 

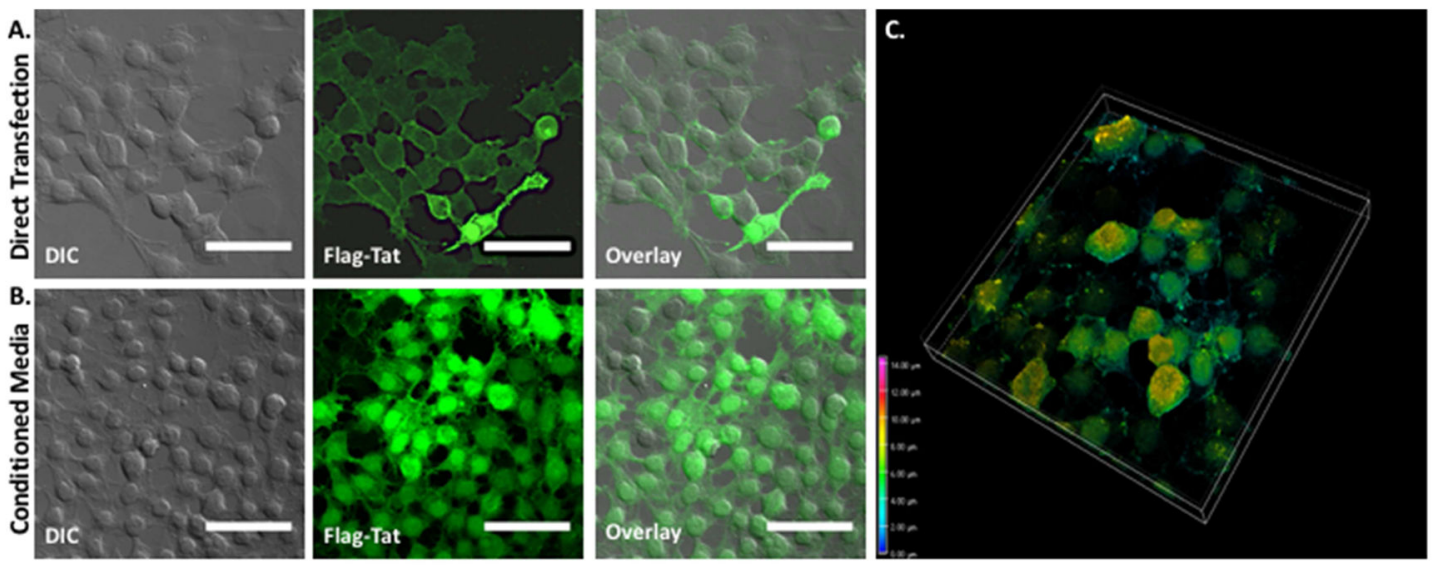

Figure 2. HIV-1 Flag-Tat 1 -101 Uptake In HEK cells

A. HEK cells were transfected with $1 \mathrm{ng}$ of a plasmid containing the HIV-1 FLAG-Tat 101 gene (pcDNA3.1+/Tat 101 -flag(PEV280), NIH AIDS Reagent Cat. No. 10453), immunostained with the monoclonal ANTI-FLAG® M2 primary antibody (Sigma-Aldrich, St. Louis, MO, USA) and secondary antibody conjugated to Alexa 488, and imaged 72 hours post-transfection on a Nikon Multiphoton/Super Resolution Imaging System (Nikon A1RMPsi-STORM 4.0, 20X Magnification). $\mathrm{N}=5$ independent experiments. B. A separate set of HEK cells was incubated with conditioned media containing the HIV-1 Flag-Tat protein for 48 hours, immunostained as above, and imaged (20X Magnification). Flag-Tat is detected in virtually all cells under this experimental configuration. As shown in the image, almost all cells express Flag-Tat. $N=6$ independent experiments. Scale bar $=50 \mu \mathrm{m}$. C. Depth-coded 3D Z-stack of HEK cells from panel B. 

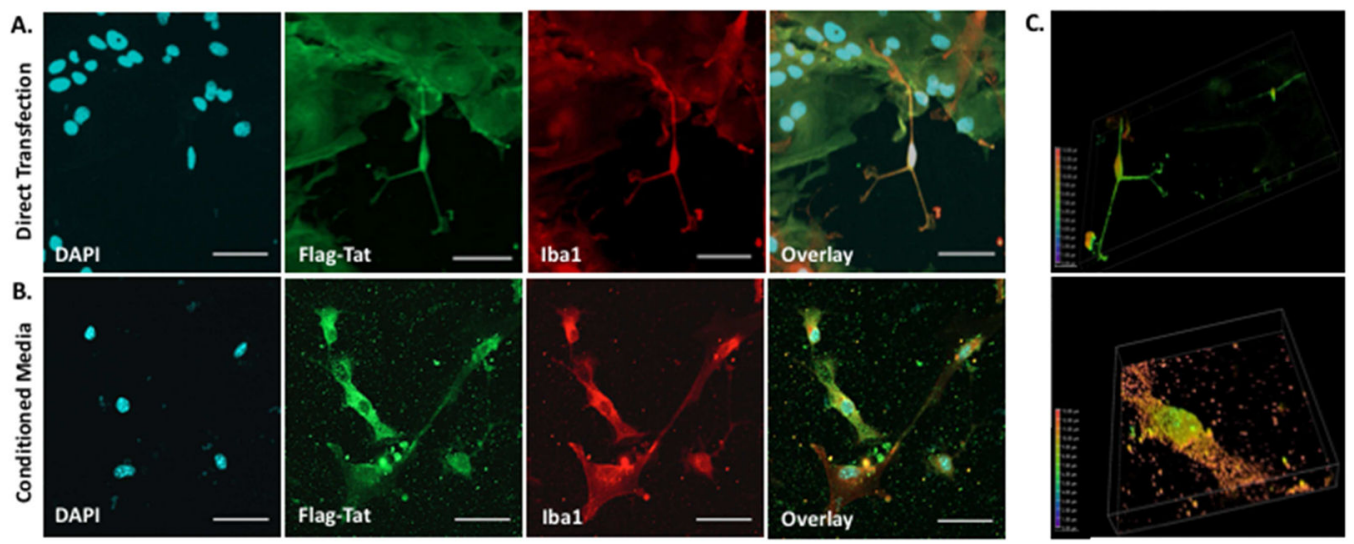

Figure 3. HIV Flag-Tat ${ }_{101}$ Uptake in Midbrain Microglia

A. Mouse midbrain microglia in a mixed glia culture at postnatal day 2 were transfected with $1 \mu \mathrm{g}$ of a plasmid containing the HIV-1 Flag-Tat 101 gene (pcDNA3.1+/Tat ${ }_{101^{-}}$ flag(PEV280)), immunostained with the monoclonal ANTI-FLAG® ${ }^{\circledR}$ M2 primary antibody (Sigma-Aldrich, St. Louis, MO, USA), polyclonal Iba1 primary antibody (Wako Pure Chemical Industries, Ltd., Richmond, VA, USA), and secondary antibody conjugated to Alexa 488 (Green) or 647 (Red), mounted with DAPI (Blue) Fluoromount-G (SouthernBiotech, Birmingham, AL, USA), and imaged 24 hours post-transfection on a Nikon Imaging System (Nikon A1RMPsi-STORM 4.0, 20X Magnification). N = 6 independent experiments (midbrain of 3-5 mice used for each experiment). B. Another set of mouse midbrain microglia in a mixed glia culture at postnatal day 2 was incubated with conditioned media containing the HIV-1 Flag-Tat protein, immunostained as described above, and imaged 24 hours later (20X Magnification). $\mathrm{N}=5$ independent experiments (midbrain of 3-5 mice used for each experiment). C. Images represent a depth coded 3D Zstack of one microglia cell from the 60X magnified image in panel A (top) and panel B (bottom). Scale bar $=50 \mu \mathrm{m}$ in 20X images and $25 \mu \mathrm{m}$ in 60X images. 

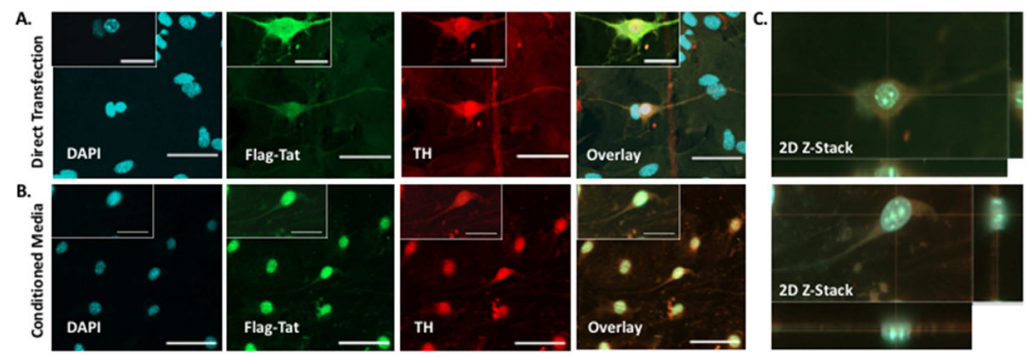

Figure 4. HIV Flag-Tat ${ }_{101}$ Uptake in Midbrain Dopaminergic Neurons

A. Midbrain neuronal cultures were obtained from a mouse strain that contained the $T H:$ RFP transgene, which labels neurons with the red fluorescent protein driven by the tyrosine hydroxylase (TH) promoter. The TH:RFP transgene was constructed by ligating a $4.5 \mathrm{~kb}$ HindIII $/$ coRI fragment of the rat tyrosine hydroxylase promoter with DsRed2-1 (Clontech, Palo Alto, CA, USA). Dopaminergic neurons (Red) at postnatal day 2 were grown on a monolayer of glia and transfected with $1 \mu \mathrm{g}$ of a plasmid containing the HIV-1 Flag-Tat $_{101}$ gene (pcDNA3.1+/Tat 101 -flag(PEV280)). The neurons were immunostained with the monoclonal ANTI-FLAG® M2 primary antibody (Sigma-Aldrich, St. Louis, MO, USA) and secondary antibody conjugated to Alexa 488 (Green), mounted with DAPI (Blue) Fluoromount-G (SouthernBiotech, Birmingham, AL, USA), and imaged 24 hours posttransfection (20X magnification and 60X magnification of one dopaminergic neuron from 20X image in corner). $\mathrm{N}=6$ independent experiments (midbrain of 3-5 mice used for each experiment). B. Another set of mouse midbrain neuronal cultures at postnatal day 2 was incubated with conditioned media containing the HIV-1 Flag-Tat protein, immunostained as previously described, and imaged 24 hours later (20X Magnification (large box) and 60X Magnification (small box in the corner of $20 \mathrm{X}$ image). $\mathrm{N}=5$ independent experiments (midbrain of 3-5 mice used for each experiment). C. Images represent an orthogonal XY, $\mathrm{XZ}$, and $\mathrm{YZ}$ projection of a Z-stack of one neuron from the 60X magnified image in panel A (top) and panel B (bottom). Scale bar $=50 \mu \mathrm{m}$ in $20 \mathrm{X}$ images and $25 \mu \mathrm{m}$ in $60 \mathrm{X}$ images. 


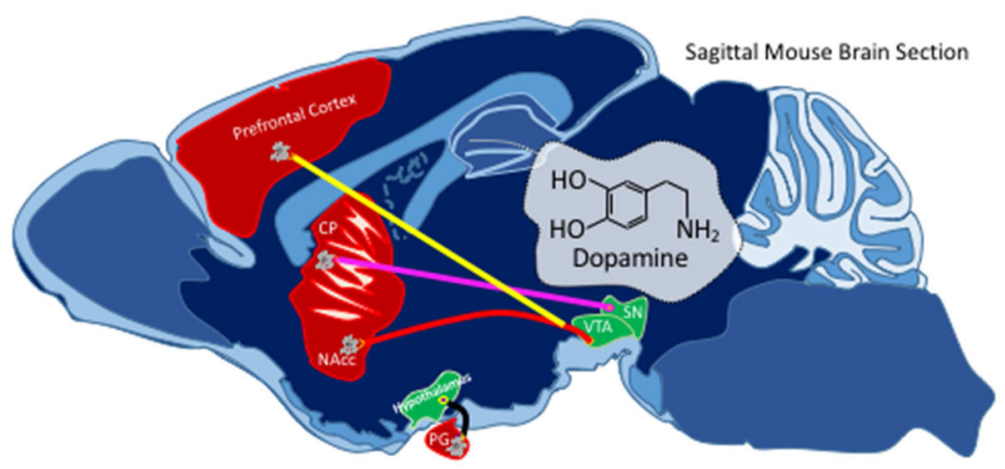

Figure 5. Diagram of the Dopamine Pathways in the Brain

In both animals and humans, the neurotransmitter, dopamine, is transmitted from neurons in the substantia nigra $(\mathrm{SN})$ pars compacta to cells in the caudate putamen $(\mathrm{CP})$ through the nigrostriatal pathway (pink). Dopamine can also be transmitted from neurons in the ventral tegmental area (VTA) to cells in the nucleus accumbens (NAcc) through the mesolimbic pathway (red), from neurons in the VTA to cells in the prefrontal cortex through the mesocortical pathway (yellow), and from neurons in the infundibular nucleus of the hypothalamus to cells in the pituitary gland (PG) through the tuberoinfundibular pathway (orange). 


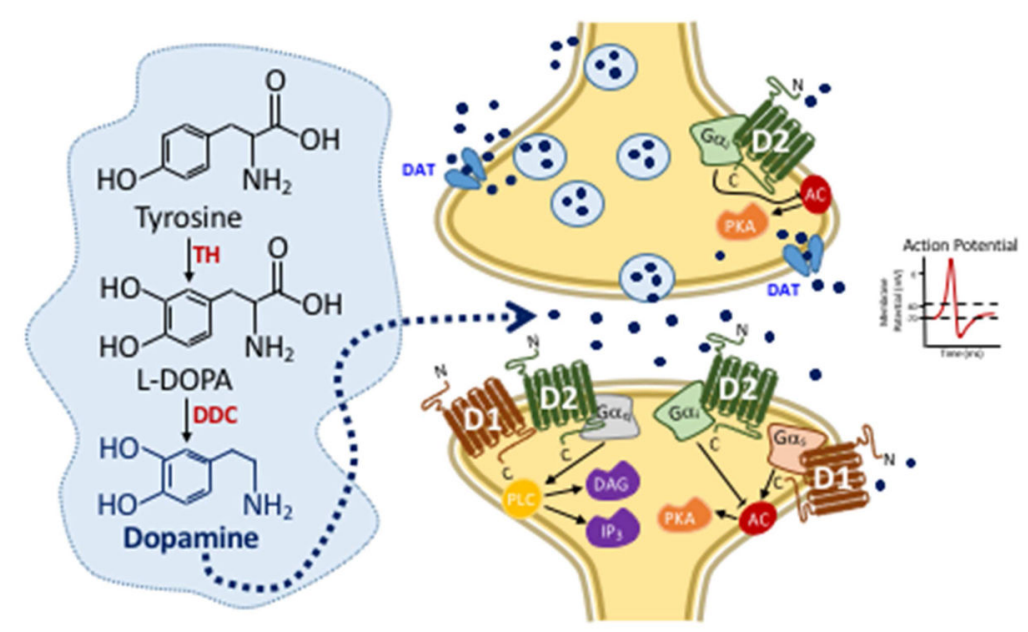

Figure 6. Illustration of Dopamine Neurotransmission

In neurons, the amino acid, tyrosine, is converted to dopamine by two enzymatic reactions. First tyrosine is converted into L-dihydroxyphenylalanine (L-DOPA) by the rate-limiting enzyme, tyrosine hydroxylase (TH), which is then converted into dopamine by the enzyme, DOPA decarboxylase (DDC). Dopamine can be released by neurons into the synaptic cleft via two distinct mechanisms, which are labeled 1 and 2. First, after an action potential has been generated (1) or through the dopamine transporter (DAT) via efflux mechanism (2). Upon release of dopamine into the synaptic cleft, dopamine can bind to $\mathrm{G}$ protein-coupled

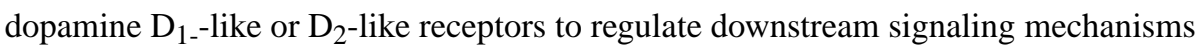
involving protein kinase A (PKA), diacylglycerol, or inositol triphosphate $\left(\mathrm{IP}_{3}\right) . \mathrm{Ga}_{\mathrm{i} / \mathrm{s}}$, the alpha subunit of the stimulatory (s) or inhibitory (i) G protein. PLC, phospholipase C. AC, adenylyl cyclase. 


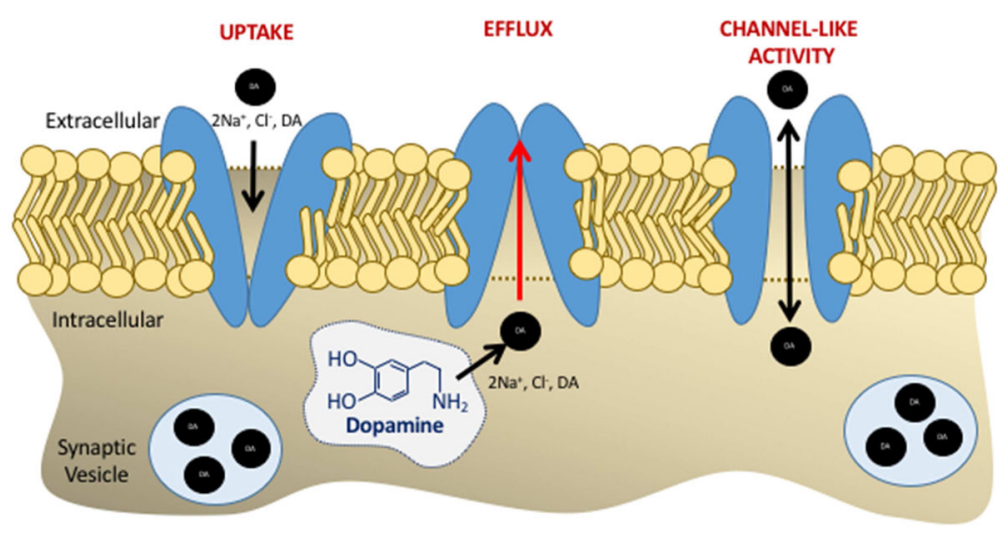

Figure 7. Dopamine Transporter has three distinct modes of activity in dopamine neurons Independent of dopamine neuron firing, the dopamine transporter, DAT, an integral membrane protein, transports the neurotransmitter, dopamine (DA), along with two sodium ions $\left(\mathrm{Na}^{+}\right)$and one chloride ion $\left(\mathrm{Cl}^{-}\right)$across the plasma membrane by three mechanisms: (1) uptake which involves a conformational change in DAT that is induced by the sequential binding of the ions and dopamine to the transporter and the subsequent release of the ions and dopamine into the cytosol (2) reverse transport or efflux mechanism which involves reverse transport of cytosolic dopamine to the extracellular space. The reverse transport of dopamine via DAT occurs via multiple mechanisms. These include but not limited to, conditions when the transporter is in an inward facing conformation, as occurs following exposure to psychostimulants such as amphetamine, when there is excess intra-neuronal DA, or when there is phosphorylation of the N-terminal domain of DAT. The third mechanism is a channel-like mechanism (3) where dopamine is transported via the DAT across its electrochemical gradient. 


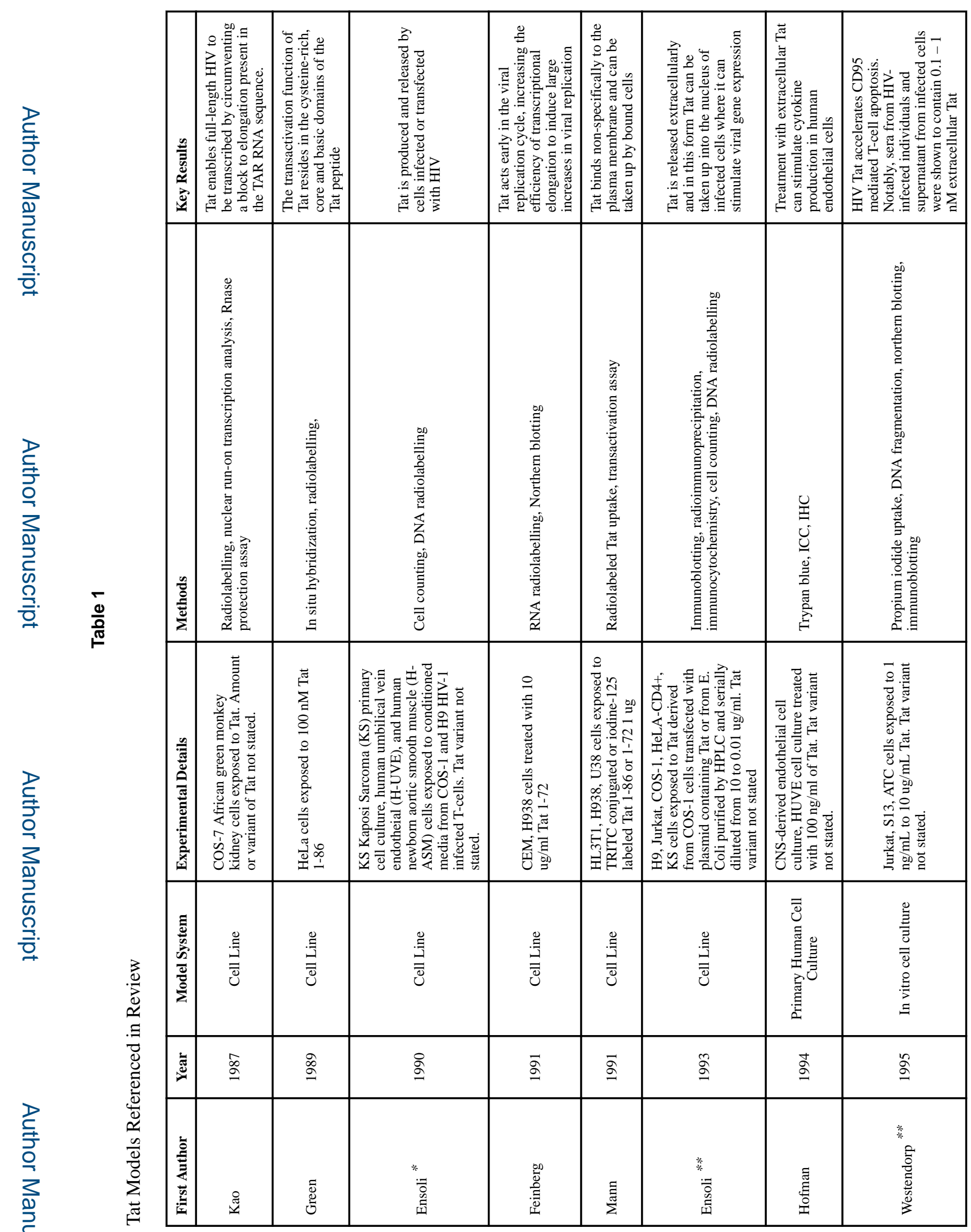

Neurobiol Dis. Author manuscript; available in PMC 2018 September 01. 


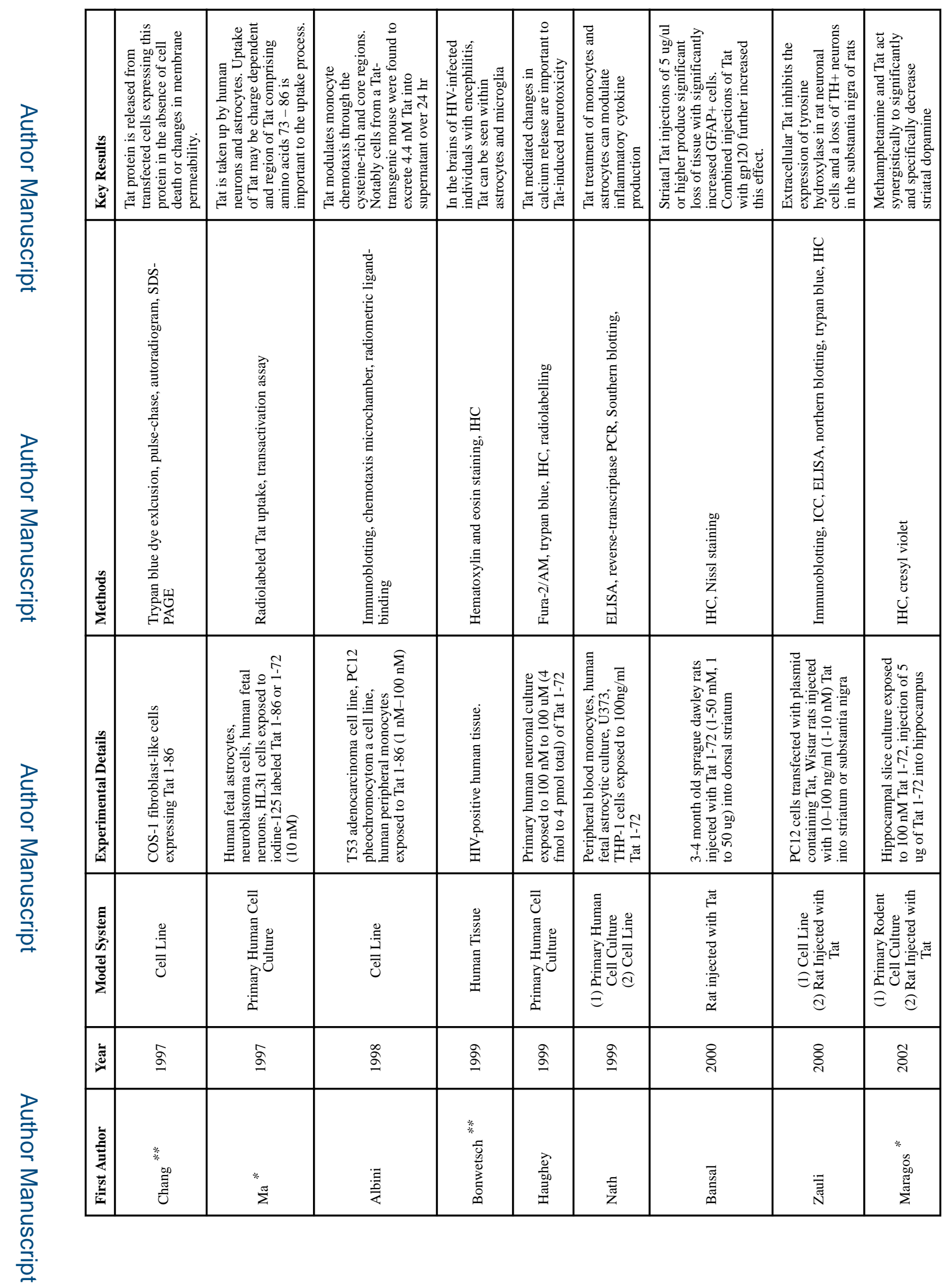

Neurobiol Dis. Author manuscript; available in PMC 2018 September 01. 


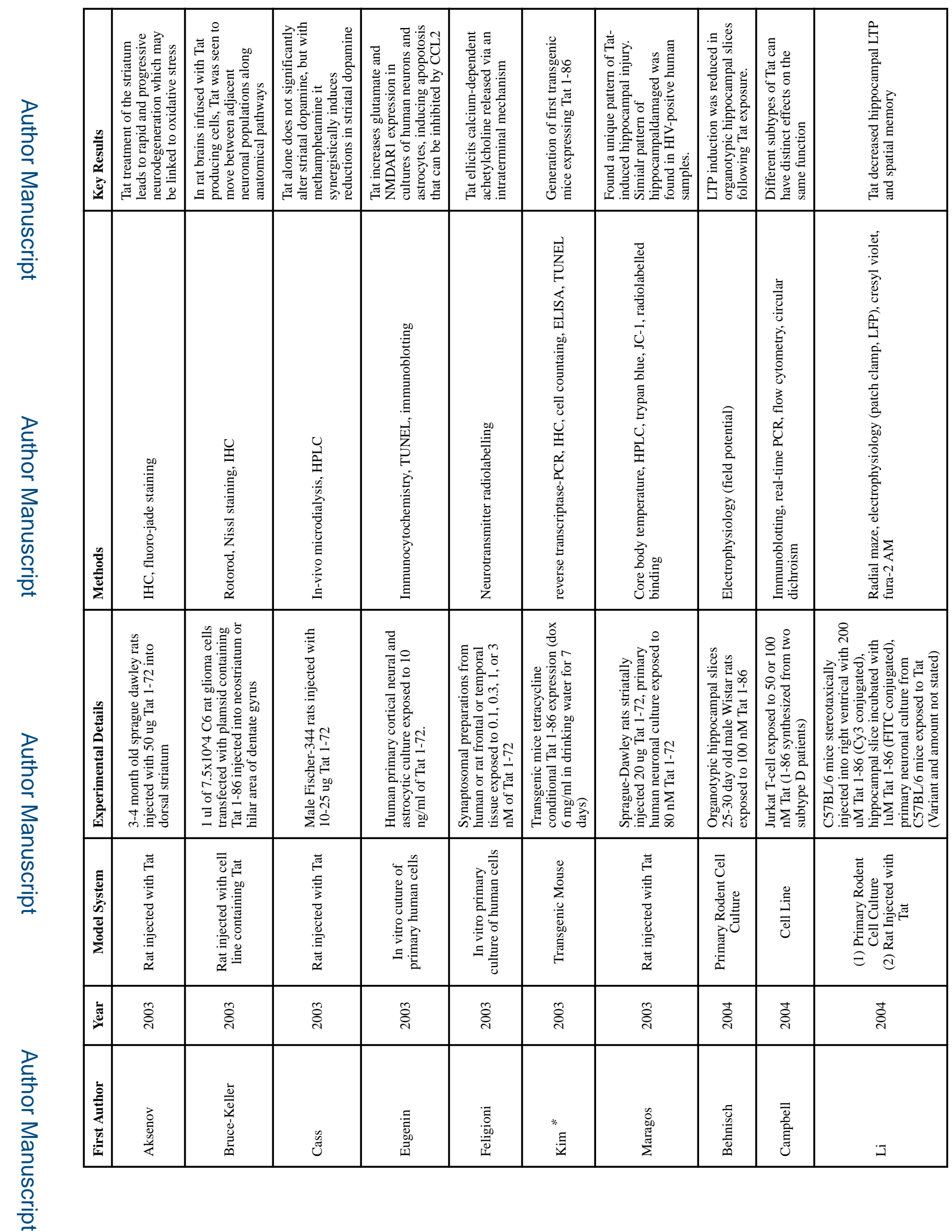

Neurobiol Dis. Author manuscript; available in PMC 2018 September 01. 


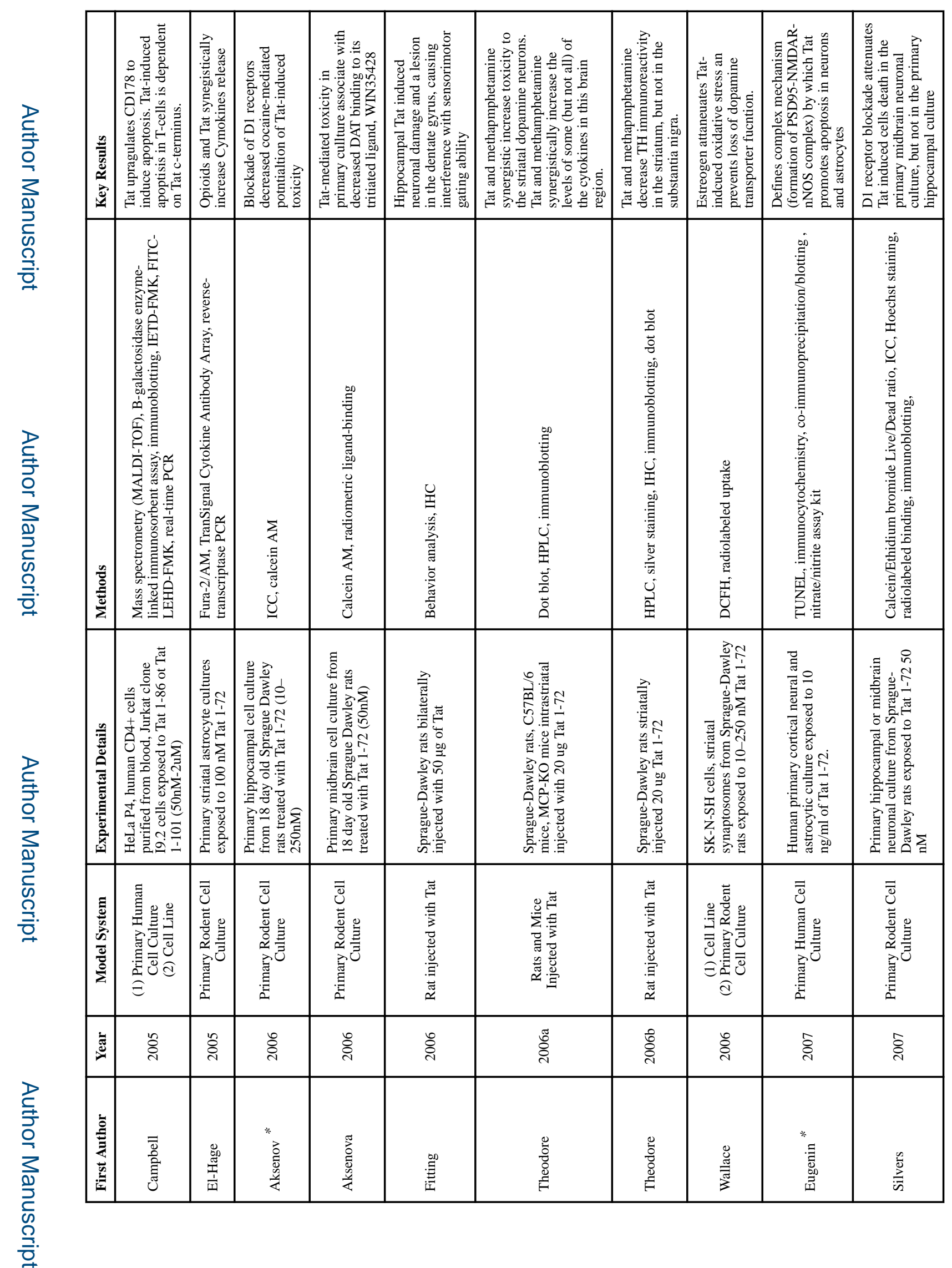

Neurobiol Dis. Author manuscript; available in PMC 2018 September 01. 


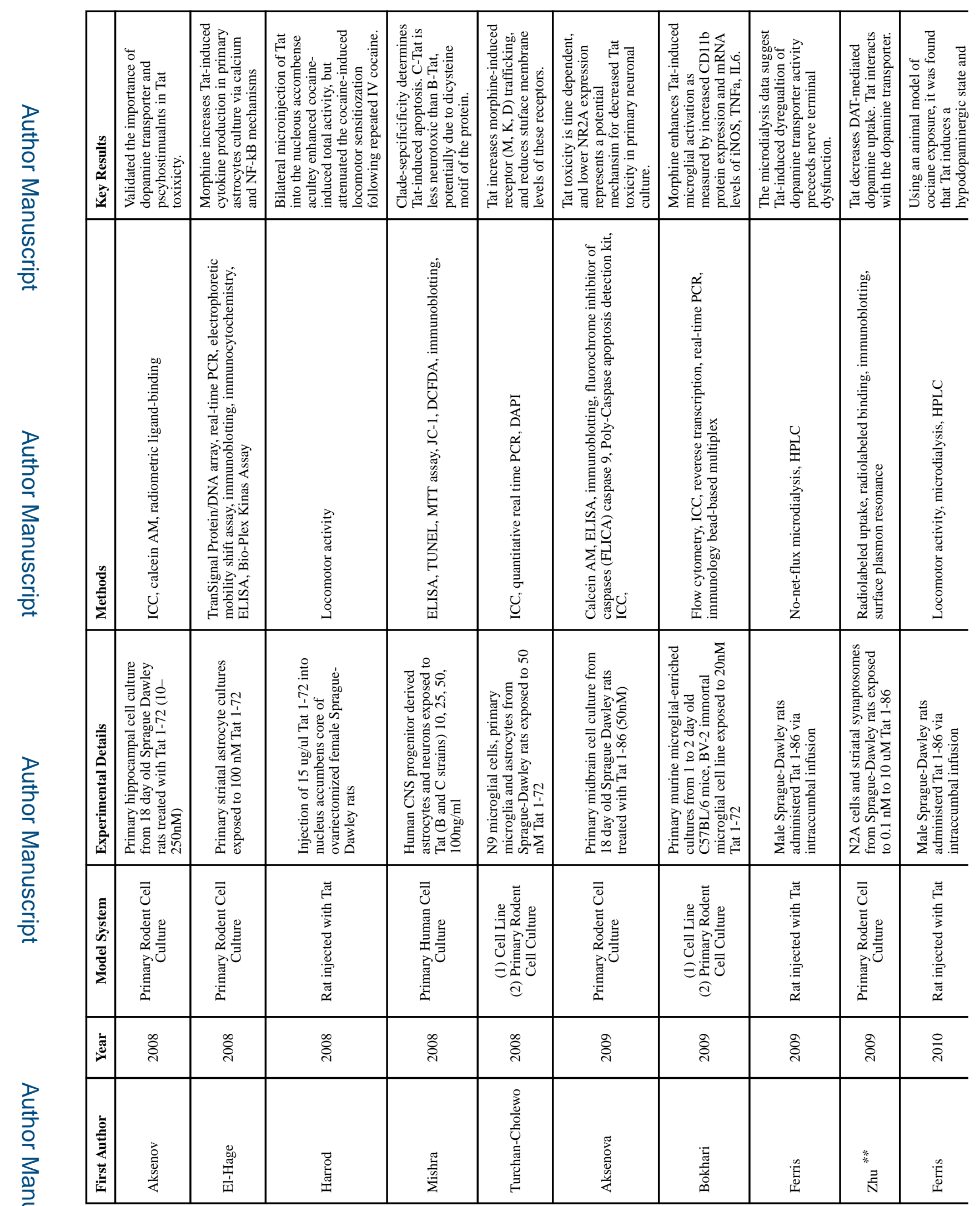

Neurobiol Dis. Author manuscript; available in PMC 2018 September 01. 


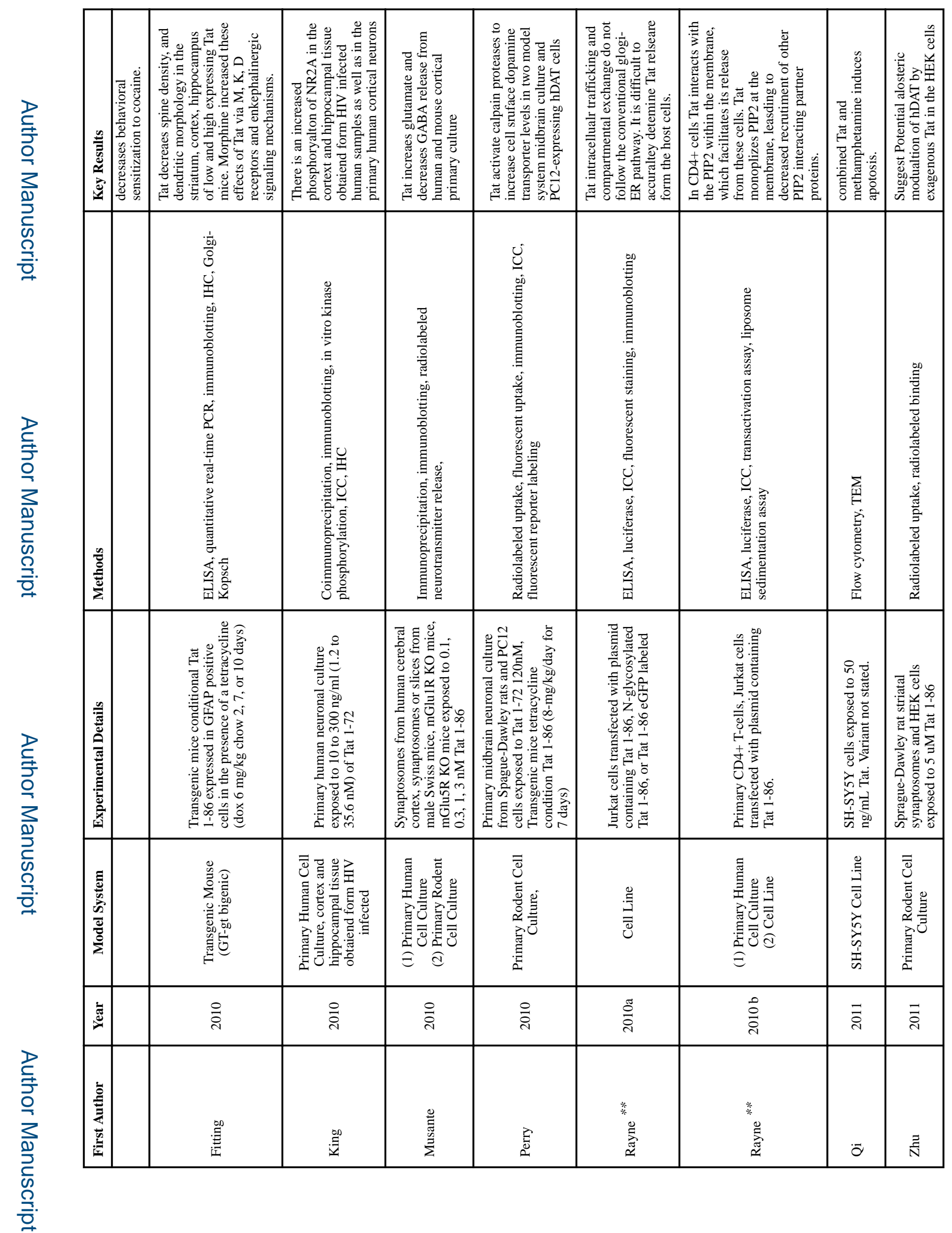

Neurobiol Dis. Author manuscript; available in PMC 2018 September 01. 


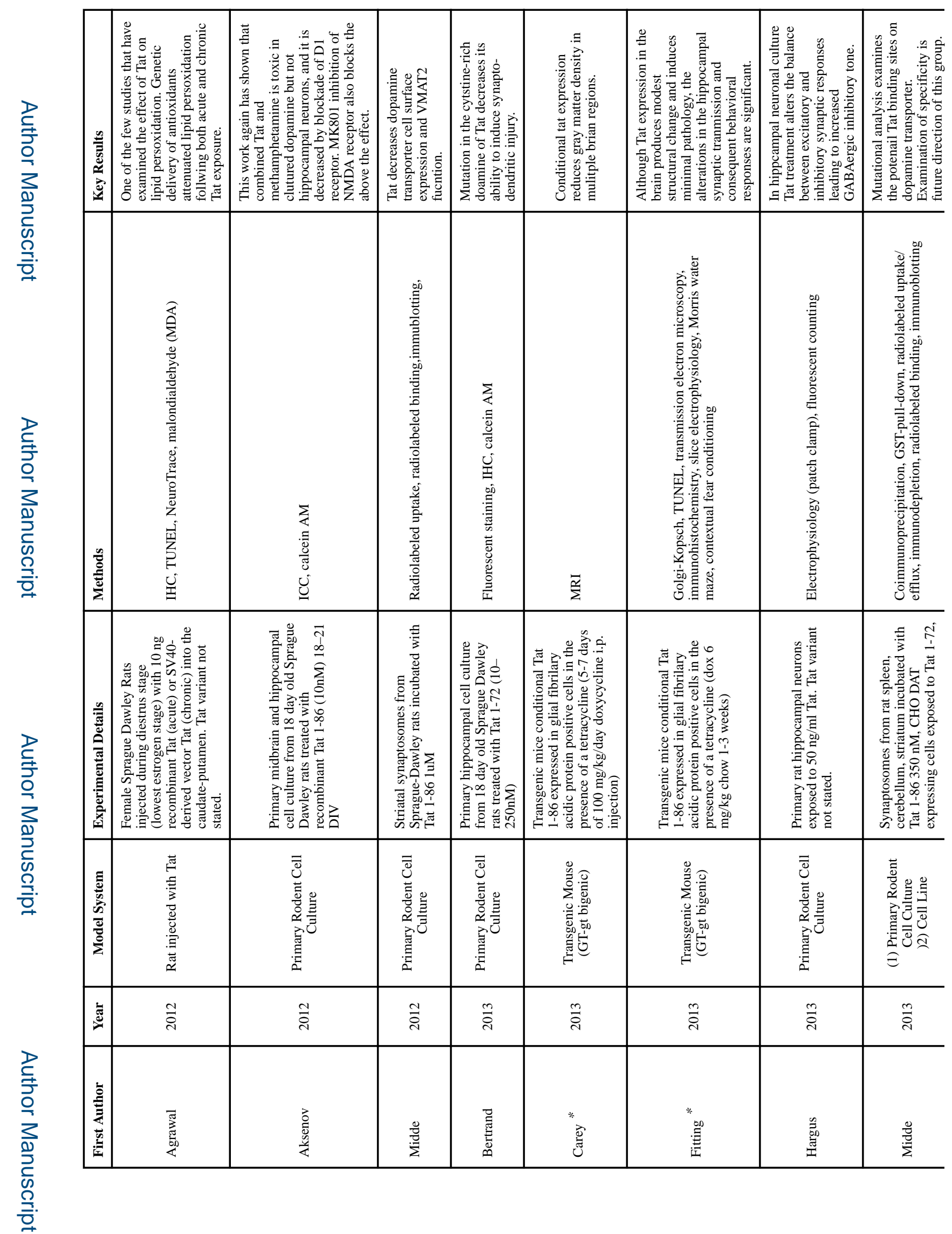

Neurobiol Dis. Author manuscript; available in PMC 2018 September 01. 


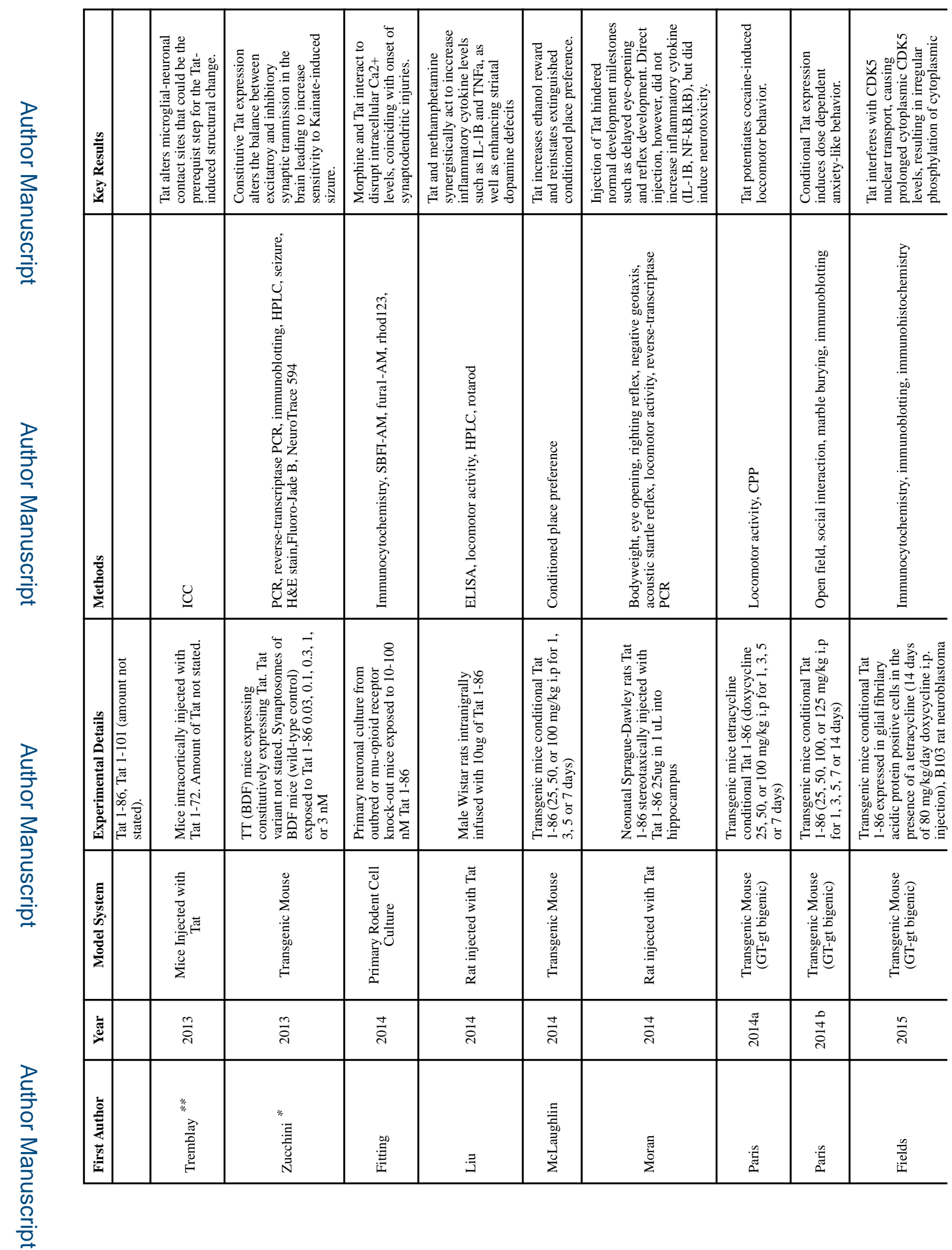

Neurobiol Dis. Author manuscript; available in PMC 2018 September 01. 


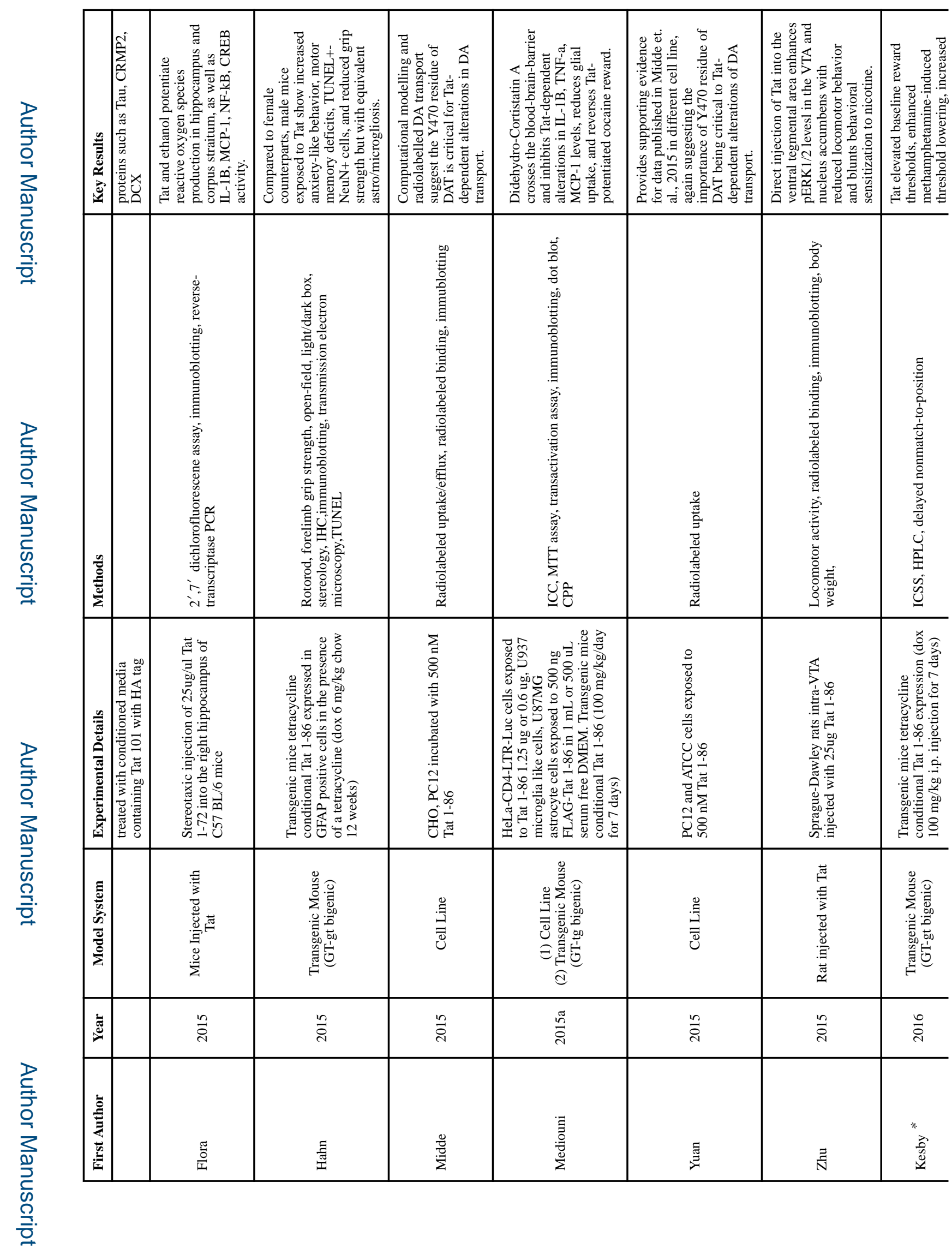

Neurobiol Dis. Author manuscript; available in PMC 2018 September 01. 


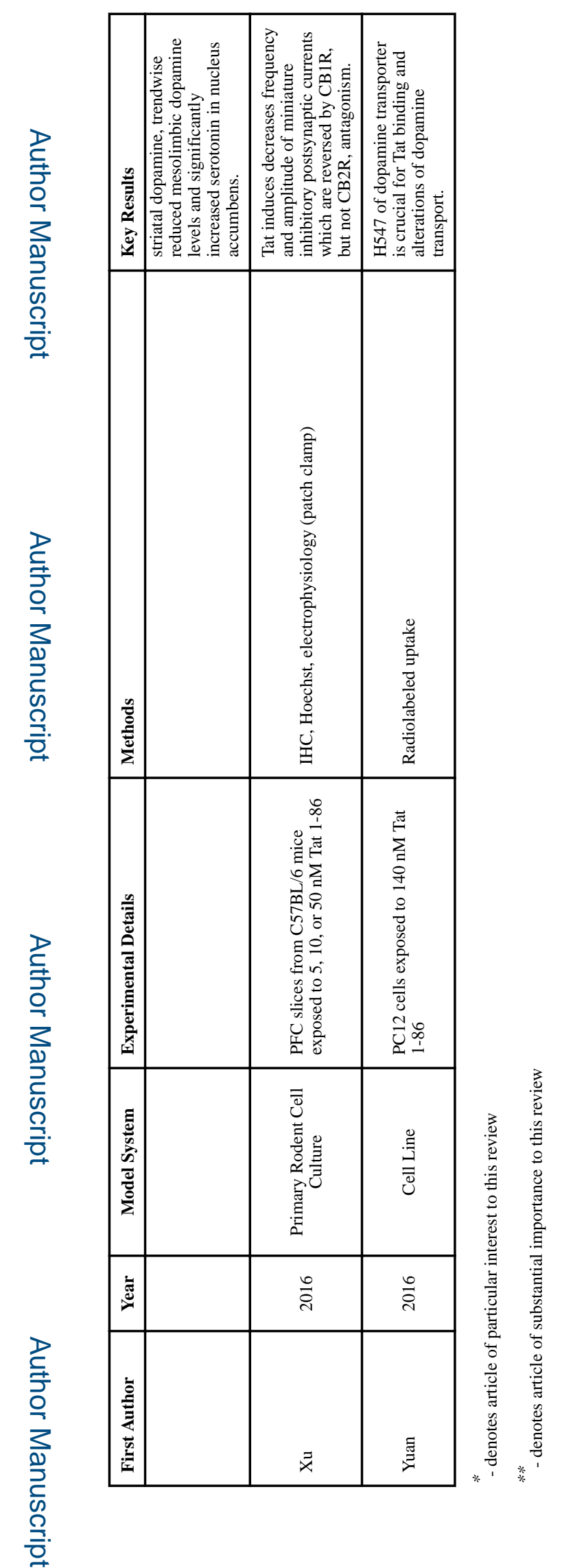

Neurobiol Dis. Author manuscript; available in PMC 2018 September 01. 